


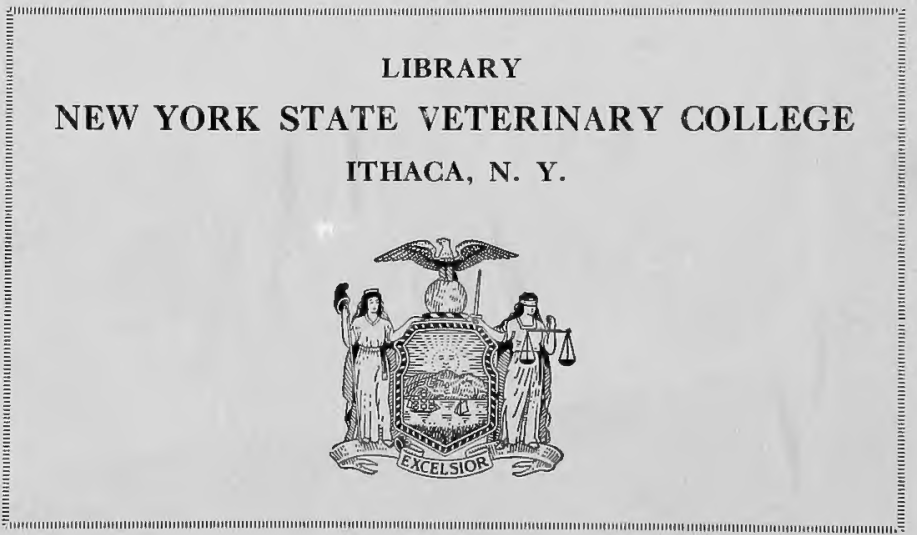


The Canadian horse and his diseases,

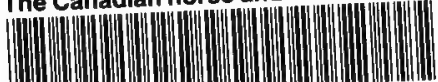

31924000921738 


\section{Cornell University Library}

The original of this book is in the Cornell University Library.

There are no known copyright restrictions in the United States on the use of the text. 






\section{THE CANADIAN HORSE}

\section{AND HIS DISEASES.}

BY

D. M'EACHRAN, M.R.C.V.S.,

GRADUATE OF THE EDINBUROH VETERINARY COLLEGE,

LATE LECTURER ON MATERIA MEDICA IN UPPER CANADA VETERINARY SCHOOL, LECTURER AND CONSULTINO VITERINARY SURGEON TO THR BOARD OF AGRICULTURE, MONTREAL, C.E.

AND

\section{ANDREW SMITH, V.S., EDINBURGH,} GRADUATE OF EDINBURGH VETERINARY COLLEGE, PRINCIPAL OF THE UPPER CANADA VETERINARY GCHOOL, CONSULTING VETERIISARY SURGEON TO THE BOARD OF AGRICULTURE, TORONTO, C.W.

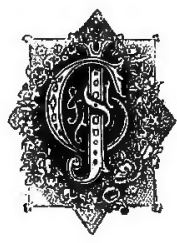

TORON TQ PUBLISHED BY

JAMES CAMPBELI: 
Entered according to Act of the Provincial Legislature, in the year One Thousand Eight Hundred and Sixty-seren, by D. MoEAchraN, M.R.C.V.S., and ANDREw SMith, V.S., in the Office of the Registrar of the Province of Canada. 
George Buthiand, Esquire,

Professor of Agriculture, Toronto University.

\section{SIR,}

As an expression of our appreciation of the great interest you have taken in advancing the veterinary science in Canada, and our high estimation of your private as well as professional worth, this work is most respectfully dedicated to you by

Your obedient Servants,'

Canada, $\longdiv { 1 8 6 7 . }$

\section{THE AUTHORS.}

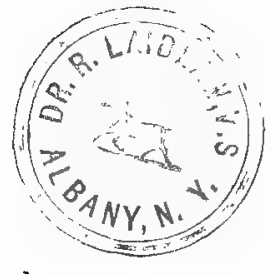





\section{PREF A CE.}

THE want of a popular hand-book on the diseases of the horse has been so much felt and complained of that we have been induced to prepare this little work to supply the desideratum, until some more extensive treatise takes its place:

In placing this work in the hands of the public, it may be urged that we are injuring the business of the qualified practitioner, by teaching the owners of horses to treat their own stock; to this we have only to say, that there are so few qualified practitioners in the province, and the necessity for sound advice on the subject is so urgent, that withholding it on these grounds would be doing injustice to farmers beyond the reach of professional advice. We feel confident that this little volume will be the means of opening up the way for educated veterinary surgeons, by exposing the impositions and denouncing the cruelties of quackery.

In the following pages the farmer will find explained, in simple language, the common diseases which occur in the horse in Canada, with the most successful plans of treatment, by a careful study of which he will not only be able to 



\section{INTRODUCTION.}

IN introducing this volume to our readers, it is well to state at the outset that in the preparation of it we have paid more attention to its practical usefulness than to flowery language and literary flourishes. We have endeavoured to produce a condensed manual of veterinary science in such a form as would place it within the reach of every man who keeps a horse: hence we have been obliged to condense our matter, and deal with the principles of the science rather than with the details of individual cases. We present it to the public, not with the idea that we have added much that is new, or added much to what is already known of the nature and treatment of disease generally; but being thoroughly Canadian, and in a great measure the result of our experience in the country, we trust it may prove more useful than any similar work in circulation; for it is well known that the difference of climate, the consequent change in constitution and temperament, and the irregular management of our horses, produce corresponding ehanges in the nature and treatment of the diseases to which they are liable-hence British and French works are inapplicable to horses in Canada.

In collecting our materials we have endeavoured to follow 
the advice of Lord Bacon, who says of the lecturer :- "He must be, not like the ant, collecting all things indiscriminately from all quarters as provender for his discourses; nor the spider, seeking no material abroad, but spinning his web of speculative doctrine from within himself; but rather the bee, extracting crude honey from various flowers-storing it up' in the recesses of his brain, and submitting it to the operation of his intellectual faculties until it be matured and ready for use."

We have obtained our material from various sourcesparticularly the book of daily observation and practical experience. The sound practical lectures of our late distinguished teacher, Professor Dick, of Edinburgh, and the deep studied lectures of the late Professor John Barbow, also of the Edínburgh Veterinary College, indelibly impressed on our memory, have been freely used. The works of Percival, Blain, Youat, Clarke, Coleman, and others, have also been referred to; and although, as will be seen, in some very important points we have been obliged to differ in opinion from these learned authors, it must not be supposed that we undervalue their teachings; but as the wheels of time roll on, and every day brings some new light on science, the veterinary no less than the medical profession makes rapid strides in the onward march of improvement. Many of the theories which they in their day advocated and held to be correct are now more clearly comprehended ; and we only do what they themselves would have done when we correct their erroneous views.

It is a familiar saying that "prevention is better than cure;" hence to know the means of preventing disease must be more valuable even than curing it. 
Most diseases arise from causes which are evident, and within our power to prevent. In the wild state the horse enjoys almost perfect immunity from disease: it is only when subjected to the abuses consequent on domestication that we find disease in all its varied forms attacking his noble frame and breaking down his iron constitution.

The most common forms of disease met with in Canadian horses are connected with the progressive organs-the limbs and feet. Lameness constitutes the principal part of veterinary practice in this province, and is therefore deserving our particular attention, and as the foot is very frequently the seat of injury, we have devoted a chapter to that subject.

Most of the acute diseases of the digestive organs arise from injudicious feeding, both as regards quantity and quality of the food. Diseases of the respiratory organs are produced by undue exposure, improper ventilation, sudden transition from cold to heat and from heat to cold. Many diseases are hereditary, and traceable from parent to progeny, thus ringbone, spavin, navicular disease, specific opthalmia, \&c., are well known to be hereditary, consequently no horse or mare suffering from these diseases should be used for breeding purposes. In the text we have been careful to enumerate the causes of the diseases as we take them up, so as to enable the owners of horses to avoid them, and thus save themselves from loss, and their horses from suffering. Much could be said on the important subjects of ventilation, feeding, exercise, \&c.; but our limited space prevents us entering on them.

To many our systematic arrangement of diseases into nature, causes, 'symptoms, and treatment, may appear too 
formal, for disease presents many variations in character under different circumstances. Thus the breed, age, size, and sex of the animal, the circumstances under which it occurs, and the stage in which it is seen, all produce variations in the appearances of the same disease. As before remarked, we merely give the most common characters of the disease, leaving the common sense of our reader to make allowances for circumstances. We would advise a careful study of the first chapter, as it explains the general principles of treatment contained in the text, for every disease partakes more or less of an inflammatory character.

To enable our readers to apply our directions to advantage, we would recommend that loose-boxes, roomy and well ventilated, be attached to every stable in every section; a syringe should be kept, drenching horns, \&c.;-and with these appliances, and access to an intelligent druggist, we feel confident that our little volume will prove very valuable where the services of a veterinary swrgeon cannot be obtained; and we trust it may be the means of saving many a noble animal from the tortures of the rude farriers.

To the matter of the text we have added an alphabetical list of prescriptions, which cannot but prove to be valuable if judiciously used. On the whole, we hope that we have succeeded in supplying what we had mndertaken : and should we meet with a favourable reception, we may at some future date be induced to attempt a more extensive work.

Upper Canada Veterinary School,

Toronto, C. W., $1 \& 67$. 


\section{THE CANADIAN HORSE AND HIS DISEASES.}

\section{H A P T E R I.}

\section{INFLAMMATION.}

INFLAMMATION, in one form or other, constitutes the greater part of medical practice : it is therefore necessary, in the outset, that we obtain as correct a notion of the inflammatory process as possible.

Within the last few years, the mieroscope has done much to elucidate the real nature of this process, and even now the subject is far from exhausted. Inflammation "may be defined to be an alteration in the healthy structure and function of a part, accompanied by a perverted condition of the blood and capillary blood-vessels; ordinarily attended with redness, pain, heat, and swelling; and inducing more or less febrile disturbance of the general system."-MILLER.

Let us suppose that we have a living tissue under the focus of the microscope. We observe the circulation in the arteries, where it is so rapid as to prevent our seeing the 
constituents of the blood ; ${ }^{*}$ but, if we follow it on till it terminates in the capillaries, the current becomes much slower, and we can distinctly observe the corpuscles, (or blood globules,) red and white, moving regularly and smoothly through them, without any tendency to adbere to one another or to the coats of the vessels. If an irritant be applied, or the part pricked with the point of a needle, the vessels at once contract or lessen their calibre, but almost immediately dilate to more than their natural size; the blood now rushes through them with increased rapidity, and the minute vessels which before were invisible are now distended with red blood. If at this stage the stimulus be withdrawn, the vessels resume their usual appearance, and the circulation goes on as before. If, on the other hand, it be continued or increased, the dilatation increases, the flow of blood becomes slower, the corpuscles adhere to one another and to the coats of the vessels, the capillaries are distended, exudation through their coats takes place, and the circulation becomes sluggish, and at last stops altogether. The blood still continuing to arrive in increased force and quantity, the surrounding vessels are engorged, and extravasation of liquor-sanguinis, and in some instances blood itself, takes place, and the part becomes red, hot, swollen, and tender, and is now in a state of inflammation. The prominent local phenomena observable in a

- Diagram of the Buood.

Chemical Components.

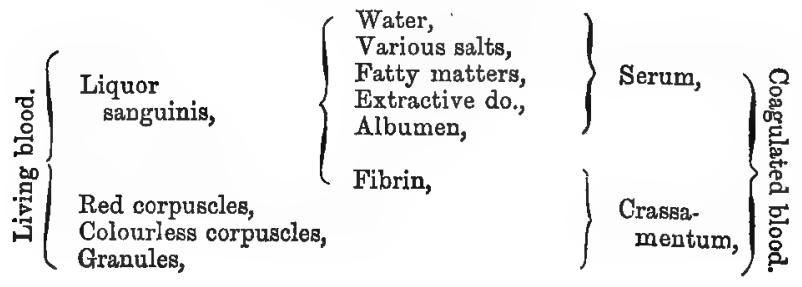


part in which these changes are going on, must be carefully noted as diagnostic of the different stages in the progress of the inflammation.

1st. The Heat.-This is an invariable symptom, being always present to a greater or less degree. It is produced by the more rapid oxidation going on, consequent on the increased quantity of blood circulating in the parts immediately surrounding.

2d. Redness is due to the increased determination of blood to the part, the distension of the hitherto invisible capillaries with red blood, and sometimes, when extensive, to the extravasation of blood from the bursting of the thin walls of the vessels.

3d. Pain.-The pain in an inflamed part is almost the first and most characteristic symptom. It is due to the tension of the tissues, and implication of the nerves and nerve centres. The degree of pain varies according to the seat of the inflammation and the degree of its intensity : the more sensitive the part, the more painful will it be under inflammation. Thus, it is sharp and cutting in inflammation of serous membranes, dull and gnawing in diseases of bones, and burning in inflammation of the skin. When matter is forming, the pain becomes throbbing and intense.

4th. The swelling is due to the vascular engorgement and the exudation of serum in the first place, and afterwards the formation of fibrin, and in the latter stages to the development of matter. The other concomitant symptoms of inflammation will be noticed when we come to treat of local inflammations, or inflammation of particular organs.

Inflammation, though regarded as a disease, is the principal agent which nature employs in repairing or rebuilding parts which have been injured by accident or disease. Thus, when a fracture has taken place, the ends of the bones have 
to be united-inflammation is set up, lymph is thrown out around the fractured ends, small capillary vessels soon shoot into the coagula, from which bony particles are deposited; and thus by a process of inflammation the continuity of the parts is restored. Inflammation is often made nse of to cure diseases and remove callous enlargements. Thus, when a thin opaque film is left on the eye, from a blow or otherwise, a stimulating wash is injected to set up inflammation, to cause blood-vessels to shoot into it, and remove it by absorption. We blister callous enlargements for the same purpose. It will thus be seen that, in many cases, inflammation becomes a remedy instead of a disease, and is in all cases a necessary and natural process for the repair of an injury.

When a part presents the appearance of inflammation, becoming red, hot, tender, and swollen; and a time these appearances subside, without producing any alteration in the structure or functions of a part, it is said to have terminated in Resolution. When two cut surfaces are brought together, and exudation takes place, and the surfaces are united, as in the healing of a wound by the first intention, it is called Adhesion. When an inflammatory tumour, as that of Strangles, or "Horse Distemper," - at first hard, hot, and painful, goes on, softens in the middle, points, and bursts, discharging a yellowish, creamy fluid, called pus,-it is said to terminate in Suppuration.

When a part is tardy in healing, and presents an open spreading sore, with red, irregular edges, presenting a mouseeaten appearance, discharging a thin irritating pus, mixed up with the débris of the tissues in which it is formed, floating in serum and pus cells, it is said to be in a state of Ulceration.

Gangrene, or Mortification, that is, the entire death of the whole or part of a tissue,-is apt to occur when the inflam- 
mation has been sudden and violent. When this has occurred, no recovery can take place, as the blood-vessels and tissues are destroyed: the part gradually becomes cold, the colour becomes blue or purple, a foetid moisture covers the surface, and noxious gases are evolved. There is always a red line of demarkation between the dead and living tissues; and if the constitutional depression, which generally accompanies it, $_{2,}$ does not produce death, this red line becomes converted into pus, and the dead part is removed by a process called sloughing.

Treatment of Inflammation.-We will merely notice the general principles to be observed in the treatment of inflammation, leaving the treatment of different parts till we take them up in their proper place. Our first thought must be, to inquire into the cause of the inflammation; that being found and removed, the effects will soon cease; without that, a cure cannot be established. Matter may be forming in the foot, indicated by intense pain, heat, and great lameness. We may foment or poultice or do what we may: the removal of the faulty nail must be the first step in the cure; and that done, we will be able to attain our object by comparatively slight means.

The remedial treatment may be divided into local and constitutional:

Local Treatment.-Our object is to produce resolution, if possible. This will be best done by placing the patient in a cool, comfortable box. He must be secured, so as to give the inflamed part complete rest; and then the constant and copious application of cold'water, cooling lotions, and freezing mixtures, will retard, and often arrest the inflammatory process. Cold, to be of any service, must be kept up for several hours, otherwise the reaction it produces will do more harm than good. Should this not arrest its progress, 
and the inflammation becomes accompanied by pain and throbbing, heat must be substituted. Hot fomentation and poultices soften and relax the tissues, thus opening the pores, and encouraging the formation of matter, which, when matured, must be opened and allowed to escape. When, as in sprain of the tendons, instead of going on to suppuration, the swelling becomes callous, the inflammatory action subsides, leaving the effusion unabsorbed. In this stage, and only when heat and tenderness are gone, should blisters be applied. The severity of the counter-irritant must be regulated by the site, condition, and nature of the inflammation.

The remedies which are used to arrest the inflammatory process are called Antiphlogistics, the most important of which are blood-letting, purgatives, sedatives, and diuretics. Blood-letting, which has now come almost into disuse, was at one time looked upon as the sheet-anchor in the treatment of inflammation. Without entering into any discussion of the subject, we will simply remark that, though from the abuse which was made of this operation, by being employed unnecessarily, when milder and more simple measures might do, frequently producing injurious results, it has justly been dispensed with; yet we are convinced, that to abandon the practice entirely would be depriving ourselves of a valuable remedy in checking inflammation.

We will meet with cases in which bleeding will be found very useful, not only in checking the inflammatory process, but in promoting the absorption of medicinal agents. At the same time, we are convinced that, in the majority of cases in which it is practised, it is useless, and often injurious, prostrating the patient already reduced by disease. When bleeding is resorted to, it must be speedily extracted from a large orifice, to make any impression on the system; and the quantity must be regulated by the effect on the 
pulse, rather than by the quantity withdrawn. It is only in the earlier stages that this operation is warranted; it should never be resorted to in any case showing a tendency to weakness.

XPurgatives are very beneficial, and must be given early. They prevent constipation, a 'symptoni very frequently. attendant on inflammation, besides emptying the system of noxious matters, stimulating the sluggish secretions, and draining off impurities from the blood.

Sedatives are invaluable in extensive inflammations, by subduing the action of the heart. They lessen the fever, and keep down constitutional excitement. They have the advantage over blood-letting as antiphlogistics, inasmuch as they can be kept up much longer, and do not reduce the strength unduly, to harbour which we cannot be too careful. Fleming's tincture of aconite, opium, calomel, digitalis, and belladonna, are the principal sedatives used.

$X$ Diuretics reduce fever by evacuating the system of fluids and by stimulating the secretions in the kidneys and skin. Small and repeated doses of nitrate of potash, (saltpetre,) bitartrate of potash, sweet spirits of nitre, dilute acids, \&c., by their cooling action, and by favouring absorption, tend greatly to reduce fever and relieve inflamed parts.

Nothing tends more to success in the treatment of inflammation than attention to diet and regimen. The comfort of the patient must be attended to ; he should have a cool roomy loose-box; and laxative, easily-digested food, such as green food, bran mashes, \&c., should be given, so as to keep the bowels open.

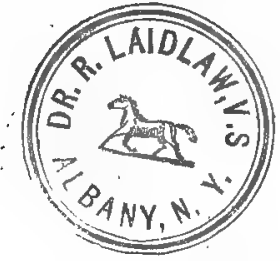




\section{H A P T E R II.}

\section{DISEASES OF BONE.}

Tre skeleton of the horse is made up of 242 bones ; and as these bones are the hard framework of the animal body, serving for the support and attachment of the softer textures and the protection of delicate organs, they are consequently liable to the same accidents and diseases as other parts of the body. They are composed of animal and earthy matters, in the proportion of one-third of the former to twothirds of the latter. They are covered externally by a sensitive and vascular membrane called the periosteum, and lined internally by a similar membrane called the endosteum. They enter into the formation of joints, their ends being held together by the ligaments, and their adjoining surfaces being covered by cartilage or gristle, with a lubricating fluid between, called synovia or joint-oil, to prevent friction, and facilitate the motion of the joint.

Diseases of bones are not very numerous in the lower animals: the most common are:-Exostosis, in which we have an enlargement or bony tumour thrown out on the surface of the bone; when between two bones, and uniting them together, it is called Anchylosis Caries, generally defined to be an ulceration or disintegration of the bony texture; Necrosis, which is the entire death of the whole or part of a bone; Osteo-sarcoma, (which is a disease more particularly 
of the ox tribe,) in which we have a tumour on the bone, partly bony and partly fleshy, occurring commonly on the jaws or ribs ; Enchondroma, consisting of a cartilaginous or gristly tumour on a bone; it is more common in man, but is also seen in cattle, and occasionally in the horse.

\section{EXOSTOSIS.}

Exostosis is, in general, the consequence of periostitis, or inflammation of the vascular membrane covering the bone, though it doubtless also arises from other causes. It sometimes comes on without having attracted the least attention, or produced the least apparent disturbance to the animal, and may appear on any bone in the body, or on any part of a bone, sometimes so small as to escape observation altogether, and sometimes, as observed by Professor Dick, as large as a child's head. It may be caused by external injury, or it may be the result of constitutional disturbance, more commonly the former. Its nature, causes, symptoms, and, treatment will be better understood by taking the most common example-viz., Splint.

\section{SPLINT OR SPLENT.}

Splint is a hard bony tumour occurring on the inside of the shank or cannon-bone of the fore-leg, between the knee and fetlock. It is situated partly on the splint-bone, (from which it takes its name,) and partly on the cannon. It occurs most commonly, nay, almost invariably, in young animals, the reason of which is obvious. The periosteum in them being more vascular than in old animals, it is more liable to inflammation; which is very readily induced in the unsolidified bones of the young animal, when exposed to concussion or external violence." It occurs in the inside, because the centre of gravity falls through that part; when it 
does occur on the outside, it is caused by a kick from the toe of a groom, or from the centre of gravity being altered by the toes being turned in.

Splints do not always cause lameness; it is only in exceptional cases that they do, and only while the process of inflammation is going on. The pain which gives rise to the lameness is caused by the deposition of bone being faster than the parts can accommodate themselves to, whereby the periosteum is distended, and, being a fibro-vascular and highly sensitive membrane, pain, intense pain, is produced, and of course lameness. It is a common belief with most people that splints cause lameness by interfering with the action of the tendons. This idea we hold to be quite fanciful, not from any theoretical view of the case, but from the examination of numerous specimens. We quite agree with Professor Dick in saying, "It is a general rule in the animal econony that the hard parts give way to the soft, and arteries, veins, nerves, tendons, \&c., will be accommodated by the absorption of the bone."

It is more apt to cause lameness when placed near the head of the bone; it sometimes involves the knee-joint. In walking, the lameness may not be observable, but in the trot he is "dead lame;" he drops very much. The part is" swollen and tender, pain being evinced by pressure on the enlargement.

Treatment.-When splint does not produce lameness, it is best not to interfere with it; but if the process of inflammation is going on, accompanied with swelling, pain, heat, and lameness, rest must at once be given, a thick woollen bandage applied, and cold water constantly poured on. This simple plan of treatment is no doubt the best and most efficacious of all remedies, if fairly tried; but this is seldom done, from the trouble of keeping a man constantly apply- 
ing the water. It gives great relief, by constringing the vessels, and subduing the inflammation.

The common practice is, after having reduced the inflammation by cooling applications, to apply a blister, as cantharidine ointment, or iodine, or bin-iodide of mercury ointments. Others have more faith in setons, and we have seen most beneficial effects from them.

X Professor Sewell was the first to introduce the operation of cutting the periosteum, or periosteotomy. This has found many advocates among veterinarians of the present day. It consists in making an incision in the skin, and passing in a probe-pointed bistoury, and idividing the distended membrane. It sometimes gives immediate relief, the periosteum in these cases acting the same as a tight shoe on a person's foot. It is-always advisable to follow this up by the inser-

- tion of a seton, which should be kept in for several weeks. In the majority of cases, it is best not to meddle too much with them, particularly if near the knee, as we cannot remove them. We can only arrest the inflammation, or hasten its consolidation. In most old animals, nature absorbs the superfluous deposits, and leaves the bone nearly as fine as before.

X Splint, really speaking, is an unsoundness; but in our opinion it should seldom be called so, unless it is situated near the knee, or is very large, and on a badly-formed leg.

\section{BONE-SPAVIN.}

Another very common form of exostosis is bone-spavin, which consists in a bony enlargement on the antero-internal part of the hock.

There are two distinct kinds of bone-spavin. The first is in all respects similar to splint, and arises from inflammation of the periosteum. It frequently comes on insidiously, 
without causing much annoyance. The other form, arising from inflammation of the internal structures of the hockjoint, is frequently attended by caries or ulceration, and from the first produces intense pain and lameness, when the bones rub on one another.

$X$ The hock-joint corresponds to the heel in man, and has no fewer than ten bones entering into its formation, an acquaintance with the arrangement of which is necessary before the complexities of hock diseases can be understood.

As in the fore-leg, we have the cannon-bone, with the two snrall splint-bones, one on each side. Upon the heads of these rest or articulate the bones proper of the hock, in the following order. $X$ The middle cuneiform or wedge-bone lies inmediately on the head of the cannon; closely fitting the upper surface of this bone, we have the large wedgebone, and articulating with the upper surface of whieh we have the knuckle-bone or astragalus, which presents on its upper surface a pulley-like articulation, fitting a corresponding surfáce on the lower end of the tibia, or thigh-bone, of the horse. IThis joint is the true hock-joint. / On the outside of the joint we have the cube-bone or cuboid. It articulates with the greater and middle cuneiform-bones by its inner surface, by its upper surface with the astragalus and os calcis or heel-bone, and by its under surface with the cannon and outer splint-bone. We have next the small cuneiform, placed at the back part of the inner side of the hock, resting partly on the large and partly on the middle wedge-bone, but principally by its under surface with the head of the inner splint-bone, and slightly with the cannon. Lastly, we have the os calcis or heel-bone. It forms the projection called the cap or point of the hock; it articulates principally with the astragalus, and slightly with the cubebone. It will be well to bear in mind the four principal ar- 
ticulations-viz., one between the cannon and middle wedgebone; one between the middle and great wedge-bone; one between the great wedge-bone and the astragalus; and the true hock-joint, between the astragalus and the tibia. The former do not possess any very extensive motion, serving more to break concussion. It must be remembered that all these joints have their own capsular and binding ligaments. The surface of the bones are covered by articular cartilage, and lubricated by synovia, or joint-oil. Need we wonder, then, that a structure so complex should present a corresponding complexity in its diseases?

$\downarrow$ The seat of spavin, arising from inflammation of the periosteum, is generally between the head of the cannon and the inner splint-bone. The author of the "Horse" thus very plainly accounts for this:- "The middle wedge-bone rests upon the cannon-bone, and the smaller wedge-bone rests in a very slight degree on the shank-bone, but principally, or almost entirely, on the inner splint-bone. Then, the splintbone sustains a very unequal degree of concussion and weight. Not only is the inner one placed more under the body, and nearer the centre of gravity, but it has almost the whole weight and concussion communicated to the little wedge-bone carried on to it. / It is not, therefore, to be wondered at, that in the violent action of this joint in galloping, leaping, heavy draught, and especially in young horses, and before the limbs have become properly knit, the inner splintbone or its ligaments, or the substance which connects them to the shank-bone, should suffer material injury."

The plausibility of the above reasoning is evident, and many cases of spavin arise in this way; and the process tof inflammation goes on, ossifying the splint to the cannion, extending upward, involving the wedge-hones, sometimes producing anchylosis, or complete union between these 
bones, extending sometimes even to the true hock-joint itself. Other causes give rise to spavin as often, if not more often, than this, as sprain of the ligaments of the joint from slipping or twisting the joint in leaping, or by a false step on the road. It may result from a partial fracture of the head of the cannon, or from severe stress before the bones are perfectly ossified, whereby they become crushed, and inflammation is set up. Certain conformations, particularly that known as "curby hock," are more liable to spavin. Hereditary constitution most certainly predisposes to it, as to all other bone diseases, and spavined animals are therefore not advisable to breed from.

This bone-spavin, with simply exostosis, is not always a very serious detriment to the animal; particularly, if on a well-formed hock, and placed well back, it seldom does much harm; but when occurring on a narrow, ill-shaped joint, and toward the front, it will greatly interfere with the integrity of the joint. However, spavin, no matter where it occurs, is always to be viewed with suspicion, and the animal must be kept off the hard road; but on the farm he may be nearly as useful as ever, if not very lame.

It is of great importance to be able to detect spavin ; and it can only be done (except in very prominent cases) by knowing the natural appearance of the joint. In a sound hock, if you stand about three feet from the shoulder and look back, you will observe a uniformity of the line from the upper prominence to the head of the cannon: any unnatural prominence can at once be seen, which should be felt with the hand; and if a hard tumour is felt, it is bone-spavin. Care must be taken, however, not to mistake a natural fulness, known as "rough hocks;" and it is always advisable to compare the one hock with the other. We must not be understood to mean that the enlargement is observable in 
all cases ; on the contrary, we frequently have spavin uniting the cuneiforms, without the least outward enlargement.

Symptoms.-The bony enlargement is conclusive evidence; but in most cases other symptoms are required. When spavin is coming on, he may only show occasional lameness ; but as it becomes more confirmed, the lameness increases, being always worse in the morning, or when starting, getting better as he becomes heated. The hock is observed to be less freely used than the other. $\mathrm{He}$ is worse on the hard road. He limps considerably when he strikes his toe to a stone or the ground. If the leg be taken up, and the joint forcibly extended or flexed, he will limp considerably. Spavined horses generally lose condition, and from the pain caused by rising, they frequently stand for a long time.

Treatment.-The treatment of spavin does not differ in any material degree from that of splints. Cold applications freely applied will be found very advantageous in the outset of the disease. In simple cases, if taken in the early stage, and sufficient rest allowed, the inflammatory process may be stayed by blistering. Firing is frequently resorted to, and is much practised at the Edinburgh College, with considerable success. Setons, however, are now more in use by private practitioners ; and we must admit we have seen more benefit from them than firing; In cases where it is very large, punching is found more advantageous. It consists in reflecting part of the skin over the spavin, and driving a three-pronged punch into the bony tumour, which sets up a discharge from the bone itself. Those of the older school use powerful caustics, corrosive sublimate, or arsenic, which they insert under the skin. The extensive sloughing which ensues from these barbarous practices are sufficient to condemn them. The days of the chisel and mallet, the 
gimblet, or the pointed red-hot iron, in these cases, are gone, we hope, for ever.

\section{RING-BONE.}

Ring-bone is another very common form of exostosis occurring to a ruinons extent in the lower breeds of horses in Canada.

It consists of a ring of bone, deposited around the head of the small pastern-bone, or the lower end of the large one. This, properly speaking, is ring-bone; but the term is applied to all osseous deposits around this joint, no matter whether in the form of a ring or not. It is seen on both the hind and the fore limbs.

Causes.-It is notoriously hereditary ; and so long as ringboned mares are bred from, ring-bone must continue to be the source of much trouble and loss to the farmer. Another very common cause, which may be either a primary or merely an exciting one, as the case may be, is the absurd custom of allowing foals a few weeks old to follow the mare, of ten for ten or twelve miles, at a brisk trot over a hard road. With such treatment, need we wonder, then, that the unsolidified bones of the colt should suffer from the concussion, and "throw out" ring-bones, spavins, \&c.

In older animals, the cause is concussion of the bones, by which inflammation is set up, followed by bony deposition. In some cases, it arises from violent inflammation of the ligaments of the joint, which, extending to the surrounding tissues, produces the osseous enlargement.

In sonie cases, we have merely two enlargements at the sides of the joint; in others, it surrounds the whole articulation, extends to the coffin-joint, involving the whole of this part of the foot in one mass of spongy bone.

Symptoms.-An enlargement, which, on examination, is 
found to be bone, is observed round the pastern-joint; it may be confined to the sides, or it may encase the whole of the joint. It is attended at first with but a slight stiffness, which gradually increases to a considerable amount of lameness, and, like all other joint lamenesses, is worst at starting.

Treatment.--In the early stages, when the heat, pain, and swelling are noticed, cold applications, with rest, laxative diet, \&c., may check its progress ; but, when it is of any standing, blisters, repeated active blistering, or, better still, the judicious application of the firing-iron, are the most effectual means of arresting it. The idea of "cutting out the feeders" by removing the horny excrescence at the fetlock tuft, is too absurd to require remark. No man of any sense, or with any feelings of humanity, will ever submit his horse to the brutal operation of "cutting the ring-bone," as most quacks practise in this country; which consists in taking a pointed jackknife, and hammering the sharp point downward, in three or four places, not unfrequently severing the ligaments and laying the joint open, and in many cases setting up so much irritative fever as to carry off the poor victim. We cannot reprobate such brutalities too much. Neurotomy is recom-mended, but we have not found it answer in all cases, though we think in bad cases it is well worth a trial. The high operation is preferable, and nearly an inch of the nerve must be cut out.

Ring-bone is one of the worst lamenesses a horse can have. So much stress is thrown on that part, that whatever interferes with its integrity produces a serious detriment to the animal : it entirely unfits him for road-work ${ }_{2_{\alpha}}$ and even on the farm it keeps him in low condition.

Ring-bone in the slightest degree is unsoundriess. 
SIDE-BONE OR FALSE RING-BONE.

Side-bone, properly speaking, is not exostosis, but ossif-. cation of an already-existing structure, it being ossification of the lateral cartilages of the os pedes, or bone of the foot. It is most common in the fore-feet, especially where the pasterns are short and straight.

Symptoms.-The lateral cartilages, which in health are soft and flexible, become enlarged, project above the hoof, and are hard and bony. While the inflammatory process is going on, there is heat and pain in the part, and consequently lameness, which in most cases ceases when the ossification is completed; but there is always a degree of stiffness observable, and the lameness is apt to return if the animal is much used on the road.

Causes.-Short upright pasterns predispose to them; they are most common in heavy draught-horses, used for teaming on the road. Sometimes it arises from a tread from another horse, which causes inflammation of these structures, which is followed by ossification of the cartilage.

Treatment.-The same principles must be observed in all these cases. Rest is most essential ; continued cold applications, by making him stand up to the fetlocks in soft clay, with cold water frequently applied, are indicated in the outset. The subsequent treatment may be blisters, firing, or, these failing, neurotomy may be tried.

Side-bones are also unsoundness, and should be carefully avoided for road-work.

\section{ANCHYLOSIS.}

Anchylosis is simply extensive exostosis, in which we have the ends of two or more bones united by bony matter, as we find in some cases of ring-bone, spavin, sometimes in the 
knee-joint; in fact, every joint in the body is liable to be rendered stiff by anchylosis.

Symptoms are enlargement round the joint, which is stiff and inflexible, and in most cases the animal is lame.

Treatment.-Nothing can restore the motion of the joint. Punching is sometimes tried.

\section{CARIES OF BONE.}

Caries is generally defined to be ulceration or disintegration of the bony texture, and is supposed to be ulceration of the soft tissues; but this is not, histologically speaking, correct. We find in caries the bone undergoes several very marked changes-it decreases in density, (owing to a decrease in the proportion of organic matters entering into its composition,) and presents a peculiar worm-eaten appearance, which enables us always to recognise a carious bone in the dried state.

Causes.-It may arise from whatever will produce inflammation of the bone, or arrests or suspends its nourishment. It is a frequent sequel of fracture of the ribs, sometimes from neglect or mismanagement of pole-evil, or fistula of the withers; in cattle, sometimes from "foul of the foot." Whatever destroys the periosteum may produce caries.

Symptoms.-The surrounding tissues are swollen; there is an opening into the diseased bone, from which acrid, badsmelling matter discharges, in which float speculæ of disintegrated bone. On examining the bone, it presents a fungus which readily bleeds when touched; on pressing the finger into it, sharp processes of bone are felt, which are the bone breaking up. The bone is easily punctured with a probe or knife.

Treatment.-This, in most cases, is a very tedious affair. 
In the first place, the wound must be freely opened, and the parts touched with dilute hydrochloric acid several times a day. Mineral and vegetable tonics must be given. Where practicable, as on the withers, the diseased portion should be cut off with a fine saw. Occurring in a joint, we must endeavour to produce anchylosis of the joint.

\section{NECROSIS OF BONE.}

Necrosis is generally defined to be the entire death or mortification of a bone. It differs from caries, in which the bone is discharged in particles; whereas in necrosis not unfrequently the whole bone dies and becomes encased in a new bone of exactly the same shape, which is perforated by numerous holes, through which the old bone exfoliates.

Causes.-In man it not unfrequently arises from constitutional causes-scrofula, \&c.; but in the lower animals it generally arises from local causes, mechanical injuries, extensive destruction of the surrounding soft parts, especially if it involves the artery supplying nourishment to the bone. In young, thorough-bred horses, we are familiar with it from sore shins, which arises from the animal being put in training too young. The concussion sets up inflammation of the periosteum, which may be followed by caries, but more commonly necrosis of the cannon bone.

Symptoms.-The external appearances do not differ very materially from caries. We have sinuses penetrating the bone, from which there is a copious discharge of most offensive smelling matter, in which is occasionally discharged pieces of dead bone, which have escaped through the holes in the new bone: this is called the process of exfoliation. It is easily distinguished from caries by the surface of the bone not being worm-eaten, but smooth, and studded with 
numerous holes. Again, it is not soft, as in caries : it cannot be punctured with the probe, and it is as heavy, if not heavier, than in health.

Treatment.-It must be treated on the same principle as caries; the sinuses must be kept open, frequently washed out, and some stimulant injected, as hydrochloric acid, (diluted,) and tonics, and good food must from the first be given.

EBURNATION OR PORCELANEOUS DEPOSTT.

This is, properly speaking, a disease of joints, and should come under that head. However, as the bone undergoes several very important pathological changes, it may be well to notice it here. It consists of, a polished appearance, presented by the lower end of the thigh-bone and the astragalus or pulley-shaped bone of the hock, the effects of continued friction.

Causes.-It generally arises from some injury of the lateral ligaments of the joint, causing an alteration in the motion of the joint. The consequence. is, that the friction between the ends of the bones is increased, which produces absorption of the cartilages, and the bones are allowed to rub on one another. The continued friction of the bones, lubricated with synovia, produces the polished appearance. Whatever causes abrasion of the cartilages may give rise to this condition, as concussion, over-stress, \&c. In all these cases, nature throws out an increased secretion of synovia to prevent friction, which causes bulging of the capsular ligament, which is known as bog-spavin.

Symptoms.-Bog-spavin is always present in these cases, and not unfrequently accompanied by bony deposits around the joint. There is always a certain degree of stiffness or lameness at starting, which goes off as he proceeds. 
Treatment is very unsatisfactory and uncertain. It should be treated the same as bog-spavin, which see, page 30 .

\section{INTERSTITIAL ABSORPTION.}

The process of absorption is constantly going on in the tissue of bone, as in all other tissues of the body. Sometimes this goes on to such an extent as to almost destroy the texture of the part. This absorption of the inner textures of the bone is sometimes met with in the stifle-joint, where we find the condyles of the femur sometimes waste away, become light and porons, and less in size, which allows the patella or "knee-pan" to glide off and on as the joint is extended or flexed.

Symptoms.-In almost all cases of chronic lameness in the stifle or shoulder which do not yield to treatment, we find that interstitial absorption is going on. If in the condyles of the femur, of course, we have luxation of the patella at every step, which may be heard knacking into its place when the animal is walking.

Treatment.-Continued rest in a level straw-yard or large loose-box must be given. $\mathrm{He}$ must be liberally supplied with good nourishing diet; the tipped shoe should be put on, and repeated blisters may help to hasten the process of reproduction of the condyle.

\section{ENCHONDROMA.}

Enchondroma is a cartilaginous growth on a bone. It is not very common in the lower animals; but we occasionally meet with it in cattle. Sometimes it grows to a considerable size on the ribs, seldom causing any constitutional disturbance whatever, unless it becomes so large as to interfere with some vital organ, as it sometimes does, when it occurs on the cartilages of the ribs. 
Causes.-It is generally considered to be constitutional. . Symptoms.-It is easily recognised; it is generally attached to some cartilaginous substance. It is a hard tumour, without heat or pain on pressure, quite immovable, and on passing a scalpel into it, it feels cartilaginous.

Treatment.-If situated superficially, they can be easily dissected out, being non-vascular, and seldom occurring in the neighbourhood of any important blood-vessels. When once properly removed, they seldom return.

\section{OSTEO-SARCOMA}

Is a disease which we find is not uncommon in this province, especially in working oxen. It consists of a tumour, partly fleshy, and partly bony, occurring on the jaws or ribs; but all bones are liable to it. In man it is not considered to be a malignant disease; that is, it does not poison the system, and when removed, it is not apt to return; but in the ox it certainly partakes of the malignant type.

Causes.-We are inclined to consider this as a constitutional disease of the bone; but it is often brought on by external injury, or in the jaws, by a diseased tooth. The tooth being fractured or decayed, food getting into the cavity, sets up irritation, and the process of disease is set agoing in the bony texture.

Symptoms. - It is easily recognised. 'If occurring in the jaws, there is considerable enlargement both externally and internally, the teeth become almost covered up in the mass of fibrous fleshy-like fungus, soon loosen, and can be removed without trouble by the hand. This spongy tumour is easily broken, up with the finger, and bleeds freely. On pressing the fungus with the finger, the bony speculæ can be easily felt. It frequently spreads until all the bones of the face become involved in disease. Of course; he cannot eat any- 
thing requiring mastication. His appetite is generally good, and excretions normal.

Treatment.-It is generally considered to be incurable; all that can be done is to cut off as much of the tumour as possible, and dress with dilute muriatic or nitric acid, wash the mouth out often, and feed off for the butcher as soon as possible, which can be easily done, as the health is seldom impaired.

\section{FRACTURES.}

There is scarcely a bone in the horse's body but is liable to fracture, the bones of the legs and quarters more especially. When the bone is simply broken, it is called a simple fracture; when the bone is broken, and the integuments lacerated with the ends of the bone (in most cases) protruding through the soft parts, it is compound; when the bone is splintered, it is called comminuted, and transverse, oblique, \&c., according to the direction of the fracture.

Causes.-It is invariably caused by external violence, kicks, blows, falls, \&c.- -sometimes as a consequence of previously-existing disease of the bone.

Symptoms.-When occurring in a deep-seated bone, it is sometimes difficult of detection, but when in any of the larger bones of the limbs, it is easily recognised by the lameness, displacement, swelling, and crepitus. In most cases, the suddenness of the lameness, taken along with the circumstances under which it occurred, will lead any observing person to detect it at once.

Treatment.-It is a common opinion that horses' bones will not reunite. This, however, is a mistake. They unite as readily as man's bones; but, owing to the difficulty experienced in keeping them in situ, the expense, and the chances of reduction in value, and uncertainty of success, 
they are seldom attempted. Indeed, if any important bone is broken, it seldom repays the trouble, unless it be a very valuable mare.

Before determining the course to pursue, the full extent of the injury must be ascertained as near as possible. Having determined to treat the case, the animal must be slung, the ends of the bones replaced, and kept in place by the judicious application of bandages and splints. The limb must be fixed to prevent motion, cold water constantly applied to subdue the inflammation, perfect stillness enjoined, and the animal fed on laxative, easily-digested food.

Compound fractures are not worth troubling with; it is much better to destroy the animal at once.

In cases where portions of bone are detached, as is com-1 mon in the haunch, cut into it and remove it, when it will soon heal up. If broken pieces of bone are allowed to remain, they act as foreign bodies, and set up irritation; matter forms, which is discharged, and it heals up, to break out at some future time. In all these cases, the part must be laid open, the irritant extracted, when it soon heals up.

There is no common rule for the treatmént of fractures; they must be treated according to circumstances. Observe that the bones are kept in their proper places, retain them there, keep down the inflammation by cold applications, feed the patient on easily-digested food, and attend to his general comfort. 


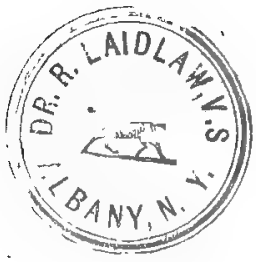

\section{CHAPTER III. ,}

DISEASES OF JOINTS.

IN this chapter we will consider the diseased conditions to which joints, and the different structures entering into their formation, are liable.

It may be necessary, first, to remark, that joints are formed by the ends of two or more bones, coated by an elastic substance called gristle or cartilage, their approximated ends being enclosed by a thin membrane or capsular ligament, the inner surface of which secretes the synovia or joint-oil which lubricates the ends of the bones, and prevents friction, and they are held together by means of short, white, glistening bands, called ligaments.

Before entering into the more complicated diseases of the joints, we will notice first the more simple.

\section{KNUCKLING OVER.}

Knuckling, or standing over, is very common in cab and stage horses. It gives the animal an ungainly, worn-out appearance. It may occur on one or both knees, which are bent forward and are very shaky, or the fetlocks may be knuckled forward. Veterinarians differ as to the real nature of this condition, or as to the part really at fault. Some suppose that it is from "a relaxed and lengthened state of the extensor muscles;" others " of the ligamentous tissue at the anterior part of the joint;" others "an inordinate 
contraction of the flexors, to such a degree that the equilibrium of the flexors and extensors is destroyed." Dissection, however, fails to confirm these views. It appears to us to depend on contraction of the ligaments at the back of the joint.

Causes.-It is generally caused by too hard work when young, particularly continued road-work, which causes the joints to start forward,; and, if it is continued, it becomes habitual.

Symptoms.-It requires but to be seen to be recognised. Instead of the beautiful, symmetrical form of the limb, the joint is thrown forward, throwing the shank-bone more oblique and the pastern-bones more straight, giving the animal a jaded, tottering appearance.

Treatment--Some blister, or fire and blister; but we think these do no good whatever. All we can do is to give rest; leave the rest to nature. Turn him into a large loosebox or small paddock, and feed him well, and it is astonishing how the patient will sometimes improve.

Unless accompanied by some morbid growth, or other diseased state of the joint, we are not justified in calling it unsoundness.

\section{WIND-GALLS.}

Wind-gall is the name given to those soft, puffy swellings found at the back-part of the fetlock-joint, from a supposition that they contained air or wind. They consist of enlargement of the little sacs or bags, which are always found to contain a mucous fluid wherever tendons pass over joints, as at the back of the fetlock. This form may be called simple. wind-gall. In other cases, again, the distension is caused by an increased secretion and bulging of the capsular ligament of the joint itself. This form may be distinguished as complicated wind-gall. 
Few horses that have done any work are free from them; and, unless dependent on some more serious lesion than simple distension of these bursoe mucosce, they, are of no consequence.

Causes.-Hard work is the well-known cause of windgall. In rapid motion, or heavy draught, the friction of the tendons is greatly increased; consequently, an increased secretion of synovia is required, and takes place in all synovial sacs during exercise; but, if the action be not so violent as to strain the parts, it is speedily re-absorbed. On the other hand, if the exertion be inordinate, these little bursce mucosce become injured, inflammation is set up, and they become permanently enlarged.

Again, the exertion may be so violent as to cause sprain of the tendon, which extends to the capsule, or the joint itself may suffer, and cause distension of the capsular ligament constituting complicated wind-gall, which is more serious.

Symptoms.-Simple wind-galls are little, puffy swellings seen at the sides of the tendons as they pass over the fetlockjoint, most common on the hind-leg. They are soft even when the weight is thrown on them. It is very important to be able to distinguish between simple and complicated, or between the harmless and what is not harmless. If situated between the tendon and the suspensory ligament, it depends on distension of the bursæ through which the tendon passes; if it feels hard when the other leg is held up, and is accompanied with slight lameness, the tendon is implicated. When placed in front of the suspensory ligament, between it and the bone, it is accompanied with increase of synovia in the joint itself.

Wind-galls generally appear suddenly.

Treatment.-Simple wind-galls, if taken at the outset, 
are easily removed. Rest must be given, and firm but even pressure applied by pads and bandages, with cold water frequently applied.

When it has been too long neglected, or the case is complicated, blistering may be necessary. The biniodide of mercury ointment may be rubbed well in several times, or a cantharidine blister may do as well; but bandaging should be fairly tried before giving it up. Some writers of high standing recommend (in cases where these fail to remove it) to "puncture the cyst, and heal it with a compress bandage." This, however, to a non-professional is very dangerous practice, as in most cases where it is advised, the joint itself is implicated, and violent inflammation often ensues, which is accompanied by so much irritative fever as to speedily destroy the animal. Some fire these obstinate cases ; but, unless accompanied by lameness, such severe measures are altogether unnecessary.

Simple wind-gall is not unsoundness, but that form of complicated wind-gall in which we have the tendon or the joint diseased is undoubtedly unsoundness; but we must be very careful in giving an opinion in these cases.

\section{BOG-SPAVIN AND THOROUGH-PIN.}

All joints having capsular ligaments and synovial membranes, particularly if from their situation they are much exposed to severe exertion, are liable to the same conditions as observed in wind-galls; and the hock being the joint on which most stress is thrown, is more liable than any other. Accordingly, we find synovial enlargements are very,common here. Bog-spavin is therefore distension of the capsular ligaments of the hock, from increased secretion of synovia. When it bulges out behind on each side of the os calcis, it is called thorough-pin. This term is also given 
to enlargement of the bursa of the perforans tendon. The term blood-spavin is given to it when the vein is made to stand prominently out from the bulging of the capsule. This term is unnecessary and unscientific, unless we have a varicosity of the vein, which is very rare, indeed, at this joint.

Causes.-Like the preceding, disease, and, indeed, all diseases of joints, over-exertion is the great cause. In young, growing animals, it frequently appears without any assignable cause, more especially in rough, coarse-boned animals; but in them it generally disappears as they grow up. In older animals, however, the case is more serious. From the increased friction during hard work, we have an increased secretion of synovia, which distends the capsule; in some cases the cartilages covering the bones are abraded, and in some bad cases the friction goes on till the cancellated structures of the bone are exposed. It is in this case that the condition called porcelaneous deposit is seen. Such severe cases are generally accompanied by osseous deposits around the joint.

Symptoms.-It is easily recognised. Instead of the hock presenting its natural smooth outline, you find a bulging in , front, which, on examination, is found to be soft, puffy, and apparently filled with fluid. In thorough-pin you have a similar enlargement on each side, filling up the hollow between the point of the hock and the joint, which can be pushed from side to side, and which, when pressed equally " on both sides, enlarges in front, and vice versa. Lameness is not often a symptom, unless abrasion is going on, or ossific deposits accompany it.

Treatment.-In many cases in young, growing animals treatment is not required. As the animal grows, nature removes the superfluous fluid, and leaves the hock as fine as 
ever. In older animals rest must be given at once, a dose of laxative medicine should be administered, and rub the spavin twice a day with the liniment for sprains, page 43 . A strong woollen bandage must be carefully applied in the following way. Take two bandages about a yard and a half long; by four inches in wrdth. Roll one up at both ends, making two pads about the same size. Place this on so that the middle of the bandage will press on the front, and the pads one on each side, of the thorough-pin, then wind the other evenly and firmly round, leaving the point of the hock free. Keep the bandage wet with cold water. By continuing this even pressure in this way for some time, the fluid becomes absorbed, the ligaments contract, and the joint resumes its natural size and appearance. When the bandages are removed, the joint should be blistered with the compound biniodide of mercury ointment, page 43 . When there are osseous deposits around the joint with bogspavin, firing is the best remedy: have it lightly fired 'and blistered, and give continued rest. Puncturing has been recommended, but it is too dangerous a practice.

\section{OPEN JOINT, BROKEN KNEES.}

The subject of open joint is one of great importance to the veterinarian, and there is no case in which the educated veterinarian can better prove his superiority over the selftaught empiric, than in the treatment of an open joint.

It is a very common occurrence in the horse, generally arising from accidents, kicks, blows, stabs, \&c. It is most common in the knee and hock; but all the joints of the limbs are liable to be punctured or laid open by some accident or injury.

Open joints are generally divided into lacerated and punctured. In the former we have the skin, ligaments, \&c., 
cut through, and the joint laid open, as is often seen in the knee. In the latter, we have merely a small opening (it may be only sufficient to admit the probe) into the joint, from which trickles the-synovia or joint-oil.

All cases are alike dangerous, and are characterised by the same general symptoms, and are liable to be attended by the same consequeaces. They differ only in degree, according to the importance and extent of the cavity exposed.

We shall therefore, to economise space, take a general view of the subject, leaving to the practitioner to apply the principles laid down to the individual cases as they may occur; and remarking that none but a qualified practitioner should undertake the management of so important a case.

Causes.-The causes of open joint are most invariably external injury - in the knee, from falling. A horse stumbles, "blunders forward," and falls upon his knees, and rises with "brëken knees." The hair may simply be rubbed off, or the skin may be cut through; but in many cases the skin, ligaments, and tendons are lacerated, and the joint laid bare. In the hock, it generally arises from kicks from other horses, and are more frequently punctured wounds. We have not unfrequently been called to cases where the farrier or blacksmith had punctured a bog-spavin with his jackknife. These cases are generally very troublesome.

Symptoms.-In giving an opinion in these cases, we must bear in mind that the joint is not always open, although we have a discharge of synovia from the wound; we may have it from the theca or sheath of some tendon, and it requires close examination in some cases to say which it comes from. What we imply by the term open joint, is where the skin, ligaments, tendons, \&c., have been cut through, and the articulation laid open.

In the first place; the animal is very lame. On examin- 
ing the wound with the probe or finger, it is found to penetrate the joint; we have a discharge of clear oily fluid, which is very smooth and slippery to the feel; the discharge may be very trifling, still it is not the less dangerous. In most cases we have symptomatic fever, which often runs so high as to cut the animal off. It is recognised by the quick pulse, hot mouth, irregular heat of the surface, costive bowels, and the excruciating pain the animal evinces.

Treatment.-This is the most important part of the subject. In the first place, the animal must be removed to a comfortable stall or loose-box, with a high roof, and well ventilated: he must be at once placed in slings, which should be gradually tightened until his toes barely touch the ground.

The wound must be washed out with tepid water, all gravel or dirt removed, and the real extent of the injury ascertained. The limb must then be placed in splints, well padded, and held together by leather straps. A very convenient plan for the knee is, to take three slips of wood, about three inches wide, and half an inch thick, reaching from the elbow to the foot, with the edges bevelled and well padded, and nailed together with three straps, which buckle in front. This placed on, one at each side, and one behind, prevents flexion or extension of the joint entirely, and leaves it open to be dressed at pleasure, without undoing the splints. A large poultice of linseed or oatmeal should be applied cold, and continued until the granulations spring up from the bottom to close the wound. This simple plan of treatment is infinitely more soothing, and at the same time more successful, than the former methods, of plastering it up with lime, flour, powdered bluestone, oxide of zinc, white vitriol. Even corrosive sublimate, and in many cases the hot-iron, have all had their advocates as means of plugging up the orifice. 
To some these may seem very convenient and effectual methods of stopping the discharge, and doubtless in some cases they may, succeed, if circumstances are favourable; but in many cases, when an artificial plug is thus formed, it merely plugs it up for a little,-by and by, ulceration of the skin occurs, the plug falls out before the internal parts have healed, and the consequence is, that we have a far larger and more dangerous wound than before. In changing the poultice, be sure not to remove any of the coagula of synovia that may have formed round the opening. The poultice must be simply removed and changed, without washing the wound. When the granulations become exuberant, they can be regulated by squeezing a sponge of cold water over it, or dust on a little oxide of zinc. Nothing, however, must be injected into the wound, as is sometimes done. Punctured wounds of joints must be treated on the same principles ; the joint must be kept perfectly still, and the granulations encouraged by poultices, \&c. Some, however, find that blisters applied around the wound close it up speedily and successfnlly, by the tumefaction they occasion. Some also approve of the actual cautery, used in the same way, to produce swelling of the surrounding parts. Of course, success in the treatment of open joint must depend greatly on the temperament of the animal. If it occurs in a nervous, restless animal, the symptomatic fever runs high, and success is doubtful; but if in a quiet, phlegmatic animal, we seldom have much fever, and he is likely to do well, if treated properly.

It is necessary in all cases of injury, particularly in this case, to give some opening medicine; from four to six drachms of aloes should be given, in a ball. Green feed, when procurable, is best; but otherwise, give bran-mash, carrots, boiled feed, \&c., and an occasional dose of nitre, or some diuretic, to prevent swelling of the legs. 


\section{DISLOCATIONS.}

Distocations or luxation of the bones in the lower animals, are very rare, owing to the strength of the joints and their binding ligaments; however, we occasionally find the patella or knee-cap dislocated, when it glides off the outer condyle of the femur, and the horse is said to be "stifled."

\section{DISLOCATION OF THE PATIELLA-“ "STIFLED."}

This is most common in colts, from the outer condyle not being fully developed, allowing the patella to glide off and on at every step.

Causes.-It occurs generally in young animals, and is most common on hilly pasture when the soil is gravelly; the feet becoming worn and tender, causes him to relax the stifle in walking, when the patella is apt to slide off. It - sometimes occurs from external violence, or from interstitial absorption of the condyle.

Symptoms.-The limb is extended backward, the foot is bent up, and the animal drags the limb as if it was cramped and unable to draw it forward. Professor Dick was of opinion that cramp of the muscles of the leg is not unfrequently mistalen for dislocation of the patella. But cramp is easily known from the suddenness of the attack, from there being no enlargement at the stifle, and from the bending up of the foot.

Treatment.-It must be returned to its place as soon as possible, which can be easily done in the following way: make one or two assistants pull the foot forward, while you push the stifle back, and at the same time push the patella forward, when it will slip into its place, and the animal will walk off almost as sound as if nothing had happened. If it is followed by lameness or swelling about the joint, rest 
must be given, and to prevent its recurrence, the stifle may be blistered.

A very good plan with colts, in which it frequently comes out, is to remove the patient to a loose-box, with a level, even floor; and to put a shoe on, with a tip projecting in front about two or three inches, slightly turned up, which will keep the muscles attached to it on the stretch, and so prevent it slipping out again. This may be worn for one or two months, as required. 


\section{CHAPTER IV́.}

SPRAINS, BRUISES, ETC.

From the amount of stress to which the several muscles, ligaments, and tendons of the horse are subjected,.in the field and on the road, we need not wonder that sprain is one of the most common cases we have to treat; and from the mischief they not unfrequently occasion, this subject is worthy of our special attention. It has been said that "a bad sprain is as bad as a broken bone;" this remark, however, does not hold good in the equine species.

Sprain may be said to consist in an overstretching of the part (be it muscle, tendon, or ligament) to such a degree as to cause rupture of some of the fibres of which it is composed, in consequence of which inflammation is set, up, and effusion takes place, producing enlargement around the part.

The reason why sprains take so long to recover is, the lacerated fibres have to be absorbed, and new ones formed in their place, or, as is often the case in repeated sprain of the same part, their place is filled up by organised lymph, leaving a permanent thickening.

Causes.-Natural weakness of the part sometimes predisposes to it. It may arise from whatever exposes the part to inordinate exertion, as, for instance, slipping on ice or on a rolling stone, awkward stepping, galloping on rough or 
uneven ground, and a common cause is, allowing the feet to grow too long.

Symptoms.-In severe cases the part is swollen, hot, and tender, the limb is thrown into a position that relaxes the sprained part. If extensive, we have symptomatic fever, and he refuses his food, has the mouth hot, pulse accelerated, \&c., which passes off when the more acute symptoms subside. Lameness, of course, is continuous, thus differing from disease of a joint, in which he is always lamest at starting, getting less lame as he gets warmed up.

Treatment.-We have three indications presented-first, to allay the inflammatory process; secondly, to promote absorption of the decayed fibres; and thirdly, to hasten the reproduction of new ones. Most authors recommend either local or general depletion, by bleeding from one of the large veins near the seat of the injury, or from the jugular vein of the neck. This, however, we think i's now-a-days very wisely dispensed with, as in our opinion it is altogether unnecessary.

The bowels must be freely opened, and kept open by laxative and easily-digested food, such as bran-mash, linseedtea, roots, \&c. The continued application of heat or cold to the part aids greatly in checking the inflammatory action. Gentle. and equable pressure, by means of a judiciouslyapplied bandage, is very beneficial in sprains of the leg.

Rest must be given from the first, and the patient must be turned into a loose-box. Having by these means succeeded in subduing the inflammation, one or two applications of some absorbing blister will generally remove any enlargement that may remain. Should the thickening and lameness prove obstinate, the firing-iron may be resorted to, which, as remarked by Blaine, will " both form a permanent bandage and promote absorption." 
A few months' run in a paddock will tend greatly to consolidate the parts.

\section{SPRAINS, SHOULDER-SLIP, SWEANEY, ETC.}

We will now proceed to notice the parts that are most liable to sprains, and the treatment of these special cases.

Beginning with the fore extremity, the first parts we find affected are the muscles which cover, and are attached to the scapula or 'blade-bone, laceration of the fibres of which, followed by their absorption, constitutes what is called shoulder-slip; or in this country, sweaney. It is most common in young horses, but all ages are liable to it.

It consists in a sprain or laceration of the muscles, covering the outer surface of the blade-bore, (antea and postea spinatus,) and sometimes other scapular muscles, (as the teres, subscapularis, \&c.) in consequence of which they become wasted, leaving their places hollow, and sometimes the spine of the blade-bone stands prominently out.

Causes.-In young animals it is usually seen when first put to work, as ploughing, \&c., on rough or soft ground, or from heavy draught. A badly-fitting collar often gives rise to it. It may generally be attributed to the usual causes of sprain. Symptoms.-At first, though it is seldom noticed, the muscles swell up, are hot and tender; in the course of a few days, the swelling has disappeared, and the muscles are becoming fast absorbed. In many cases this goes on till the bene can be felt. There is little or no pain on pressure in this stage, and no positive lameness; but there is a peculiar rotatory motion of the limb, from the other muscles having no counterbalancing power. This is sometimes mistaken by non-professional men for dislocation of the shoulder-joint. This, however, cannot occur, unless it is accompanied by severe laceration, or even fracture. 
Treatment.-In the first instance, rest and hot fomentations are indicated, which, as the process of reproduction begins, should be followed by stimulant embrocations or mild blisters, frequently repeated, with moderate walking exercise. In this case, we must trust more to nature than medicine; and in time the muscles will be reproduced, and by gentle work and well-fitting harness he will become as sound as ever. Many do nothing for them but turn them to pasture, and in most cases they come up all right.

\section{SHOULDER-LAMENESS, SPRAIN OF THE SHOULDER.}

The muscles which connect the shoulder to the trunk are frequently the seat of sprain; but those muscles, more particularly, which operate in the motions of the joint, are liable to suffer from slipping or side-fall. Thus we find the large flexor muscle (flexor brachii) which is attached to the blade-bone above (coracoid process) passing over the point of the shoulder in the grooves of the humerus, and becoming inserted below to the head and neck of the radius, or bone of the fore-arm, just below the elbow-joint, is very liable to sprain. The joint itself is sometimes the seat of injury or disease; but many lamenesses are referred to the shoulder which have their seat elsewhere; for, as remarked by Blaine, "farriers and persons about horses are apt to attribute every lameness they do not exactly understand, and whose seat is not self-evident, to an affection of the shoulder."

Causes.-It is not so often caused by fair, though violent exercise, as by side-falls, slips, or wrenches, as, for instance, by slipping on the ice, or being laired in a marsh or bog; and sometimes it is caused by slipping when rising in the stable.

Symptoms.-To guard against error in diagnosing affections of the shoulder, it must be borne in mind that all 
muscular tissue is apt to waste if it is deprived of its usual amount of exercise, as we frequently see in the shoulder; the shoulder shrinking on one or both osides, while the real seat of the disease is in the feet; therefore it is very necessary to be able to distinguish shoulder-lameness from many other affections with which it is apt to be confounded.

We have seldom any recognisable tumefaction, nor much heat, unless it be recent and violent. These muscles being the chief agents in extending and flexing the limb, it gives great pain to execute these movements. For this reason, he "drags the toe along the ground," the leg being moved of a piece, as it were, and swung round so as to prevent raising the shoulder. Most pain is evinced in going down hill, when the weight is thrown forward on the shoulder. At rest, the limb is thrown forward, and he rests on the toe. By taking the leg up, and extending it forward with some degree of force, he will evince pain; extreme flexion, by drawing it backward, does the same; by pressing on the point of the shoulder, pain is evinced; or the muscle may be pinched by the fingers, and if that be the seat of the lameness, be will yield to the pressure.

Treatment.-Rest must be given, the part should be well fomented with hot water, which should be kept up for nearly an hour at a time; this should be continued till the inflammation is subdued, when blisters, setons, or firing may restore him to soundness. In many cases, however, this proves a very obstinate lameness. In simple sprain of the flexor brachii we have found setons very beneficial. They may be kept running for about a month or six weeks.

\section{SPRAIN OF THE BACK TENDONS.}

The principal seat of sprain in the fore-limb is in the tendons at the back part of the leg, usually called sprain of 
the back tendons. As these tendons (flexor perforans and f. perforatus) are the chief agents in producing the motions of the limbs, acting like levers over the pulley-like surfaces on the ends of the bones in their passage down to the foot, they are consequently very liable to be overstretched and strained, sometimes in a very slight degree, and sometimes to a considerable extent. It may be necessary here to notice the arrangement of these two tendons. The muscles (perforans and perforatus) arise from below the elbow-joint, pass down through a theca at the back of the knee; below the knee they become tendinous; the first is round, and is covered by the other, which is flatter; half-way down the cannon, the perforans is joined by a strong ligament, (the metacarpal); the two tendons pass down together through a sheath formed for them at the back of the fetlock; the latter splits into two divisions, having the perforans passing between them ; they are inserted one into each side of the lower pastern-bone, (os coronæ,) the perforans, passing down, is inserted into the sole of the coffin-bone, just in front of the navicular joint, over which it passes. In most of the socalled cases of clap or sprain of the back-tendons, the ligament, and not the tendon, is the seat of the injury.

Causes. - Whatever tends to throw unusual stress upon. these parts may produce it, such as galloping on uneven ground, allowing the hoofs to grow too long, thereby increasing the leverage on the tendon; sometimes it occurs in leaping, often while jumping around in play.

Symptoms. - The animal is very lame, the part is hot, swollen, and tender; the limb is held forward, so as to relax the part; in some cases, he can hardly touch the ground. On taking up the foot and pinching with the fingers, he evinces the pain he feels. If the outer tendon (perforatus) is injured, we have a bulging out behind, interrupting the 
evenness of the line which characterises the tendons. If the perforans, it is felt between the ligament and the perforatus; and if the metacarpal ligament, as is most generally the case, it can be felt between the bone and the tendon.

Treatment.-The animal must be turned into a loose-box, the swollen limb must be well fomented with hot water, if the injury is severe; cold may be preferable, if slight. This must be kept up for more than an hour, when the following cooling lotion may be well rubbed in, and a thick woollen bandage applied, well saturated with it, and kept wet with cold water :-

COOLING LOTION.

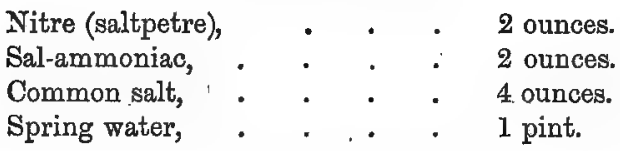

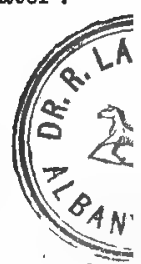

In all cases of severe sprain, a purgative should be given; it reduces the fever, and acts as a counter-irritant.

Having in this way reduced the inflammation, if the swelling still remains, it should be blistered. The biniodide of mercury ointment is best in these cases, and should be repeated :-

\section{BINIODIDE OF: MERCURY OINTMENT.}

Biniodide of mercury, . . $1 \frac{1}{2}$ drachms. Lard, . . . . . . 1 ounce.

A run at pasture will generally complete the cure. Sometimes, by repeated sprains, the tendons become considerably thickened, in which case firing is preferable.

Sometimes, from repeated sprains, the tendons become contracted, causing the animal to go on his toe; in these cases the operation of tenotomy, or cutting the tendons, is advisable. 
ABSCESS OF THE PERFORANS TENDON.

While treating of tendons, we may mention that matter sometimes forms in the tendon, from puncture by a thorn or some sharp instrument, as in a case shown us by $\mathrm{Mr}$ Anderson, V.S., Glasgow. It occurred in a draught-horse, which was very lame, and all remedies failed to effect a cure. He was destroyed by the advice of $\mathrm{Mr}$ Anderson, and the tendon was sent to his surgery, where we examined it while still fresh. It was considerably thickened, and, when cut open, about an ounce of matter escaped from a complete abscess in the centre of the tendon. This is a very rare occurrence, but is well worthy of notice, and when met with, may be recognised by the pain, thickening, and incurable nature of the lameness. The appropriate treatment would consist in making a longitudinal incision, to allow the matter to escape ; and continued poultices might restore the limb.

\section{BREAKING DOWN.}

The suspensory ligament is one of the strongest in the 'body; it is placed immediately behind the cannon-bone, from the head of which it rises, passing down it divides, one division going to each of the small bones at the back of the fetlock (ossa sessamoidea.) This ligament is the great mainstay of the fetlock-joint, and sustains the most of the weight at this part, consequently we frequently find it snap asunder under the great yeight thrown upon it in leaping, galloping, \&e. It is sometimes broken above the division; but more commonly, one or both bifurcations are torn.

Causes.-Violent exertion, or sudden jerks, as is the case in leaping, galloping, or jumping from a height.

Symptoms. - It is sometimes mistaken for rupture of the flexor tendons; but this is so improbable an occurrence, that we are almost sceptical of its occurrence at all. If it does 
occur, it is extremely rare. In rupture of the ligaments, the fetlock descends to the ground; but when raised, the animal can flex the foot, which he could not do were the tendons ruptured. It usually occurs near the sessamoides when we have swelling, heat, and pain.

Treatment.-Slinging is almost indispensable to keep the limb steady, the judicious application of splints and bandages, and a high-heeled shoe should be put on so as to keep the parts in situ; and the inflammation must be regulated by the constant application of cold, laxative medicine, and cooling, easily-digested food, sparingly supplied, when reunion will take place, but a permanent thickening is generally left. When the animal is able to use the limb, the slings and splints may be dispensed with, and it may be fired or blistered to consolidate the new fibres, and form a permanent bandage to the part. The horse can never afterwards be passed as sound, nor will he stand much hard work.

SPRAIN OF THE FETLOCK.

The ligaments of the fetlock-joint are sometimes sprained, giving rise to swelling of the joint, pain, and lameness. Its nature, causes, symptoms, and treatment differ so little from those of other parts that we will forbear further comment.

\section{NAVICULAR DISEASE.}

It is now generally agreed by veterinarians, that navicular disease consists essentially of a sprain of the perforans tendon, as it passes over the navicular bone; but as we will return to this subject when treating of diseases of the foot, , we will reserve our remarks for another chapter.

HIP-JOINT LAMENESS.

Sprain of the whirl, or round bone, as it is commonly 
called, consists of a sprain of the round ligament of the femur, which holds the ball into the socket. Sometimes it is almost torn asunder; but so strong is this articulation, that dislocation cannot occur, except as an accompaniment of fracture.

Causes.-Severe wrenching, by slipping or falling on ice or wet planks, is more likely to cause it than fair though severe exertion.

Symptoms.-We seldom find any external swelling,'unless it is very severe, and the muscles surrounding the joint are involved; when by making him stand square on his hindlegs, and standing directly behind him, and comparing one hip with the other, any enlargement can be easily detected. Sometimes we have heat and tenderness, but in most cases these are absent. One characteristic symptom is stepping short, the lame leg is not brought as far forward as the other one, and he drops on that quarter. The tendon of the gluteus maximus, as it passes over the trochanter, is frequently the seat of lameness; in this case we have swelling, heat, and pain on pressure, with short stepping.

Treatment.-Rest, fomentations, cooling lotions, \&c., until the inflammation is subdued, followed by repeated blisters, which must be freely used, as the disease is deep-seated.

Many cases are incurable, as the ligament sometimes becomes ossified; or we may have osseous deposits in and around the joint.

\section{STIFLE-JOINT LAMENESS.}

Besides dislocation of the patella or knee-cap, from laceration or extension of the lateral ligaments, we frequently find the stifle-joint itself diseased. The condyles may be diseased, or the semilunar cartilages may be displaced. Sometimes the tendinous origin of the flexor metatarsi- 
magnus (the principal muscle in bending the hock-joint) is torn or strained; this is always a serious lameness, owing to the complexity of the part involved.

Causes.-The causes are the same as in other joints-slips, blows, and wrenches.

Symptoms.-In moving, the limb is held as straight as possible; it is moved of a piece, as it were, the stifle is turned outward at every step, and the leg is swung round, and placed further forward than in hip-lameness. In most cases we have heat and swelling. If made to stand on the limb, the capsular swelling can be felt, and pain is evinced on pressure.

Treatment.-Rest must be given. If the cartilages are displaced, they must be replaced by careful manipulation; hot fomentations, or continued cold applications, must be applied; and in the latter stages, repeated blisters or setons should be resorted to.

\section{CURB.}

Curb consists in sprain of the superior straight ligament (calcaneo-cuboid) at the back of the hock-joint. This ligament is attached above to the back part of the point of the hock, (os calcis,) and is inserted below in the head of the outer splint-bone, and by a few fibres to the cuboid-bone. It is, therefore, from its position, very liable to sprain. $\mathrm{Mr}$ Percivall and others supposed that it was inflammation of the cellular tissue covering the tendon behind, or injury of the sheath of the tendon itself, at the back of the hock. However, careful dissection generally reveals enlargement, and sometimes even rupture, of some of the fibres of this ligament.

Causes.-Any sudden action of the limb more than usual may produce it, and therefore horses are found to "throw 
out curbs " after a hardly-contested race, an extraordinary leap, or a severe gallop, and sometimes from an awkward step on the road. Many horses are predisposed to curb, from the shape of the hock, having "curby hocks"- - that is, the hock narrow from back to front, with the os calcis standing prominently forward.

Symptoms.-A swelling suddenly appears behind the hock after a hard run, which is hot and tender. The lameness is sometimes considerable, but often very slight. It is best seen by looking at it sideways; the least curve here is suspicious.

Treatment.-The treatment does not differ from any other ligamentous sprain; as remarked by Youatt, "There are few complaints in which absolute and long-continued rest are more requisite than in curb." The part must be well fomented with hot water, and well rubbed several times a day. Bandages, soaked in some cooling lotion, and kept cool with cold water, or salt and water, until the inflammation is subdued, when the biniodide of mercury ointment, or equal parts of biniodide and cantharidine ointments, may be freely rubbed in, and repeated until the lameness is removed, and the enlargement reduced. The animal must not be put to work too soon, as repeated sprains make it more serious.

Many horses have curbs through life, and never go lame from them. However, curbs in all cases are unsoundness. 


\section{CHAPTER V.}

THE FOOI-PRICKING.

OUR limited space prevents us entering at any length into the beautiful structure and arrangement of the horse's foot. Suffice it to remark, that the foot is made up of the coffinbone, (os pedis,) the lower end of the small pastern-bone, (os coronæ,) and the shuttle-bone, (os naviculare,) with the tendon of the flexor pedis, which passes over the navicularbone, and is inserted in the sole of the coffin-bune. The surface of the coffin-bone is covered by laminæ or. thin plates, running from above downwards, fitting into corresponding plates on the inner surface of the hoof. The sole is also covered by a sensitive structure which is villous, that is, presenting elevations and depressions, which fit into reciprocal horny villæ on the sole of the hoof. At the back part of the sole we have the sensitive or fatty frog, covered in a similar manner by the horny frog. These, with the coronary ligament, (which occupies the groove in the upper margin of the wall of the hoof, and from which the hoof grows, and the coronary frog-band, blood-vessels, nerves, and lymphatics, constitute the foot of the horse.

Accidents and injuries of the foot constitute the principal causes of lameness. It is liable to injury from various causes, as bruises from stepping on stones, sharp bodies, treads, \&c., besides occasionally participating in constitutional derange- 
ment; but by far the greatest amount of injury arises, directly or indirectly, from shoeing.

\section{PRICKING IN SHOEING.}

Sometimes, from carelessness, a nail penetrates the sensitive part of the foot, (usually called the quick;) sometimes the nail itself does not penetrate, but is driven so close as to cause the wall, in its course, to press on and bruise the quick, giving rise to inflammation, and usually terminating in suppuration.

Symptoms.-Lameness may appear in a day or two, sometimes not for a week. The foot is found to be hot and tender, and the least tap with a hammer causes pain ; in moving, the animal sets the foot down so as to throw the pressure off the tender part, and when standing, he will rest the foot. Sometimes the leg swells considerably ; the swelling is sometimes painful, and is very apt to mislead the inexperienced.

Treatment-Remove the shoe, and having with the hammer or pincers discovered the faulty nail, thin the sole around it, and with a fine drawing-knife follow the course of the nail till the matter is evacuated, make a free vent for it, and immerse the foot in a warm poultice for a day or two. When the symptoms subside, the shoe may be applied, and the sole filled with tow and tar, retained by cross slips or a leather sole, care being taken not to bruise the sole. The crust at the injured part should not rest on the shoe.

\section{CORNS.}

A corn results from continued pressure and bruising of the sensitive parts at the angle of the heels, generally the inner heel.

Causes.-Weak, flat feet, with thin crusts, are very liable to corns; but they more commonly arise from the shoes 
pressing too much on the heel; either by being improperly applied, or by being allowed to remain too long on, wearing down, and turning the crust over, enclosing sand or gravel; and from this continued pressure we have effusion of serum and discoloration of the horn. In bad cases, the horn becomes laminated, and produces constant uneasiness, and, of course, lameness.

Symptoms.-The animal in standing raises the heel, and in walking throws the weight on the toe and outer quarter, bringing the limb as much under him as possible. On tapping the foot with a hammer, pain is evinced at the inner heel. On removing the shoe, and pairing the angle of the heel, the discoloured horn is seen, and sometimes matter will be found.

Treatment.-In slight cases, all that may be required is, to pare the seat of the corn well down and lower the heel, so as to remove the pressure; and by. carefully shoeing for a few times, it will disappear.

In bad and long-standing cases, however, it is more difficult of removal. After thoroughly cutting out the corn, it may be necessary to poultice for a time; and if matter forms, to give free vent to it, a bar-shoe * is advisable, or a three-quarter bar, by which the pressure can be kept off the heel. It must be frequently pared out, and filled with hot tar and tow. Sometimes a run at pasture is beneficial.

* Horse-shoers in the country, as a general thing, have very erroneous views about the application of the bar-shoe. From some mistaken idea, that the frog cannot bear pressure without injury, they, instead of allowing the bar to rest on the frog, (as is the intention of it,) carefully arch the bar so as to clear the frog, thereby, instead of relieving and distributing the bearing, they increase the pressure on the heels. In a bar-shoe, properly applied, the weight removed from the injured heel is sustained by the frog, thus equalising the pressure, and relieving the heels. In "springing the heels" with the plain shoe, the shoe must be level throughout, and the heel sprung by lowering the crust at the heel. 
SEEDY TOE.

This is the name given to a dry, mealy secretion of horn, which is sometimes seen to take place between the horny and sensitive sole at the toe. It is seldom seen in this country, owing to clips not being much used.

Causes.-It is generally caused by large clips being hammered firmly on the toe, bending in the hoof, and bruising the part.

Symptoms. - Pain and lameness, with heat and tenderness, on pressure at the toe. The horn is dry and mealy, and matter is generally found at the bottom of it.

In bad cases, horny processes are found pressing inward, producing absorption of the coffin-bone, with a tendency for fungus-growths to shoot up, producing a very troublesome disease.

Treatment.-In a simple case, open it up, cut down to the bottom, and poultice for a few days, when the shoe may be applied, removing the pressure by cutting down the crust, and fill it up with tow and hot tar, when it will soon get well.

In bad cases, with fungus and bony absorption going on, free incisions must be made; sometimes it will be necessary to cut through the wall. Caustics must be freely nsed, such as muriate of antimony, dilute hydrochloric acid, \&c., with pressure judiciously applied; the process may be arrested, and the part healed.

\section{BRUISE OF THE SOLE.}

The sole is liable to bruise from the shoe being improperly seated, sometimes from sand or gravel being impacted in the web of the shoe, or by "picking up" a stone, which, getting wedged in the foot, bruises the sole.

Symptoms.-Lameness first attracts attention to it; in 
removing the shoe, the sole is found tender and the foot hot; on paring the sole, it is found discoloured at the bruised part.

Treatment.-A few days' rest may be necessary, with the foot immersed in a poultice, or stopped with some emollient dressing; and by using a leather sole or felt pads for a short time, it disappears.

\section{TREADS OR CORKS.}

Injuries to the coronet are very common in this country, from the soft ground our horses, particularly those in the lumbering districts, have to work in. Cork or caulk, but more properly tread, usually happens on the hind-foot, by the animal accidentally setting one foot on the other, or another horse stepping on it. We sometimes meet with very serious cases, especially in the winter season; the caulks being long and sharp, sometimes cut right through the coronet, or split the hoof, producing a dangerous wound.

Symptoms.-In general, it is easily distinguished, the wound being visible; sometimes, however, the coronet is simply bruised, and, matter forming, the animal becomes very lame. The action and manner of setting down the foot will lead to an examination of it. It is found hot and tender at the part, and generally enlarged.

Treatment.-Treads or wounds here should never be neglected, as serious implications may follow. In the first place, wash all sand and dirt clean out; if extensive, a cold poultice of any emollient should be applied, and all loose and detached parts removed, and free vent given for the matter, to prevent it forming sinuses. When thoroughly cleaned, it may be bound up with a pledget of tow dipped in tincture of myrrh, or compound tincture of benzoin.

Sometimes all that will be required is to clean it 
thoroughly, and relieve it from the pressure of detached horn; then smear it over with a little tar, to keep flies and dirt from it, and it soon heals up; but when lameness is severe, matter is forming, and must be freely opened up, else the matter burrowing beneath the hoof forms pipes and sinuses, constituting quittor.

If the hoof has been split, it must be treated as directed for sand-crack. Not unfrequently, in bad cases, fungusgrowths spring up, which must be removed by caustics and pressure, or the actual cautery.

\section{OVERREACH.}

When a horse, in a fast pace, over-reaches the fore with the hind-foot, the inner rim of the shoe cutting a semicircular flap on the heel or quarter, it is called an "overreach." It should be treated as a tread; but when practicable, the edges should be brought together by a wire suture, and bound up with Friar's balsam, or tinct. benzoin co.

\section{/. QUITTOR./}

In all cases in which matter forms in the foot, whether from pricks, corns, bruises, or treads, unless it has free openings to escape by, it acts as an irritant, extending in every direction, forming sinuses, and at last working its way to the coronet, where it bursts, producing a very troublesome disease, and requiring both patience and perseverance to effect a cure.'

Symptoms.-It is recognised by the small aperture at the coronet, which seems almost overgrown with "proud-flesh." The discharge is glarey and constant. On examining it with a probe, sinuses are found running in all directions. The quarter is enlarged and bulging, and the lameness severe and protracted. 
Treatment.-The cause must be inquired into, and as far as possible removed ; as remarked by $\mathrm{Mr}$ Dun, "The great principle in the treatment of quittor, and of similar wounds, such as poll-evil and fistulous withers, is to remove as soon as possible the internal cause of the irritation, and provide a sufficient dependent opening for the matter." It may be necessary to remove a considerable portion of the hoof, so as to get to the bottom of the core; but we must open it up freely, thinning the hoof, both the wall and sole, and softening it by poultices, and the sinuses stimulated by injections of corrosive sublimate, (twenty to thirty grains to an ounce of alcohol or whisky,) two or three times a day, care being taken that the whole of the diseased surface is exposed to the stimulant, and that the matter bas a dependent orifice to escape by. Where it has been of long standing, or improperly treated, and the lateral cartilages, or the bone itself, is involved, more heroic treatment will be necessary. We must cut freely away all dead or diseased parts; sometimes the lateral cartilages may require to be removed; still, however, when necessary, we must not hesitate to cut freely, and by following it up with mild dressing we will in most cases effect a cure.X Such severe treatment as was formerly practised by French veterinarians, at Alfort, and largely by our own rude farriers, called "coring out the quittor," should never be resorted to. Our modern practice of bold and free openings by the knife, and removal of irritation, followed by soothing treatment, is not only more humane, but much more speedy and effectual, with less risk of injuring and destroying healthy and living tissues. A bar or three-quarter bar-shoe, should be used for some time, and the diseased quarter cut down to keep it from pressure; and in the course fime the foot will become uspful, if not sound. 
FALSE QUARTER.

When the coronary ligament has become diseased or injured from any of the foregoing diseases, that quarter secretes a soft, weak, and porous horn; sometimes the continuity becomes lost, and a crack or fissure divides the sound from the unsound crust. This is false quarter.

Symptoms.-It is easily recognised ; the quarter is generally deformed more or less. The effects of disease in the coronet are evident, from the rough soft crust which grows down. It must evidently weaken the foot, and renders the horse unfit for anything but slow work.

Treatment.-It is incurable ; but most cases will be palliated by dressing the crack, if such exist, as recommended in sand-crack, and using a bar-shoe, so as to remove the weight entirely off the weak quarter, and keeping the foot regularly dressed with hoof-ointment. The only benefit we can look for in the treatment of false quarter is in the restoration of continuity in the wall. The rest is dependent on care in shoeing.

\section{SAND-CRACK.}

Sand-crack consists in a crack or separation of the fibres of the hoof, in a longitudinal direction. It is most common in the fore-feet, though it also occurs in the hind ones. Whatever tends to interrupt the continuity of the crust may produce it. It often accompanies false quarter, but most commonly occurs independently of previous injury or disease - of the coronet, arising from brittleness of the hoof, the liability to split being frequently increased by the too free use of the rasp.

Symptoms.-It occurs generally on the inside quarter of the fore-feet, but is also seen in front and on the outer quarter. On the hind-feet it is more often seen in front. It may be simply a slight crack, without penetrating the en- 
tire thickness of the crust, but it must not be overlooked on that account; for the insinuation of sand and dirt, the increasing tendency to disunite on any sudden overstress of the foot, may change it from a comparatively harmless crack to a very sérious fissure. Frequently, however, it extends to the quick, when lameness is a prominent symptom. By the opening and closing of the fissure at every step causing intense pain, the sensitive laminæ become inflamed, and fungus growths are apt to fill up the crack, attended with a slight discharge.

Treatment-In cases where the division is complete, the animal must be kept off work, the shoe should be removed, and the crust cut down at the quarter, to remove all pressure off the part. A bar-shoe is best adapted for these cases. The edges of the crack must then be thinned to the quick for half an inch on each side; if much inflamed, apply a poultice for a day or two. The firing-iron should then be run across the crack at the coronet, deep enough to separate the crack from the sound coronet. It should also be applied in the same way a little below, to prevent it extending downward, and interrupting the opening tendency. The fungus should then be dressed with butter of antimony, or, what is better, calomel should be freely dusted over, and a pledget of dry tow laid over the fissure, and bound on with coarse tape, strong cord, or wire, thickly covered over with tar or pitch. It is seldom necessary to remove this, unless it becomes painful, when it must be removed to let the matter escape, and then bound up again.

Different methods are employed for bringing the edges of the crack together. Some recommend to drive one or two fine nails transversely across the fissure, which plan, when the hoof is thick enough to admit of it being done, holds it firmly in situ. 
Professor Dick recommends to "leave a strong nail at each heel, rough, and turned down, and take some wire and twist it round them." This is a very simple and very convenient plan. When the sound horn begins to come down, the patient may be turned to pasture with the foot bandaged, and in a few months the crack will have grown completely out. The hoof should be kept soft by stopping, and frequent applications of tar or hoof ointment.

\section{THRUSH.}

"Thrush," says the author of "The Horse," "is inflammation of the lower structures of the sensible frog, during which pus is secreted with or instead of horn." It is most common in the hind-feet, and also occurs in the fore. It occurs at all ages, and is frequently seen in the colt running in the straw-yard, arising from the acrid moisture of urine, dung, \&c., softening and corroding the frog, and extending to the sensible structures above. It is also seen in roadsters whose feet are not exposed to acrid moisture. In them it is caused by contraction, or the insinuation of sand and dirt into the cleft of the frog, producing irritation, followed by suppuration of the sensitive frog, causing it to secrete unhealthy horn, and discharge offensive matter.

It may sometimes be constitutional, as we often observe it appear just as the coat is being changed, and other constitutional changes are taking place in the system.

Symptoms.-There is seldom much lameness, unless the animal steps on a stone, or sand or gravel gets into the cleft; but it is always attended by a tender, gingery action. The cleft of the frog is deeper than in health, and a thin acrid discharge oozes from its sides and bottom, emitting a characteristic and foetid-odour. If not checked, it extends, and the frog becomes loose and ragged; scales fall off in layers, 
exposing the sensitive parts, which are tender and contracted. If neglected, the entire foot may be involved; and it may degenerate into canker.

Treatment.-No time should be lost, and no case, however slight, should be neglected. The foot must be thoroughly cleaned, and all loose, detached parts freely removed. The secreting surface should be exposed, and calomel dusted on, and pressed with a spatula or thin slip of wood into every crevice. Keep the foot thoroughly dry, and seldom will more than one or two dressings be required. Sometimes it readily yields to cleanliness and simple dressings, with hot tar placed in the cleft with tow, and retained with

- cross slips, or applications of sugar of lead or sulphate of zinc.

It is generally advisable to give some opening medicine, and attend to the general health and exercise.

\section{CANKER.}

Canker of the foot is apt to supervene in cases of neglected or maltreated thrush, quittor, or puncture, and often follows bad cases of grease. It is most common in heavy draught-horses, that are kept in damp, filthy stables, and is seldom seen in this country, being most prevalent about large eities in Scotland and England.

It is thought to be hereditary.

Symptoms. - In this disease we find a morbid state of the sensitive sole and frog, and, instead of sound, healthy horn, fungus-excrescences are thrown out, with an offensive acrid discharge. When aggravated, the whole sole becomes covered with growth of fungus, which are like shreds of leather in appearance, with a great tendency to spread over or underrun the sole, separating the horny from the sensitive parts. It is very difficult to get the horn to grow again. 
Treatment.-In no case is so much patience required as in canker-in fact, it is generally considered as incurable, from the difficulty experienced in suppressing the fungus, and getting the horn to grow again. All loose and detached horn must be carefully removed, so as to give free vent to the irritating matter. As much of the fungus as may seem practicable, without much bleeding, should be removed by the knife or cautery, and followed up by some escharotic, such as acetate or sulphate of copper, nitrate of silver, butter of antimony, or sulphuric acid. Whatever caustic is used must be applied every day; for if neglected for one day, it is apt to under-run the sole, and may lose more than it will regain in a week. Firm pressure is very beneficial, and should be constantly applied by means of tow, firmly impacted, and retained by means of slips of wood or hoop-iron slid under the shoe, and the foot must be kept perfectly dry.

The caustic may be occasionally changed. To destroy the foetor, chloride of zinc or chloride of lime may be dusted on, or even occasional dressings of dry lime will be useful.

"Humauity," says Mr Youatt, "perhaps will dictate that, considering the long process of cure in a cankered foot, and the daily torture of caustic, and the suffering which would otherwise result from so large or exposed a surface, the nerves of the leg should be divided, to take away the sense of pain; but then special care must be taken that the horse is placed in such a situation, and exposed to such work, that, being insensible to pain, he may not izjuriousily batter and bruise the diseased parts."

We have generally looked upon cases of extensive canker as very hopeless indeed; but Professor Dick, than whom there is no better, authority, says - "Cleanliness, perseverance, and time will effect a cure; but with a dressing of tar, in which verdigris and nitric acid, two drachms of 
each to one pound of tar, are well mixed, and applied with a degree of firm pressure, at least every second day, the worst cases can be got well."

Moderate work, if it can be done without the foot getting wet, will expedite the cure.

LAMINITIS, OR ACUTE FOUNDER.

This consists in inflarnmation of the little plates, or laminæ, by which the hoof is attached to the sensitive foot. From the importance of these laminæ, the least injury or disease of them is attended with serious results.

Laminitis is very apt to occur from overtasking the feet, by pounding them over a hard road, and leaving the animal standing, heated and exhausted, in cold or snow,-frequently also, from overloading the stomach by eating too freely of wheat, oats, or barley, as we often see when a horse gets loose during the night, and gets to the oat-bin, or drinking too freely of cold water when heated and exhausted. Sometimes we have seen it occur by metastasis, or the inflammation flying from one part and settling in another. Superpurgation will also produce it.

Symptoms.-It sets in with shivering and uneasiness. He refuses his food; moves about with the fore-feet, and seems uneasy; the mouth is hot, and the pulse full and quickened; soon the pain in the feet becomes evident. He sometimes inclines to lie, points with his muzzle to the feet, which are found hot and tender.

$\mathrm{He}$ advances them in front, resting principally on. the heels, while the hind-feet are well drawn under him. On backing him, he backs with evident reluctance; when forced back, he drags one foot after the other, evincing considerable pain in doing so. When moved forward, he wallss on the heels, his movements being slow and difficult. The 
bowels are costive, and fever runs high. Generally the mane and hair on the legs are easily pulled out.

Treatment--Copious bleeding is indispensable in this case, and should be immediately resorted to,-six or eight quarts should be withdrawn from the neck; half a dose of aloes must be given, (the bowels being very easily moved,) and injections of soap and water, to open the bowels. The shoes must be removed, and the crust well cut down, to remove the pressure off the inflamed laminæ. If the animal can be induced to lie down, it will be all the betterif not, he must be placed in a clay stall or box, and made to stand in clay over the fetlocks, and the clay kept soft with cold water.

The diet should consist of bran-mashes or green food, when procurable. Small doses of nitre may be given repeatedly. He should have a mouthful or two of cold spring water every hour; nothing acts better as a febrifuge. It is infinitely better than compelling the poor, fevered patient to drink lukewarm and nauseating drinks.

Frequently, by the early and vigorous employment of these measures, the disease is conquered, and it terminates in resolution.*

Should the symptoms continue, and the heat and tenderness remain, effusion is taking place, and the whole hoof may be separated from its attachments.

Separation, more or less, takes place, and the wall losing its attachments, allows the coffin-bone to descend; the toe turns up in front, the sole becomes convex, and the condition known as pumiced foot is produced.

After the third day, warm poultices should take the place of cold. "The feet must be kept thinned, if much fever continues. The toe should be opened, and the feet placed in a 
bucket of warm water, to encourage bleeding, and the escape of pus or serum, the result of the inflammation. The recumbent position should be encouraged, and he must be well bedded up, and turned two or three times a day, to prevent scalding.

When recovery takes place, which is sometimes tedious, he will become more lively ; his appetite returns, and he feels inclined to stand up. The poultices may be removed, and he may be turned into a clay stall or loose-box, and the crust kept cut down, to remove the weight off the semidetached laminæ.

He should not be put to work for a month, at least, else descent of the sole and pumiced feet will be the consequence.

\section{PUMICED FOOT.}

Some horses naturally have weak, flat feet, with thin, convex soles ; but more commonly, pumiced foot arises in consequence of inflammation of the feet. In cases of acute laminitis, the laminæ being wholly or partially separated by the effusion, afford but very indifferent support to the foot. The horny matter secreted is thin and soft, and the coffinbone, having lost its attachments, naturally recedes from the wall, which becomes thick and projecting upward at the toe, the sole at the same time becoming convex, and the whole foot misshapen, giving the animal a very peculiar and ungainly gait.

Symptoms. - The foot is flat, the sole convex and thin, the horn' soft and porous; he walks on the heels. From the increased absorption going on, from the pressure on the sole, and the increased tear and wear to which it is exposed, the sole is thin and easily bruised, and the animal, in consequence, unfit for road-work. The wall is marked by depressed rings, which are very characteristic of recent acute founder. 
Treatment.-It is incurable; but by care in shoeing, he may be useful on the farm. The hoof must be carefully preserved, the soles well "picked" every night, to prevent sand or dirt accumulating under the shoe. The feet should be regularly dressed with tar or hoof-ointment.

A bar-shoe is indispensable; the seating must be broad, and the web wide and well hollowed out, so as to cover the sole, without the risk of bruising it: The nail-holes must be placed all round, so as to enable the farrier to get sound "holds" for the nails, which is sometimes difficult to do, owing to the thinness and softness of the hoof. The shoes must not remain too long on, as the soles or heels are apt to get bruised.

NAVICULAR DISEASE, OR " GROGGY LAMENESS."

Navicular disease is very common in this province. By farmers and farriers it is usualiy known as "Coffin-joint Lameness," which, of course, is a misnomer.

It consists (as remarked at page $4 . \overline{5}$ ) in sprain of the flexor tendon, or its sheath, as it passes over the navicular or shuttle-bone, inflammation being thereby set up, which extends to the capsule, spreading to the joint, and not unfrequently involving the bone in ulceration, thus producing a serious and often incurable lameness.

It is notoriously hereditary, but also occurs from external causes. The most common cause is, allowing the feet to grow too long, thereby increasing the leverage on the tendon, and of course the liability to sprain.

Symptoms.-It sometimes occurs in an instant, at others its progress is slow; some peculiar formations of the foot are more subjeat to it than others. When it comes on gradually, a slight tenderness is observed, particularly at starting, which goes off with exercise. This gradually increases, the 
foot is found hot, and as a result of the increased heat, contraction sets in, the foot becoming dry and brittle. $\mathrm{He}$ steps on his toe, and when standing, points his foot, that is, places the foot in front, resting on the toe; and if both are involved, alternating the feet. Contraction is not an invariable symptom, as we have seen the disease in wide-spread feet, perfectly free from contraction.

$X$ The best time to examine a horse suspected of being "groggy" is in the morning; observe if the stable whether he "points," see if the foot is, contracted, or if the toe of the shoe is worn. On takjing him out, he stumbles, stubs his toe into the ground. On examining the foot with the shoe off, he winces by pressure in the hollow of the pastern with the thumb. The bars in some cases will betiscoloured and tender, if tapped with a hammer. The leg should be stretched forward, and the foot bent upward, to put the tendon on the stretch, when pain will be evinced.

$X$ In all cases of long standing, the muscles of the shoulder shrink, and this is often mistaken for sweaney; however, it is different, being merely wasting of the muscles from want of exercise, similar to what occurs in the arm of a man, such as a blacksmith or chopper, when obliged to sling his arm for a month or two.

Treatment:-Rest must be given, the shoes removed, the toes cut down, and the sole thinned, the feet being immersed in poultices, or made to stand in clay, till the heat and tenderness subside, when the hollow of the pastern and coronet should be blistered, or frog-setons inserted, and kept in for a month or six weeks.

Many cases will recover under this treatment, if fairly tried and persevered in.

Some cases in which we find the bone ulcerated, its surface being rougb and jagged, irritating the tendon at every 
step, are totally incurable, although even in some of these frog-setons have done wonders.

In these aggravated cases, a palliative treatment must be adopted. The shoes must be regularly removed once a month, the toe well shortened, and the sole thinned. The shoe should be light, turned up at the toe, and "kept easy at the heels ; " the heel caulkins should be long, and the shoe must not be driven very tightly on. The feet nust be well stuffed, and kept cool. In aggravated cases of long standing, which defy all treatment, the operation of neurotomy should be performed. For the sake of humanity, we recommend it to be performed, to relieve the poor sufferer from pain, which is constant and intense, and at the same time restore the animal to his former usefulness.* Did our limits permit, we might cite numerous cases which have been for years pitiable cripples, which, since we operated on them, are free from pain, and step as free and safe as ever they did.

* See Neurotomy, page 200. 


\section{CHAPTER VI.}

DISEASES OF THE DIGESTIVE ORGANS.

These organs are all very liable to injury from the mouth to the anus; accordingly, we find that under this heading are included a long category of formidable and often fatal affections.

\section{DISEASES OF THE MOUTH.}

The mouth is liable to injuries from foreign bodies being impacted in the back part of the tongue and cheeks, such as thorns or thistles, which, being taken up in the hay, become lodged here.

Symptoms. - The animal is unable to eat, he works the tongue and jaw from side to side, saliva dribbles from the mouth, and he appears very uneasy.

Treatment.-Introduce the hand with a balling-iron, and exanine minutely the sides, roof, and back part of the tongue and cheeks, and carefully remove the offending body, and the uneasiness soon subsides. Soft food may be given for a day or two.

\section{IRREGULARITY OF THE TEETH.}

In old and long-stabled horses the grinders sometime become long, and the edges sharp and ragged; not unfrequently one or more become elongated, and the opposing tooth being worn down, the gums or jaw get injured, or the 
cheeks get nipped, preventing the animal from feeding, and keeping him poor and unthrifty.

Treatment.-The tooth-rasp, the chisel, or the tooth-key, should be used as the case requires. The surfaces must be levelled and made śmooth, and boiled oats or barley, or branmashes, with chopped hay, are the best sorts of feed for horses thus troubled with their teeth.

\section{CARIES TEETH.}

Toothache is not very common in horses, but we have a number of specimens beside us of genuine caries of the tooth, which we have extracted since coming to this country. It sometimes originates in the jaw, but more commonly in the pulp cavity of the tooth itself, and renders the tooth perfectly hollow, proving a source of constant annoyance to the animal.

Symptoms.-The animal is observed to have pain in masticating, by turning his head on one side, and quidding his food. The jaw is generally enlarged, and food is apt to collect in the cavity. Sometimes, when in the upper jaw, the maxillary bones are involved, giving rise to a discharge from the nostril of a very offensive smelling matter, (such cases have often been mistaken for glanders.) When in the under jaw, we frequently have a fistulous opening in the cheek, with the characteristic smell of diseased bone; from the matter which, says Professor Dick, "once smelled is never forgotten."

Treatment.-The animal must be cast, the diseased tooth discovered by the hand or a probe, and with a strong toothkey or forceps carefully extracted. It sometimes requires considerable force to draw a horse's tooth, and the key must be strong. The mouth should be washed out two or three times a day to prevent food collecting in it. Thin gruel 
and linseed-tea only should be given for a few days, and then with a little attention it will soon heal up.

\section{LAMPAS.}

Lampas is the name given to a slight enlargement of the bars or ridges on the palate behind the incisor teeth. It is mostly confined to young horses, and is a natural congestion of these parts, consequent on the shedding of the teeth. It is, says the eminent author above quoted, "not so much a disease as a natural and salutary process, which in general is best let alone, and in which cruel remedies, such as firing, should never for a moment be thought of." If much inflamed, a slight scarification, with sloppy feed for a few weeks, will suffice to remove it. In older animals, similar swellings are sometimes seen arising from indigestion; a slight physicking will generally remove it, without resorting to such outré practices as "cutting out the lampas."

\section{INJÙRIES OF THE TONGUE.}

The tongue is often injured by violence, pulling it out in giving medicines, either by the restlessness of the animal or clumsiness of the operator, often by being tied up with a " hitch" of the halter in his mouth; by running back, he sometimes cuts it nearly through.

Treatment.-If not too much lacerated, the divided edges should be brought together by the metallic suture, and dressed frequently with the following lotion :-

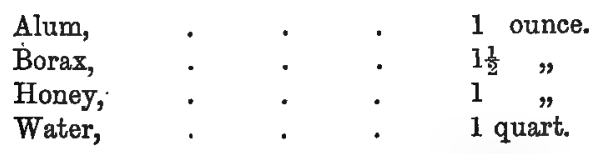

If it is nearly cut across, it may be necessary to remove it, and tie the blood-vessels, and dress frequently with the 
above lotion. A horse having lost part of the tongue cannot drink, without plunging the head deep in the water.

\section{INJURIES OF THE GULLET-CHOKING.}

The osophagus or gullet is the soft muscular tube through which the food is conveyed from the back part of the mouth (pharynx) to the stomach. It first passes above and behind the top of the windpipe, (larynx,) then inclines to the left side of the neck, down which it passes, entering the chest with the windpipe (trachea) between the two first ribs; passing through that cavity, it penetrates the midriff, (diaphragm, ) and enters the upper (cardiac) portion of the stomach.

The gullet of the borse is not very liable to injury.

OBSTRUCTION OF THE GULLET-CHOKING.

This, when it does occur, arises generally from eating ravenously of dry food, as branchaff, chopped hay, \&c., or from a hard ball getting across the passage, or an egg, which grooms are sometimes in the habit of giving, to improve the coat.

Symptoms.-He manifests considerable uneasiness, twisting his head, and stretching his neck, making frequent attempts to vomit. If he swallows any fluid, it distends the gullet, and it runs out at the nostrils.

Treatment.-Until the symptoms are alarming, nothing should be done but turn him into a loose-box, and give him some well-boiled gruel, which, says Professor Dick, "is grateful to the animal, which freely tries to gulp it, and often succeeds. The bland fluid lubricates the part, softens down the foreign body, and in this way it will often slip down. Should this not succeed, the probang must be resorted to. The mouth being held open with a gag or balling-iron, the head stretched out, and tongue taken out to one side, 
the tube being well oiled, is cautiously passed down; too much force must not be used, however, else it may be pushed through the gullet. If it moves with steady pressure, push it right down into the stomach. In case of a ball, it may often be got rid of by external manipulation, and an egg may be crushęd, if not too far down.

When all means fail in removing it, as a last resource, it may be cut down on, and removed, and the wound sewn up, and a pad and bandage applied. This iotperation, however, rarely succeeds.

SEQUELS OF CHOKING.

Dilatation.-Dilatation of the oesophagus in pouches, in which the food accumulates, sometimes follows choking.

Treatment.-If occurring in the neck, a pad should be applied, supported by a bandage round the neck; the pouch being occasionally cleared with a probang; and nothing but sloppy food should be given, and a little at a time.

Stricture.-Contraction of the tube sometimes results from repeated attacks of choking, giving rise to frequent and troublesome collections of food at the part. These animals are poor feeders, and consequently are always thin.

Treatment.-The greatest care is necessary in feeding these horses, and nothing but slops and easily-swallowed food should be given.

Rupture of the Gullet.-This accident can only arise from the incautious use of the probang forcing the obstructing body, or the instrument itself, through the walls of the tube giving rise to the swelling of the neck, with high fever, great anxiety and suffering expressed on the countenance. If the probang is passed down, it is withdrawn bloody.

Treatment.-These cases generally prove fatal. Remove the foreign body by cutting it out, then clean the wound out thoroughly; make a fresh wound, and bring the edges nicely 
together by wire sutures, and apply a pad and bandage; allowing nothing but bland nourishing fluids.

\section{DISEASES OF THE STOMACH.}

The stomach is that pouch or bag into which the food passes from the gullet, and in which it undergoes the primary and essential changes in the process of digestion. The stomach of the horse is comparatively a small organ; its shape is generally compared to the air-bag of a pair of bagpipes. It has two openings, the cardiac, into which the food enters from the gullet, and the pyloric, through which it passes into the bowels or gut. Its inner surface is lined by two distinct membranes, a cuticular and a villous. The former lines the cardiac portion, and is white and wrinkled; the latter covers the pyloric, and is yellowish red, soft, and velvety to the feel. The latter is the true digestive stomach : in it the gastric juice is secreted, and the essential process of chymification, or the formation of the food into chyme goes on, the former being merely for macerating and further triturating the masticated food.

\section{INDIGESTION.}

Indigestion in one form or other is very common in the horse. It occurs in two forms, which may be distinguished as acidity of the stomach or heartburn, 'and acute indigestion or total arrestment of digestion.

ACIDITY OF THE STOMACH.

Acidity of the stomach arises from bad food and irregular feeding.

Symptoms.-The animal is observed to lose condition; the skin is dusty and unthrifty; he is continually poking and picking among the litter, licking out the corners of the 
manger, occasionally stretching out the nose, and pouting the upper lip. If turned out, he licks earth or sand, and evinces a depraved appetite; at work he is easily sweated; his bowels are irregular, the dung being light-coloured and glazed.

Treatment.-Change the feed, give sweet, well-cured hay, a few bran-mashes, and gentle walking exercise. Give him the following laxative ball :-

\section{Laxative Ball.}

Barbadoes aloes,

Ground ginger,

Carbonate of soda,

made into a ball with molasses or lard. Place a lump of rock salt in his manger, and give a little carbonate of soda or magnesia twice a day in the feed. When recovery begins, give bim tonics for some time, with gentle exercise. If he persists in devouring the litter, muzzle him up for a few days. This, if neglected, is apt to run on to diabetes or jawpis. See page 102.

\section{ACUTE INDIGESTION.}

Acute indigestion is very common in this province, especially in spring, from the continuous hard work, and necessarily liberal feeding. It is usually induced by over-feeding, that is, eating too much at a time, more especially when the animal has been fatigued and hungry. It sometimes occurs from his breaking loose in the night, and gorging himself at the corn-bin. Another frequent cause is, overloading the stomach with clover or green feed when wet; this often induces violent and fatal indigestion.

Symptoms.-Digestion may be arrested, either by "the food undergoing no change, forming a dangerous load, or running rapidly to frightful fermentation." In the former 
case the animal is dull and stupid, the pulse is slow, and the breathing oppressed; he is stiff, and inflammation of the feet, or acute founder, is apt to set in. If he have access to water, it speedily sets up fermentation, gas being rapidly evolved; the stomach is greatly distended, the belly swollen, colicky pains set in, he rolls about in great agony, looking wistfully to his flank, kicking his belly with his feet; he tosses about in despair, the bowels being unmoved. He gets up and down frequently, the sweat rolls off him in streams, and in many cases death puts an end to his suffering in from four to six or eight hours, caused by rupture of the stomach or bowels, or violent inflammation of the intestines.

Treatment.-It is more easily prevented than cured, by simply attending to the following rules:-Never let a horse get too hungry. Never give him too much at a time. Never put him to work on a full stomach ; and never let him drink too freely after eating, and we will seldom see this fatal disease.

Treatment to be effectual, must be prompt. The following drench will be found useful :-

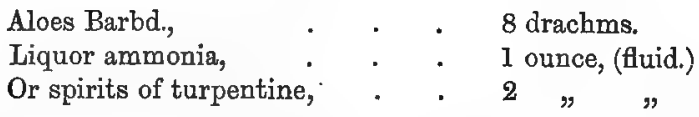

The aloes dissolved with a little carbonate of soda, in nearly a quart of warm water, and the other added.

Rub the belly well, and apply cloths rung out of boiling water diligently to it. Give copious injections of soap and water ; or a mild infusion of tobacco, or tobacco-smoke. If no relief is given in one or two hours, give at intervals of an hour:-

Carbonate of ammonia, $\quad \cdot \quad \cdot 2$ drachms,
Ginger, (powdered, 
in gruel. Advantage will sometimes be found from giving copious drenches of fluids, to liquefy the contents of the stomach, and assist in removing it.

\section{RUPTURE OF THE STOMACH.}

When rupture of the stomach occurs, he generally stands, braces himself up, with his legs like four props, to prevent his falling; the membrane lining the nose and eyes is pale and blanched; the mouth, legs, and ears are deathly cold; the pulse almost imperceptible; the countenance is haggard; the breathing is quick and spasmodic; he works his head toward his chest, and attempts to vomit. He sits on his haunches like a dog; strains, and presently reels and falls suddenly, and expires with a few struggles. Attendants cannot be too careful in working about them in these cases, as they are apt to fall upon them.

\section{BOTS.}

As in the days when disease of the navicular joint was a mystery, every "occult" lameness was pronounced to be in the shoulder; so in Canada, if a horse is taken sick, ten men out of every dozen pronounce it "the bots." It is, in fact, the convenient cloak to hide the ignorance of the empiric.

As a general rule, bots are harmless parasites, seldom producing much mischief, and to be found in almost every horse that dies, sometimes in great numbers, adhering to the coats of the stomach.

History.-To the researches of the late Mr Bracy Clark are we indebted for the real history and nature of this fly, of which there are several varieties. Those described by him as peculiar to the horse are the cestrus equi, gadfly or breeze, which is by far the most common enemy of the horse, and produces the more common bot; it is described as 
being " barrel-shaped, with a thick annular skin, beset with spines around the joints ;" oestrus hemorrhoidalis, with wings not spotted, but otherwise resembling the former; cestrus veterinus and $c$. salutiferus. These, however, may be looked upon for all practical purposes as one and the same, though distinguished by the characteristics of the bot, and its choice of location.

During the summer months a large fly may be seen busily darting about the horse's legs and belly, to his no small discomfort, causing him in harness to stamp his feet and switch his tail, and in pasture to gallop about in apparent terror, to escape his tormentor. This is the common gadfly. The female hovers around her victim, and now and then darts down and deposits her eggs on his legs and sides, such places as he can reach at with his teeth. These eggs are covered in a case of gluten, and may be seen in great numbers adhering to the hairs as little yellowish neats. The animal, on licking the parts, bursts the covering, and the larvæ adhering to the lips or tongue are carried into the stomach, and there adhere to the coats of the organ by means of two little hooks, between which is placed the mouth, and here they are anchored, as it were, floating on the contents of the stomach, and living on the gastric and mucous secretions, until they become thoroughly matured, and in spring loosen their hold, and pass off in the dung; they remain in the chrysalis state for a time, then burst their covering, and throw off the chrysalis, and assume the parent form.

Great diversity of opinion exists as to whether the bots do any harm or not, some even asserting that they assist digestion, and are therefore beneficial. In this country there is no doubt but in many cases they produce considerable mischief, but not nearly so often as they are said to do. 
We have frequently found them so thickly studded on to the pylorus and duodenum, (first bowel,) as to give rise to considerable disturbance, by mechanically interfering with digestion and the proper contraction of the pylorus. It is very rarely, indeed, that they "eat through the coats of the stomach," though we have seen cases of ulceration which have been set down as the work of the bot, because they happened to be found in the stomach after death.

Symptoms.-It is very seldom that any symptoms are presented of their existence in the stomach, unless accompanied by some functional or organic disease, existing independent of the parasites. Sometimes, however, when occurring in dense clusters around the pylorus, or in the first bowel, they interfere (mechanically) with digestion, and keep the animal weak and emaciated, and subject to slight attacks of colic, capricious appetite, and irregular bowels.

Treatment.-The popular remedy in Canada is sweet milk and molasses, which, however, is more safe than certain. We are of the opinion of $\mathrm{Mr}$ Youatt, who says, "they cannot be removed by medicine;" and Professor Dick, who remarks that, "when arrived at maturity, they cease to retain their hold of the stomach, (before this all efforts to force them are vain,) commingle with its contents, pass into the intestinal canal, and to the horror of stablemen, are ejected in multitudes from the anus." Various mixtures are prescribed for their removal, such as

Aloes and assafœetida, of each,

3 drachms,

rubbed down in hot water, and when cool add an ounce each of turpentine and ether; to be given every second day for a week, leaving out the aloes, if the bowels become too open. To relieve the pain or uneasiness, any of the usual colic mixtures will give relief. See Colic, page 79. 


\section{COLIC.}

Colic is usually known as bellyache, gripes, batts, \&c. It is a very common disease in our inferior breeds of horses, arising from long and fast driving, irregular feeding, injudicious watering, and improper care. It is usually distinguished as spasmodic and flatulent, or windy colic. We will, however, treat of them under the one head.

Colic is generally found to occur from a sudden change of feed, very often during summer, when running at pasture, if taken up for a day, and a feed of oats or dry food given; peas, when not accustomed to them, are apt to cause "gripes ;" drinking freely of cold water, when heated, will often give rise to violent spasm of the bowels; worms and other intestinal irritants may induce it; costiveness or constipation often causes it; over-loading the stomach, or being put to work on a full stomach, will give rise to it.

Symptoms.-The animal is suddenly seized with pain in the bowels, becoming restless and uneasy, crouching, kicking at his belly with his hind-feet, looking round to his flanks. He gets down after several apparent efforts, rolls about, sometimes on his back, sometimes quite over; perspiration breaks over him. This paroxysm passes off, and he gets up, shakes himself, and begins feeding. During the interval, the pulse is unaltered, the legs and ears are natural. The bowels are constipated, though a few glazy purls may be forcibly passed during the gripe. After an interval of longer or shorter duration, it returns, perhaps with increased violence, when he gathers himself together, and lets himself fall down with a groan, and rolls about as before, dashes wildly about. If flatulent, the belly is distended and hard, and wind is freely expelled. If it terminates favourably, the gripes becomes less severe, and recur at longer intervals; if the contrary, they are increased in frequency, and augmented 
in violence, he tosses about in despair, sweat rolls off him in streams, and the pain becomes continuous.

The legs and ears get cold, the pulse becomes small and thready, inflammation of the bowels sets in, and speedily terminates in death. Death sometimes occurs from the violent spasms of the bowels, which are sometimes found twisted, and firmly contracted in places.

Treatment.-The number and variety of popular remedies are abundant in the extreme. It will often pass off with a little friction to the belly by hand-rubbing, or a little walking exercise. If it does not soon pass off, place him in a loosebox, with plenty of room and litter; let him roll as he chooses. Give him the following mixture, or any of the drenches given at page 211 :-

\section{Colitc Drench.}

$\begin{array}{lll}\text { Alkaline solution of aloes, } & \cdot & 4 \text { ounces. } \\ \text { Tincture of opium, (laudanum,) } & \cdot & 2\end{array}$

Mix.

Give copious injections of soap and water, or salt and water, or tobacco-smoke. If no relief follows in an hour or an hour and a half, repeat the mixture, or try some of the others; continue the injections, and foment the belly well with bags wrung out of boiling water. If the symptoms become more frequent and violent, 'extract from three to five quarts of blood, and discontinue the stimulant, but give opium or chloroform.

When the case goes favourably, the symptoms gradually abate, and soon leave him entirely. He should not have any hay for twelve hours after, and nothing but bran-mash or gruel. A few days' rest is always advisable, and care in management will prevent its return.

When there is much flatulence, turpentine or liquor 
ammonia may be substituted for the sweet nitre. Rubbing and fomentations to the belly must be persevered in.

\section{JNFLAMMATION OF THE BOWELS.}

Enteritis, also sometimes called red colic, may occur as a primary disease, but more often it is seen as a consequence of colic or constipation of the bowels. It generally proves fatal. As an idiopathic affection, that is, occurring independent of any other disease, it may occur from any of the causes of colic, particularly over-loading the stomach.

Symptoms.-The animal is noticed to be unwell; he is dull and stupid; refuses food; has shivering fits, the mouth becoming hot, and extremities alternately hot and cold, the pulse being quick, small, and wiry. He looks towards his flanks; the bowels are costive; after a time, violent pain sets in; the mouth becomes hot, the pulse increases in fre-.. quency, and the pain is continuous and violent. $\mathrm{He}$ rolls about, the sweat pouring off him in streams; the eyes are blood-shot; the belly hot and tender. He does not throw himself violently down, as in colic, but lies down cautiously, and tries to steady himself on his back. As it goes on, the symptoms are augmented, the legs and ears get deathly cold, the pulse gets smaller, and soon becomes imperceptible; the mouth gets cold and clammy; extravasation of blood is going on in the bowels; mortification sets in, the pain ceases, and he may stand up. The pulse is imperceptible; he is dull and stupid; surface of the body cold ; mouth cold; twitching of the muscles, and retraction of the upper lip. He soon falls violently to the ground, endangering the lives and limbs of the attendants who happen to be near him, and after a few struggles expires. After death, the bowels are very much inflamed, and the inner surface black and clotted with extravasated blood. 
Death sometimes occurs in from six to eight hours, and even shorter time. When occurring in consequence of colic or constipation, it is very difficult to determine the exact transition from spasm to inflammation.

Treatment.-In the outset, especially when occurring as a primary affection, and not as a consequence of other disease, copious blood-letting will be advisable-from four to six quarts, or sufficient to make an impression on the pulse. He should be turned into a well-littered loose-box, and allowed to roll as he pleases. The bowels are obstinately constipated, but drastic purgatives are apt to increase the inflammation; our utmost efforts must therefore be directed to open them by copious injections, (of linseed-tea, soap and water, tobaccosmoke, or infusion of tobacco,) back-raking, \&c. A quart of linseed-oil, with two ounces of laudanum, should be given, and repeated, in half the dose, every one or two hours, if required. Fomentations of hot water must be constantly applied to the belly, or bags even wrung out of boilingwater. Where, from the violent tossing of the animal, this is impracticable, blister the belly with tincture of cantharides or mustard and turpentine.

If the symptoms do not moderate in two hours, the pulse continue full, and the legs and ears not very cold, a second bleeding may be advisable; but this is seldom the case, as the prostration is rapid, the pulse becoming small, wiry, and almost imperceptible, and the legs and ears deathly cold. In this case bleeding but hastens the fatal termination.

When it has' continued eight or ten hours, if it takes a favourable turn, the pulse becomes fuller, the surface warmer, and he will lie for some time stretched out, apparently asleep, being weakened from the disease and bleeding, and probably partially narcotised from the laudanum. In this stage he 
must be made comfortable, and covered up in straw or sheets; we usually "bury" him in straw. This restores the balance of the circulation, often causing him to sweat; and after lying thus for one or two hours, he will get up relieved, and begin to feed.

No hay must be given him. After a little, he should be encouraged to drink well-boiled gruel, or eat a thin branmash. Injections must be continued till the bowels are freely opened. For a few days he must be kept warm; a few mouthfuls of cold water may be given every hour; gentle walking exercise and sloppy diet must be continued for some time. About the fourth day, even although the bowels have become regular, he should have a purgative, (from six to eight drachms of aloes, made into a ball,) to remove ingesta, and restore the secretions to their natural condition.

SUPERPURGATION, DIARRHEA, ETC.

An over-relaxed state of the bowels may arise from various causes. In some animials it is favoured by peculiarities of conformation, as is seen in washy borses, animals with long legs, open ribs, and flat sides, with tucked-up bellies, such being liable to purge from the simplest cause.

Change of feed, especially from dry to green, is apt to produce scouring. It is generally, as remarked by $\mathrm{Mr}$ Dun, "the evidence of something amiss, and the natural effort to remove the evil," some irritant or indigested food being lodged in the bowels, to remove which the intestinal fluids are poured out in superabundance. The incautious use of purgative medicines is a common cause of superpurgation. It often occurs in the latter stages of debilitating diseases, when it is always an untoward symptom, betokening a breakingup of the vital powers. The presence of little white worms 
(ascarides) is occasionally the cause. It sometimes follows the drinking of cold water when an animal is in a heated state.

Symptoms.-The symptoms vary according to the nature of the case, and the causes that give rise to it. It may be simply an increased fluidity of the contents of the bowels, as is seen in washy or nervous animals, unaccompanied by pain or constitutional disturbance; or, on the other harid, it may be (as in superpurgation) attended by pain, expressed by the uneasiness, pawing, looking to the flanks, \&c. He strains frequently, and the fæces are very watery; the pulse is small and hard. Rapid and increasing weakness and emaciation, loss of appetite, and, unless means are speedily adopted to check it, inflammation of the bowels is apt to set in.

Treatment.-Great care must be exercised in feeding and watering washy horses, dry feed being best suited to them. They should not be allowed to drink too freely of water, especially before work. In many cases, it may be necessary to give them some starch or chalk mixed up in the feed.

In all cases, the main point is to discover the cause. If arising from improper food, it must be changed at once.

If some irritant be suspected, nature must be assisted in her efforts by giving a quart of linseed or castor-oil, followed up by starch or well-boiled flour-gruel, keeping the animal warm. If worms are suspected, or seen in the dung, one or two ounces of spirits of turpentine should be added to the oil. Should it not yield to this, give the following astringent drench, or any of those given at page 208.

\section{Astringent Drence.}

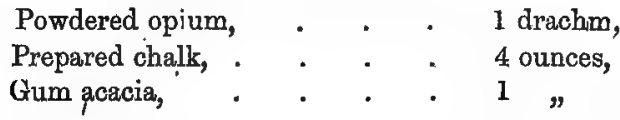

carefully dissolved in warm water, and given in well-boiled 
flour or starch gruel. It may be given two or three times a day, the gruel being given frequently. If very severe, injections of solution of catechu and starch, with a little tincture of opium, should be given.

The belly may be stimulated with liquid blister. He must be kept perfectly warm, and the legs bandaged.

Care must be taken not to induce an opposite state of the bowels by the injudicious use of astringents. An ounce each of carbonate of soda and ginger should be given daily for some time after recovery. Rest and good dry food are necessary for some time.

\section{CONSTIPATION,}

Constipation is a condition the very opposite of the above, in which we have a diminished action of the bowels, the dung being dry and voided with difficulty, leading to dangerous "stoppage of the bowels."

Constipation arises from various causes, especially from being fed on dry fibrous food, as most pastures are in the fall tough and fibrous, with perhaps a scarce supply of water, the fibrous ingesta becoming felted together, and impacted in the bowels. Pea-straw is apt to produce very troublesome constipation, unless bran-mashes and plenty of water are given with it.

It often accompanies colic, either as the cause or consequence. The formation of dust and calcareous balls in the stomach or bowels causes complete stoppage, by becoming displaced from the pouch which forms for them, and mechanically closing up the passage. Sometimes, during the struggles in colic, the bowels become entangled, producing gut-tie, or knot of the intestines, or the bowel becomes folded in like a double night-cap, forming intussusception, producing most obstinate and fatal constipation. 
In sandy districts, horses are sometimes observed to eat sand in mouthfuls-usually arising from acidity of the stomach-which produces very troublesome constipation. We have seen ten or twelve pounds of pure sand passed in the course of a day from one horse.

Symptoms. - When the colon is impacted with fibrous fæces, the animal is dull, stupid, and refuses food;'the bowels are inactive, and the pulse is slower than natural. There is seldom any pain evinced, but the bowels remain unmoved. Similar symptoms are presented when sand has accumulated in the gut, and it is only to be distinguished by the history of the case, or the passage of some of the sand. In most cases of constipation, however, the symptoms are more violent; colicky pains set-in, with unsuccessful efforts to void dung. The pulse, at first slow, soon increases in frequency, and shows a decided tendency to run on to inflammation of the bowels. When dust-balls are present, it is slower in its course, resembles colic more, but is distinguished by the animal sitting on his haunches and straining. This may continue for days, and be at last relieved by the ball shifting its position, and allowing the dung to escape, but to return again before long.

Intussusception resembles dust-balls, but is more violent and more rapidly fatal. Mortification of the inverted gut

speedily cuts him off.

X Treatment.-Simple costiveness, unaccompanied by pain, should be treated by abundance of gruel or thin bran-mash, to soften down the contents of the bowels, followed by a full dose of purgative medicines, as six drachms of aloes with one drachm of calomel, made into a ball, with copious injections of soap and water given every two hours, and slow walking exercise. If it proves obstinate, the belly may be fomented or well rubbed with croton liniment. 
When sand is present, he should be encouraged to drink freely of gruel, or drenched with linseed-oil or tea. Copious injections must be given ; and even after apparent recovery, doses of oil and abundance of slops should be given, so as to clear the bowels thoroughly.

When accompanied by colic, the pain must be relieved, and otherwise treated as in that disease. Dust-balls and intussusception must be treated by purgatives, antispasmodics, back-raking, and injections. Relief will sometimes be given by a colic mixture allaying the spasm, or causing a change in the position of the ball.

Constipation is to be prevented by giving occasional branmashes, carrots, linseed, \&c., with regular exercise and sufficient water, narrowly watching the state of the bowels, and regulating the diet accordingly.

\section{WORMS.}

Several species of worms are found in the intestines and other parts of the horse. The most common variety is the ascaris or ascarides, a little thread-worm, of a dirty white colour; like little pieces of thread, usually from half an inch to an inch long. They are sometimes found in thousands. Professor Dick has observed them chiefly inhabiting the mucous coat of the cœenm, on the surface of which they are developed in little cells, which, when matured, they burst, producing considerable irritation, and of ten fatal diarrhoea.

Varieties of strongyli and oxyures also occur, and are sometimes mistaken for ascaris. They are, however, distinct species; the former is tapered, and terminates in a spine, whereas the latter is blunted, with a head like a leather sucker. The strongyli inhabit the coecum, colon, and duodenum; the oxyures the coecum, mesentery, spermatic cord, and in fact almost every organ in the body. The tricho- 
cephalus dispar, aphinis, common whip-worm, or longthread-worm, are found in the coecum. They resemble a whip, the shank being about a third, and the thong twothirds of the length, usually about two inches.

The teres lumbrici are very common, but seldom numerous, and rarely produce much mischief. They are from six to ten inches long, yellowish white, with a thick skin, about the thickness of a goose-quill, and tapered at both ends. The tape-worm, so common in man and dogs, is rarely seen in horses.

Symptoms.-Many horses have worms, and their presence is never suspected till they appear in the dung. When ascaris are numerous, they occasion indigestion, capricious appetite, and irregular bowels, the coat being rough and dusty; he rubs the tail, and appears uneasy about the fundament. The anus is surrounded with yellow mucus, which is produced by the worm being crushed in its passage through the sphincter.*

He is usually in an unthrifty condition, weak, and easily sweated. Troublesome diarrhœa is sometimes produced by the presence of ascaris in the cœcum. They are sometimes found in vast numbers in the rectum.

Treatment.-Most of these parasites are very difficult to destroy, and but few medicinal substances are known that have the power to dislodge then. Turpentine given in oil, on an empty stomach, is found the most effective.

When they are known to exist, the animal should be put on bran-mashes for a few days, then either muzzle him or

* Authors differ in opinion as to the origin of this yellow matter. Some suppose it to be "an excrementitious product of the worms themselves," others "a morbid secretion from the rectum." We are satisfied, however, that it arises from the crusbing of the animal itself, as the dried skin of the worm will sometimes be found adhering to the anus in connection with it. 
tie up his head, allowing him nothing but water for eight or ten hours, when the following drench should be given-

WORM DRENCH.

Linseed oil,

Spirits of turpentine, .

Mix.
1 quart.

2 ounces.

In an hour after he may have a bran-mash, and next morning a dose of physic. This may be repeated, if necessary, in about a week. Tartar emetic, calomel, santonine, oil of male-shield-ferns, and assafotida, are also recommended, but none have proved superior to turpentine. Other vermifuges are given at page 218. As after treatment he must be liberally fed on good oats, boiled barley, a little oil-cake or boiled linseed, with occasional bran-mashes ; then, with light work, and good grooming, he will soon recover his condition.

$X$ The use of sulphate of iron and arsenic-2 drs. of the former, and 5 grs. of the latter - twice a day for a week at a time, will improve the appetite, and give tone to the system, the iron proving a poison to the worms or their oviparous remains, as no iron enters into the composition of their blood $x$

\section{PROTRUSION OF THE RECTUM.}

The bowels terminate in a straight gut called the rectum, in which the fæces accumulate until they are expelled. Sometimes, in consequence of the painful straining in superpurgation and diarrhoea, or loading of the colon and constipation, the gut is forced out, and protrudes to the length of one or two feet.

Treatment.-It must be returned at once, wash it with tepid water and a little spirits, pass up the hand well oiled, and remove any fæces that may be within reach, and it will be easily replaced. Some bland gruel injection, with one or 
two ounces of laudanum, should be thrown up, the tail being tied down, and a tight surcingle placed around the loins. He must be kept quiet, and sparingly fed on easilydigested food, to prevent recurrence.

Sometimes, when neglected, and allowed to remain long out, it becomes swollen and dark coloured, when it should be scarified lightly, and washed with dilute laudanum. If cold and black, without feeling, gangrene has set in, and it may be removed, or allowed to drop off. Animals have been known to live with a considerable portion of the rectum removed.

\section{HERNIA OR RUPTURE.}

From the natural habits of the horse, and the circumstances in which he is placed, accidents frequently occur, whereby the walls of the different cavities, containing the delicate organs of the body, are ruptured or burst, allowing the contents to escape out of their natural position. This is what is known as hernia or rupture; however, the term is usually limited to the most frequent form of that protrusion, viz., that from the cavity of the belly, (abdomen.) In scien-. tific works, hernia receives different names, according to the situation of the rupture, or the part protruding, or the pathological condition of the part. In all cases, however, it consists of the escape of a portion of the gut, either through a natural opening unduly enlarged, or an opening produced by accident.

Causes.-Rupture is not uncommon in young foals, occurring at the navel-opening, (umbilicus,) either from nonclosure after birth, or the cord being stepped upon, tearing it open again, thus allowing the gut to protrude, forming a . . tumour large or small, according to the quantity of gut that has escaped. It also occurs in the scrotum (bag containing the testicles) in foals at birth. 
In older animals it usually arises from violent exertion, and may occur in any part of the belly. It is often produced by being hooked or gored by an ox, or staked in leaping a fence-not unfrequently by coming forcibly in contact with a rail or a snag in galloping in a clearing. In the entire horse the gut frequently escapes into the scrotum from violent kicking or jumping. A very formidable case of rupture sometimes occurs from castration, in which the bowel escapes after the removal of the stone, caused either by previously existing hernia, or produced at the time by the violent struggles during the operation. Occasionally, during an attack of colic, from the rolling and tossing about, the midriff (diaphragm) is ruptured, allowing the stomach or part of the bowels to escape into the chest, as in one case which occurred in our practice in Toronto, in January 1865, in which the small intestines, to the extent of thirty feet, were forced into the chest.

Symptoms.-In foals, when occurring at the navel-opening, the tumour is soft and pendant, and by steady pressure can be pushed entirely up, and the opening through which it escapes can be felt with the finger, returning very soon when the pressure is removed. When occurring in the scrotum of the foal, it is easily distinguished by the size of the bag. The symptoms in older animals vary according to circumstances. When occurring in the belly from accident or injury, the foreign body may penetrate the skin and muscles of the belly, perhaps wounding the bowels themselves, allowing them to escape to a considerable extent, or the muscular walls alone may be burst, and the bowel and its covering (peritonæum) descends into the sac formed by the skin. This is recognised by its soft nature, and being easily pushed up. The symptoms of displacement into the scrotum of the stallion, or, as more commonly happens, merely into the 
opening communicating with that bag and the cavity of the belly, (inguinal canal,) are apt to be mistaken for colic. They are very much alike; but there is this difference, that the pain is continuous, and if the hand be passed down the groin, an oblong tumour will be felt, which may be elastic from distension with gas, containing fæcal matter, and if he is coughed, the tumour is increased in size. It is apt to become strangulated, that is ${ }_{2,}$ the passage of the contents of the bowel is interrupted from the tightness of the constriction at the neck, and the circulation of blood is impeded, giving rise to inflammatory swelling. When this occurs, the colicky symptoms give place to those of acute inflammation of the bowels, the pulse becomes small, quick, and wiry, he suffers intense pain, looks round to his flanks, but does not kick at his belly. He rolls about, endeavours to steady himself on his back, there is no remission of pain. Mortification soon sets in, if not relieved. When the pain ceases he stands up, quivers, has a haggard look, extremities deathly cold, vomiting is sometimes seen, the pulse is imperceptible, he sways on his legs, and ere long drops dead.

Treatment.-The principles to be observed in the treatment of hernia are, to return the bowel as soon as possible to its natural cavity, and retain it there; when, unless the opening be very large, it soon grows over.

In the case of foals, it is best done by judicious bandaging and properly adjusted pads, which must be kept constantly applied until the opening has been filled up. In older animals it is sometimes necessary to cut into it, and, replacing the gut, bring the muscles together by strong metallic sutures or wire skewers. Sometimes it is sufficient to pass two skewers through the loose skin at right angles to one another, and tie a hard whip-cord tightly on above it, which stops the circulation in the skin, which in a few days drops off. 
The treatment of scrotal or inguinal hernia in stallions requires a considerable amount of anatomical knowledge of the part, and should not be undertaken by an amateur. A gentle effort should be made to press it up from without; no force, however, should be used. The operation known as taxis must be resorted to if this fail,-it consists in securing him on his back, removing the fæces from the rectum, and passing the hand, previously well oiled, into the rectum. With the other hand passed up the sheath, by gentle pressure from without, and slight pulling from within, it can sometimes be replaced-if not, the inguinal canal must be enlarged by passing in a bistoury, and returning the gut by taxis, if it does not return itself. However, before this is resorted to, antispasmodics and copious blood-letting are advisable, so as to relax the muscular contractions of the parts involved.

In young animals affected with hernia, castration in the usual way is dangerous-it must be done by the covered operation. See castration, page 203.

In all cases of hernia, care must be taken not to load the bowels with bulky food-thin gruel, and easily-digested food must be given for some time.

\section{THE LIVER.}

The liver is a well-known organ,-its function of secreting bile is also well known. It is the largest gland in the body, and differs from that of man and the ox in having no gall-bladder for the reception of the bile; which, in the horse is conveyed directly to the first bowel, (duodenum, in conjunction with the duct of the sweetbread, (pancreas.)

The bile which is secreted, or, as some express it, eliminated by the liver, may be considered as an excrement, the retention of which in the blood would be injurious to the 
constitution; but at the same time it is essential to the process of digestion in the conversion of chyme into chyle, and also by commingling with the freal matter in the bowels, assisting in keeping them open. Diseases of the liver are not very common in this eountry, or indeed in any country, owing, in a great measure, no doubt, to the simple arrangement of its structure.

\section{HEPATITIS OR INFLAMMATION OF THE LIVER.}

Acute inflammation of the liver is not often seen in the horse, or at least is so obscurely marked as to be exceedingly difficult of detection during life, and, as remarked by Professor Dick, "the pain of the affected part is very obscure, and the natural language of the sufferer not expressive, nor is the symptomatic fever marked."

Causes. - The most likely cause to give rise to it are high feeding with insufficient exercise, especially during our hot summer months, or it may happen in consequence of injury to the right side of the belly, as, being kicked or otherwise bruised.

Symptoms.-It is usually ushered in by dullness, inaptitude for work, uneasiness, more or less fever, bowels costive, fæces small and of a reddish brown colour, urine scanty and high-coloured, membranes of the eyes, mouth, and nostrils of a yellow tinge, tenderness on pressure over the region of the liver. Lameness of the off-shoulder has been observed in these cases, and in so marked a degree as to have been mistaken for the principal disorder.

Treatment.-The appropriate remedies are purgatives, sedatives, and blisters to the side. Give from seven to nine drachms of Barbadoes aloes made into a ball, followed by injections of soap and water, or solutions of aloes. Give also fifteen drops of Fleming's tincture of aconite every two 
hours. When the fever has somewhat abated, apply a strong liquid blister to the right side of the belly, from the girth to the border of the ribs. On no consideration must calomel be given until recovery begins to take place, when, if there be any, suspicion of portal stagnation, indicated by increased yellowness of the membranes, scantiness of the secretions from the bowels and kidneys, the following may be given with advantage : $X$ Barbadoes aloes, one ounce; calomel, two drachms; linseed meal and soft soap, sufficient to make a mass-divide into four, one daily, unless the bowels become too open. Ph

\section{CHRONIC HEPATITIS.}

Complete recovery from acute inflammation of the liver seldom takes place: it usually assumes a chronic form, giving rise to enlargement and softening of the gland, and not unfrequently abscesses are formed in its substance.

Causes.-It most commonly comes on without our being able to trace it to any direct cause; however, it no doubt sometimes does arise as a sequel of acute hepatitis; also, in old, highly-fed animals, having little or no exercise, arising in the first place from functional derangement, leading to organic disease, and gradual breaking-up of the structure of the organ. It is also seen in old hard-worked horses, which have never been too highly fed, and often is never suspected until attention is drawn to the "rotten" state of the liver after death.

Symptoms are, irregular appetite; he is dull and languid, and easily sweated; the coat is rough and scurfy ; he gradually loses condition. The membranes of the eyes, mouth, and nostrils are yellow, the bowels costive, dung dark-coloured and glazed. The urine is scanty, and of a brownish-yellow colour, with, in most cases, lameness in the right shoulder. 
Treatment.-The appropriate remedies are blisters to the right side, occasional small doses of aloes and calomel, moderation in feeding, gentle exercise, with tonics, as sulphate of iron and arsenic, or iron and quinine. See tonics, page 217.

\section{RUPTURE OF THE LIVER, (HEPATARRHEA.)}

In old pampered horses rupture of the liver sometimes occurs, usually producing sudden death, at other times more gradual. The symptoms are obscure and seldom observed. After death the belly is filled with blood, the liver is pale and flaccid, and the lesion can usually be easily detected.

\section{DISEASES OF THE SPLEEN.}

The spleen or milt is that soft spongy bluish-red organ found at the left of the stomach, between it and the false ribs, the use of which has never been determined, nor are its diseases well defined. We have never met with a case in the horse in Canada. Professor Dick remarks, that " the diseases which have been principally signalised in the spleen are enlargement, usually chronic, of ten united with tubercles, sometimes with softening and rupture, of course, speedily followed by death." He also mentions a case where this gland was found to weigh not less. than seventy-two pounds. $\mathrm{Mr}$ Percivall also mentions several cases of enormous enlargement of this organ. The only symptoms by which it can be recognised are gradual loss of condition and inaptitude for fatigue, with the negative symptoms of absence of disease in any other organ.

\section{THE PERTTONEUM.}

The peritoneum is the thin serous membrane which lines the cavity of the belly, and is reflected over the organs contained within it, forming a complete covering to them. It 
also suspends and retains them in their proper relative positions by its folds and reflections, vulgarly known as the caul, (omenta.) This membrane also secretes a delicate serous fluid, for the purpose of lubricating the surface, so as to prevent friction during the ceaseless motions of the viscera. It is also the matrix over which the blood-vessels are distributed to the organs contained in the belly; hence the inflammations of these organs are apt to extend along this vascular-investing membrane, constituting

\section{PERITONITIS.}

Peritonitis occurs in two forms, acute and chronic. Acute peritonitis, as a primary disease, is not very common in the horse.

Causes.-It is usually caused by external violence, as from being hooked by a cow's horn, or staked in jumping a fence; it also sometimes follows castration, operations for hernia, and other operations involving a division of it, and occasionally from exposure from damp and cold, especially when heated.

Symptoms.-It usually sets in with shivering fits, general uneasiness in the region of the abdomen ; quick, short breathing; pulse quick, small, and wiry; tenderness on pressure on the belly; lying down and rising frequently; he moves about uneasily in his box, and is very feverish; the bowels are costive, and he strains occasionally. The pain is not so violent as in colic or inflammation of the bowels, for which it is apt to be mistaken.

Treutment.-Relieve the bowels by injections, give a brisk purgative, as six drachms of aloes, with a drachm of calomel. Drachm doses of extract of belladonna or hyoscyamus, should be given every hour, for three or four doses ; or tincture of aconite, from fifteen to twenty drops every two hours, in a little cold water, till the fever is subdued. Apply smart counter-. 
irritation to the whole surface of the belly by rubbing in a strong liquid blister. The treatment of peritonitis does not differ very materially from that of enteritis,-which see.

\section{CHRONIC PERITONITIS.}

We sometimes meet with cases of chronic inflammation of this membrane.

Causes.-It may arise as a primary affection, but more commonly it occurs in connexion with chronic chest diseases, or as a consequence of acute peritonitis. Occasionally when peritonitis terminates favourably, morbid adhesions are found as the result of exudation, causing ${ }^{2}$ dangerous agglutinations of the parts, and not unfrequently the membrane is so wealsened by the disease as to assume a new character, and secrete watery fluid, giving rise to the condition known as dropsy.

Symptoms.-When occurring, independently of pre-existing inflammation, it is characterised by slight uneasiness, pawing, occasionally looking to the flank, lying stretched out, gnawing, \&c., with tenderness of the belly ; and when effusion has taken place, the symptoms of dropsy are well marked.

Treatment.-It is best treated by purgatives, with stimulants and diuretics. In the outset, give a purgative, and apply a blister along the whole course of the belly, gentle exercise, and good grooming and liberal feeding, with about two ounces of sweet spirits of nitre, and two drachms of iodide of potassium given daily in two doses; ; and afterwards small doses of mineral tonics.

\section{DROPSY OF THE BELLY (ASCITES.)}

Ascites consists of a collection of serous fluid in the cavity of the belly. It is not very often seen, unless in connexion with some other disease. 
Causes.-It is usually the result of chronic peritoneal inflammation, or a sympathetic extension, or accompaniment of "water in the chest," (bydrothorax)-chronic disease of some importan't organ contained in the belly, which it invests. Occasionally it occurs in conjunction with enlarged liver or spleen. Sometimes also from impeded circulation, consequent on abnormal tumours pressing on some important vessels; and, unquestionably, as in the human subject, some animals have a dropsical tendency (diathesis.)

Symptoms.-The animal is observed to be dull and inactive, the bowels are costive, and the urine scanty; he is always thirsty, watery swellings appear between the fore legs, which soon extend backward along the belly to the sheath or udder; the belly is large, and when struck, emits a dull heavy sound. As it goes on, the breathing becomes hurried, and the pulse quick and small, the thirst intense, the appetite fails, the enlargement of the belly becomes more perceptible, the external swelling greater, and the breathing much increased; as death approaches, the pulse becomes imperceptible, and as Blaine remarks, "the peritoneal inflammation produces colicky symptoms frequently, and in this way being occasionally but little disturbed, and at other times very ill, a few active symptoms carry off the poor beast."

Treatment.-When the watery effusion is extensive, few cases recover; however, much can be done to arrest it in the early stages; the prospects of recovery, of course, depending a good deal on the cause of the complaint: when accompauied by hydrothorax, it almost invariably proves fatal. The strength from the first must be harboured, stimulants must be given from the beginning; open the bowels by an active purgative, smart friction being frequently applied to the belly, or if the swelling is considerable, it should be sup- 
ported by bandages; should the state of the patient permit, walking exercise should be persevered in. The following ball should be given daily :-

$$
\begin{aligned}
& \text { Iodine, ·. . . . . } 1 \text { drachm. } \\
& \text { Iodide of potassium, . . . } 1 \text { " }
\end{aligned}
$$

Linseed meal and soft soap, sufficient to form a ball. Occasional doses of sweet nitre and warm beer should be given. Free scarifications with a lancet or sharp knife should be made in the swelling.

Tonics should be more early used than they generally are; a very good tonic ball in these cases consists of-

$$
\begin{aligned}
& \text { Sulphate of iron, . . . } 2 \text { drachms, } \\
& \text { Iodine, }
\end{aligned}
$$

made into a ball with linseed meal and soft soap; or,

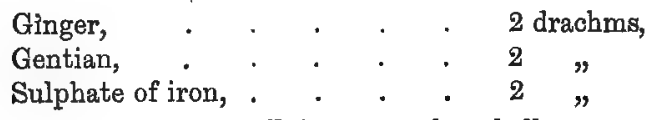

Molasses sufficient to make a ball.

When medicinal treatment fails, temporary relief may be obtained by tapping (paracentesis abdomenis), which consists in puncturing the belly, in the line between the navel and the sheath (or udder), taking care not to injure the bowels, or any important vessels, in doing which the belly must be tightly bandaged, and kept compressed. 


\section{CHAPTER VII.}

DISEASES OF THE URIN̈ARY ORGANS.

THE urinary organs consist of the kidneys-two oval-shaped bodies of a reddish-brown colour found lying close under the spine, in the region of the loins, (lumber region), the use of which is to eliminate from the blood the superfiuous water, holding in solution the saline and earthy impurities, retention of which in the system would be highly injurious; the ureters, two little membranous tubes which convey the urine from the kidneys to the bladder. 'The bladder itself, a large membranous bag, lying in the cavity of the pelvis, in which the urine is received and retained, to be ejected at the convenience of the animal'; and the urethra, a contractile canal leading from the neck of the bladder, along the under surface of the penis, (in the horse), at the extremity of which it terminates by an open orifice, separated from the body of the glans by a fossa ; and in the mare it opens into the floor of the vagina, about four inches from the outer opening in the meatus urinarius.

\section{INFLAMMATION OF THE KIDNEYS (NEPHRITIS.)}

Inflammation of the kidneys is not nearly so common in this country as many farmers, and most of the "farriers," would lead us to suppose. We frequently meet with wiseacres of this stanu, who, no matter what the case may be, if 
he shows symptoms of abdominal pain, "knowingly" pronounce it "inflammation of the kidneys."

However, nephritis is now and then to be met with, though rarely.

Causes.-In the acute form, it most commonly arises from over-straining in heavy draught, galloping on heavy ground with an over-weight up, injuring the muscles of the loins, and involving the kidneys; also from feeding on musty hay or oats, or the too free use of diuretics, either producing inflammation directly, or rendering them weak and more liable to it when exposed to exciting causes. It is sometimes seen in horses kept in open stables or sheds, where water gets dropping on their loims, exposure to cold when heated or wet with rain will also give rise to it.

Symptoms.--He is fevered with a quick, hard, but full pulse, sometimes he is much pained, lies down and groans, throwing his legs out, and pointing with his nose to the flank or loins, he soon gets up, and stretches as if to stale, makes frequent efforts, and forcibly ejects a small quantity of high-coloured and often bloody urine. There is pain evinced on pressure on the loins, he straddles in walking; he is very unwilling to turn or move in the stall. It may be distinguished from inflammation of the bladder by passing the band up the rectum, when the bladder is inflamed it will be hot and tender.

Treatment.-The fever must be combated, but not by the copious and repeated blood-lettings, so commonly recommended in books, which is too depleting and apt to weaken. Give in a little cold water or gruel, with the drenching horn, fifteen drops of tincture of aconite, every two hours; or either of the following balls may be given, two or three times a-day if necessary :- 
Extract of hyoscyamus, Calomel, . . . 2 scr. Linseed meal, . . $2 \mathrm{dr}$.

To be made into a ball with honey.

$1 \mathrm{dr}$.
$2 \mathrm{scr}$.
$2 \mathrm{dr}$.
with

We do not consider purgatives so very essential in the early stages. Oily laxatives are sufficient; give a quart of either linseed or castor oil. Bland fluids, such as linseed tea, should be injected into the rectum; mustard poultices, or a newly flayed sheep-skin, should be applied to the loins, but blisters containing Spanish flies (cantharides) or turpentine must be avoided; bandage the legs, and clothe the body, and encourage perspiration. He should be encouraged to drink freely of linseed tea or well boiled gruel, with a little carbonate of soda dissolved in it. In the secondary stages, when the acute symptoms have subsided, the bowels must be freely opened so as to carry off the fluids of the blood, and thus lessen the work of the kidneys. For this purpose give the following ball :-

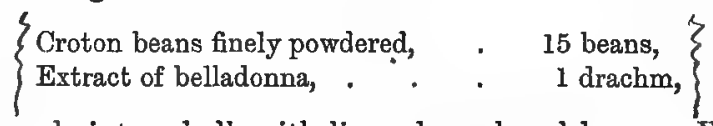

to be made into a ball, with linseed meal and honey. When recovery takes place, he must be carefully nursed, and fed on good sweet hay or oats, linseed tea, \&c., and avoid anything likely to stimulate the kidneys.

\section{PROFUSE STALING (DIURESIS.)}

Diuresis or polyurea, sometimes erroneously called diabetes, is very common in this country; its pathology, however, is not yet fully investigated. It consists principaily of simple, increased secretion of urine, without any apparent structural disease of the kidney, or much alteration of the composition of the urine, so characteristic of this affection in man. 
Causes.-Its frequency in Canada arises in a great measure from the hay, which, in some seasons especially, is in a very bad state of preservation, owing to its hurried preparation, consequent on our short season, or the insufficiency of the barns to keep out wet, and becomes heated and musty; also from exposure to the severe cold of our winters and insufficient shelter.

Frequently it occurs as an accompaniment of acidity of the stomach, or from the injudicious use of diuretics, of which most " condition powders" of the shops are principally made. Sometimes from the too free application of cantharidine blisters, which, becoming absorbed, stimulate the kidneys. Sudden checks to the perspiration often give rise to it.

Symptoms. - The intense thirst first attracts attention, he is constantly craving for water, he rapidly loses condition, the coat becomes rough and staring, he passes large quantities of clear urine, his litter being constantly wet. He will be seen poking among his litter, which he often eats with avidity, in preference to good hay. If it goes on unchecked, great prostration set's in, the heart beats tumultuously, the throbbing being often visible at the side, the pulse being irregular and intermittent.

Treatment.-It is generally very easily checked if taken in time; a complete change of diet is indispensable; give good sweet hay-carrots are recommended. The bowels must be freely opened. Professor Dick says :- " I have found iodine in doses of two drachms, once or twice a-day, a never-failing remedy, very useful in correcting the thirst and checking, the flow of urine." The following ball may be given night and morning:-

Iodine,

Iodide of potassium,

Barbadoes aloes,
1 drachm.

1 drachm.

1 drachm. 
Liquorice and syrup sufficient to make a ball. Tonics should be commenced early. In some cases it can be arrested by making him drink water with pipe-clay or peasemeal shaken. up in it. A run at pasture will often cure it.

\section{INFLAMMATION OF THE BIADDER (CYS̃TITIS.)}

The bladder may be inflamed in its body or neck; the former is rarely seen, the latter occasionally.

Causes.-It may arise from the too free use of diuretic medicines, or from the injudicious use of fly blisters or turpentine; sometimes from the presence of concretions or gravelly deposits in the bladder, or an extension of spasm, or inflammation of other organs.

Symptoms. - When the body of the viscus is the seat of the disease, it becomes very irritable, the urine being passed almost as soon as it reaches the bladder-the act of staling being almost constantly going on.

The other symptoms are nearly analogous to nephritis; when examined by the hand in the rectum, it is found empty, hot, and tender. When the neck of the bladder is the seat of the disease, it will be found distended with urine, and, instead of frequent staling, we have almost complete suppression of urine.

Treatment.-The treatment resembles that recommended for nephritis-which see. Should the contraction of the neck continue, a gum elastic catheter should be introduced, or a little warm oil may (in the mare) be injected into the bladder. Small doses of bicarbonate of sodá or potash should be given to neutralise the urine, which is usually acid.

\section{URINARY CALCULI.}

Healthy " urine consists of water, holding in solution certain animal and saline matters as its ordinary constitnents, 
and occasionally various matters taken into the stomach, as food, salts, colouring matters, and the like," (Kirkes.) In certain states of the constitution, and various stages of disease, the relative quantity of these constituents is greatly increased and apt to be precipitated, sometimes forming granular deposits in the urine when passed, at others assuming the form of gravelly accretions, or even calculous formations in the kidneys, bladder, or urethra, giving rise to much irritation and constitutional disturbance.

In the horse these accretions are of rare occurrence compared with man, owing in a great measure to the more active . habits of the former, and less variety in the articles of his diet, favouring more active digestion and assimilation, upon derangement of which important processes the disposition to calculous formation depends; also, the size and relative arrangement of the urinary organs in the horse, favouring the escape of calculous nuclii before they have attained an injurious size. However, calculi or stones in the bladder are occasionally met with in horses, sometimes in the pelvis of the kidney, but more commonly in the bladder or urethra,the former being beyond our reach, the latter removable by operation.

\section{STONE IN THE BLADDER (Vesical Calculi.)}

These concretions may be found rolling about in the cavity of the bladder, or surrounded by false membrane adherent to the walls of the viseus (encysted,) or they may occupy the neck passing into the uretbra. They are sometimes small, and more than one are present, but more generally they are as large as a pigeon's egg or a small hen egg, and single, usually oval or roundish flat in shape, and rough or smooth according to their composition.

Causes.-They are usually the result of lithic diathesis 
consequent on faulty assimilation; a nucleus, (usually of oxalate of lime, ) either forms in the bladder or escapes from the kidneys, round which the solid constituents of the urine concrete, layer after layer being deposited until a stone is formed.

Symptoms.-The early symptoms are indefinite, and seldom attract attention; he may be noticed to express uneasiness in staling, and to urinate more frequently; the urine is usually thicker, whiter, and less in quantity; he is subject to little fits of uneasiness, and the grooms remark that he is "troubled in his water ;" slight stiffness in the loins is observable in walking.

When it attains the size of a stone, the symptoms are more characteristic; he makes frequent but ineffectual efforts to stale, or a few drops may dribble away; is often found standing stretched as if to stale, the penis hangs out, the urine is continually dribbling away, the sheath is wet and excoriated, the 'legs wet, and the hair in front rough and discoloured. He rapidly loses condition. . The appetite is usually very good, and the bowels regular. He straddles in his walk, and turns with difficulty.

These symptoms should at once lead to examination by the hand introduced into the rectum, when the stone may be felt. It is distinguished from the fecal pellets by its hardness, size, and shape. It may or may not be movable.

Treatment.-It is very rarely we are called upon to prescribe in the early stages of calculous formations. The plan of treatment is evident; we must remove the uric tendency by regulating the diet and exercise, improve digestion and assimilation by tonics, vegetable and mineral, and increase the solubility of the deposits by giving appropriate medicines. Thus, when on examination the urine is found containing excess of uric acid, alkalies must be given. The carbonates 
of magnesia, soda, and potass are recommended; the latter, however, is much more preferable; the soda is apt to conbine with the uric acid, forming an insoluble compound, while the magnesia, when long continued, is apt to cause intestinal concretions. Carbonate of potash should be given from one to two ounces daily, largely diluted with water. When, however, it is found to be phosphatic or oxalic, the minetral acids should be substituted,-hydrochloric or nitromuriatic from two to four drachms daily, with plenty of water, gruel, and other dilutents.

Most cases, however, which come under our notice require surgical interference for the removal of the stone. See Lithotomy, page 193. 


\section{CHAPTER VHIT.}

THE GENERATIVE ORGANS.

THE organs of generation in the male horse consist of two oval glandular bodies called the testicles, suspended from the hollow between the thighs, and containèd in a pendulous bag called the scrotum. The office of these glands is to secrete the seminal fluid which is essential to impregnation. Two membranous ducts (vasa deferentia) which carry the semen from the testicles to two oval bags (vesiculce seminalis) lying near the upper surface of the neck of the bladder, from which during copulation it is ejected into the urethra, and conveyed by the external organ, the penis, into the vagina of the mare.

The female organs of generation are: the vulva-that part seen in the perineum immediately below the anus; the vagina-the membranous canal leading from the vulva into the uterus or womb; the uterus or womb-that membranous sac in which the impregnated ovum is contained and supported during the development of the foetus; the ovaries - two glandular bodies similar in shape to the testicles of the male, but much smaller. They are found lying under 'the loins' a little behind or in a line with the kidneys. Their use is to secrete the ova or seed of the female. And the fallopian tabes, the canals which convey the ova from the ovaries to the womb. 
DISEASES OF THE GENERATIVE ORGANS.

Diseases of this system of organs are rare, and are usually the result of accident or injury.

\section{INJURIES AND DISEASES OF THE PENIS.}

Causes.-The penis or yard of the stallion more particularly is liable to injury, from being kicked in covering, or sometimes it gets injured by awkwardness of the groom in serving mares; also from being cruelly struck with a whip or stick while in a state of erection. Warts and excrescences frequently cover the surface of the organ.

Symptoms. - We may have injuries of more or less severity from a slight scratch to deep and severe laceration of its substance; or, on the other hand, the blow may have merely bruised, without breaking the skin, producing want of power to retract it, and often accompanied by enormous swelling of the organ. When long out, the glans assumes a reddishbrown colour, and the surface is cold, with very little sensibility. This is known as paraphymosis. Sometimes these swellings subside, but thickening and enlargement of the lower part remains, preventing retraction within the sheath, proving very troublesome and unsightly.

Warty excrescences are easily recognised, and may occur on any part of the organ.

Treatment.-Injuries from kicks and blows must be treated on the general principles of subduing inflammation. If it hangs pendulous, it must be supported by a broad bandage round the body, and copious affusion with cold water, or iced water in summer, constantly applied; if very hot and tender, accompanied by fever and constitutional disturbance, hot fomentations may be more applicable; whichever is employed must be persevered in for some length of 
time. Purgatives should be given, and low diet for some time.

Unless there is extensive laceration of the substance of the organ, nothing more than cold applications are required, should it prove tardy in healing, goulard lotion, or a mild solution of sulphate of zinc will prove beneficial. When it continues, and the tumefaction increases, free and deep longitudinal scarification must be made on its surface, and repeated in a few days, if necessary. Sometimes charcoal poultices are required to cleanse the wounds and soothe the part.

\section{AMPUTATION OF THE PENIS.}

Occasionally cases occur in which callous enlargements of the extremity of the penis remain, preventing its retraction within the sheath, rendering amputation necessary. This operation is also sometimes performed in cases of obstinate - and deep-seated ulceration of the tissues of the organ. He must be cast and secured as for castration. The penis is taken up and washed clean, a catheter is introduced, and a broad tape or bandage is applied round the upper part, so as to recover it should it slip out of the hands of the assistant. It is now firmly held by the assistant, and a ligature applied tight' enough to arrest the hæmorrhage; an incision is then made with a scalpel or bistoury round the circumference, sloping toward the urethra, which should be left an inch longer than the other tissues. Having removed the part, the vessels may or may not be ligatured as the operator sees necessary ; we prefer to ligature them, as troublesome bleedings sometimes follow the operation, when performed by " one sweep of the bistoury," so frequently boasted of, and it is more surgical than the application of the cautery, which is too often made use of in arresting hæmorrhages, to save trouble to the operator, regardless of the suffering of the patient. 
Warts and other excrescences on the surface of the organ should be removed with the knife; cold water freely applied, or the muriate of iron, will suffice to close the vessels.

\section{FOULNESS OF THE SHEATH AND YARD.}

In geldings the penis becomes diminished considerably in size, and, from want of the sexual desire, seldom protrude it without its covering, the sheath, consequently the sebaceous secretion of the glands in the prepuce accumulate, forming a black soft foetid substance, with a strong persistent uric odour. This sometimes becomes irritating, and gives rise to uneasiness, and should be occasionally washed out with warm water, and a soft sponge, taking care not to scratch or bruise the inner surface, as troublesome swellings sometimes ensue.

More trouble, however, arises from the accumulation of little round "beans," (as horsemen call them,) of a soft clayish appearance, in the cavity in the head of the penis, surrounding the end of the urethra; sometimes obstructing the passage of the urine, by pressing on the urethra, or even stopping up the orifice itself, giving rise to difficulty in staling, and uneasiness.

The sheath should be washed out with soap and water, and the hand, well oiled, should be passed up, and the penis drawn out, when the accumulation should be removed, taking care not to scratch or bruise the parts.

\section{CANCEROUS DISEASE OF THE VULVA.}

Cancerous tumours are sometimes met with, involving the lips and inferior commissures of the vulva, sometimes extending inward, involving the clitoris and floor of the vagina, as in a case of a black mare belonging to $\mathrm{Mr}$ James $\mathrm{M}$ 'Kenzie, West Zorra, County Oxford. She had been affected with it for several years; on examination we found a large tumour, 
occupying the greater part of the vulva, attached to the floor and sides, very foetid, presenting angry-looking ulcerations, covered by thin sanious matters, the surface being soft and irregular, and bled very easily. From the irritation oceasioned in urinating, and by the rubbing of the tail, it produced considerable annoyance; other ways the health seemed good. We at once informed the owner that treatment was useless, but removal by the knife would afford temporary relief. We had her cast, and cut as much of the tissues involved as prudence directed us, removing the clitoris and most of the substance of the labii ; cold water, followed by muriate of iron, sufficed to check the bleeding. Arsenic in doses of five grains night and morning were now given, and arsenic ointment applied-alternated now and then with a solution of corrosive sublimate, twenty grains to the ounce of alcohol, which in some measure retarded its progress. In the space of two years, we removed it three times, each time getting more extensive and deep-seated. We have treated several such cases, but with the same result. Tumours, not of a cancerous nature, are often met with here, which are usually easily removed, and do not return again.

\section{LEUCORRHGEA OR "THE WHITES."}

Leucorrhcea consists of a discharge of white matter from the vagina, arising in consequence of a diseased state of its lining membrane, or of the womb itself.

Causes.-It usually results from chronic inflammation of the lining membranes of these parts, and is usually described as a "catarrh of the vagina."

Symptoms.-It is easily recognised by the white uniform appearance of the discharge, which in some cases is almost constant; in others it is pent up, and at intervals of one or two days comes away in large quantities, often with consi- 
derable fetor and a very disgusting appearance. The constitution is more or less disturbed, and she often becomes emaciated.

Treatment.-Cold water should be frequently injected, or a solution of. sulphate of zinc, as

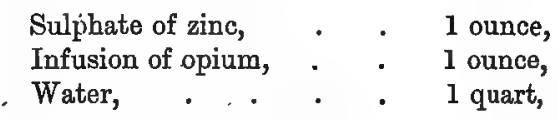

to be well shaken up, and a little injected several times a day. Tonics are very serviceable, and should be persevered in. Occasional diuretics are useful. The following balls are recommended by Mr Percival :-

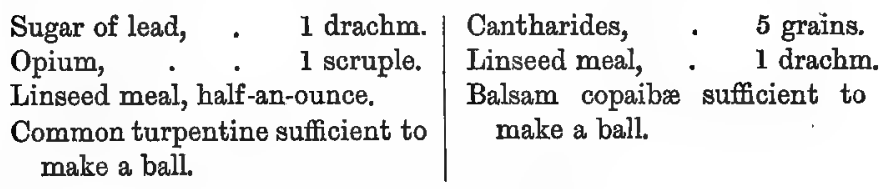

One or two of either may be given daily.

\section{PARTURITION OR FOALING.}

The period of gestation in the mare varies from eleven to thirteen months. Usually about ten days before foaling she begins to "make bag," the udder enlarges, and a thin milky fluid can be drawn from the teats, and a glairy discharge escapes from the vagina, giving warning that the foal is about to be dropped. When the time approaches, she becomes uneasy, getting up and down frequently. Presently the true labour pains begin, the womb contracts on its contents, assisted by the diaphragm and abdominal muscles; the whole body is convulsed with the effort; the mouth of the womb becomes dilated; the water-bag appears and bursts; and when the presentation is natural, a few efforts force it out-sometimes enclosed in the membranes, which 
must be immediately removed; and if the cord does not give way itself, it being sometimes thick and strong, a ligature should be put on it about four inches from the belly, and the remainder cut away. In general, mares are best left to themselves at this important period, but care should be taken that they do not get into awkward positions, as against a wall, or the sides of the box.

\section{ABNORMAL PRESENTATIONS.}

The natural position of the foal at birth is with the head resting on the two fore-legs. When in this position, and the parts natural, it soon comes away without very much exertion. In many cases, however, the foal is found in such positions as to prevent its escape without assistance. In all cases of protracted labour, where the pains continue without effect, assistance may be required. The hand being raised in temperature by washing in warm water, should be introduced to ascertain the cause. 'In some cases the neck of the womb will be found not sufficiently dilated, but the foal is found in its natural position. In such cases, it may be gently dilated with the hand, or left alone, when nature will often overcome it herself. In cases of natural presentation, we must not be in too much hurry to deliver; harm is often done by injudicious interference. One or both fore-legs may be doubled back, with the head presenting. In this case, push it back, and pass the hand down'the leg if possible; get them up into the passage, either by the hand or looped cords passed round the fetlock, when, by slight traction, it will generally be bronght away. The legs may be presented in the passage, and the head either doubled down under the brim of the pelvis, or turned over the shoulder down on the flank. In this ease, it should be pushed bodily back, and the head sought for, when a loop must be placed, if possible, 
on the lower jaw ; it must now be pushed back, while the head is to be pulled forward, and brought into the passage. This case is often very troublesome, from the difficulty sometimes experienced in reaching the head. It is sometimes necessary to remove one of the legs by cutting the skin round the fetlock, and with the embryotomy knife dividing the skin of the leg as far as the shoulder, and separating it with the fingers, when it can be removed. A cord should be attached to the loose skin to aid in traction, when the head can in most cases be reached. We have had occasion to remove both legs in the same manner before delivery could be effected.

Sometimes the buttocks and tail are only to be felt; this is often a troublesome case, especially when the legs dip under the pelvis. It must be pushed well in, and the-hind feet, if possible, secured and brought into the passage. Often, however, it is very difficult to do, when, as recommended by "Professor Dick, " the contents of the abdomen imust be removed at the rectum; the pelvis divided at the symphysis, when a cord being attached, and force used, the hind legs will get into the place of the viscera, and the quarters collapse so as to allow of extraction." The whole four feet may be presented in the passage; the simplest way of delivering in this case is to feel for the hocks, and slip loops on the hind feet; and by pushing back the fore ones, it may be removed, by the hind legs.

It is impossible to describe minutely the details of procedure in these cases, as, from difference in collateral circumstances, such as size, age, length of time she has been in labour, swelling of the parts, \&c. \&c., different plans of treatment must suggest themselves to the operator. The principles to be observed are these : endeavour to get it into its natural position, in which position it is easiest delivered; 
failing in that, to get it into the next easiest, viz., the hind legs first-that impracticable, to remove those parts of the foal which offer most resistance, care being taken in so doing not to bruise or lacerate the mare. In no circumstances are tact, coolness, and steady perseverance more required than in a protracted case of labour; however, the dictates of humanity no less than professional duty demand that we shrink rot from the most difficult. 


\section{CHAPTER IX.}

DISEASES OF THE HEART AND BLOOD-VESSELS.

THE heart is the great central organ for the propulsion of the blood to the various parts of the body; it is placed in the middle space of the cavity of the chest. Its form is that of a blunt cone, the base being turned upward, suspended from the third to the sixth dorsal vertebrae by the venous and arterial trunks which spring from it. It is a most beautiful, but complex arrangement, for the propulsion of the blood through the system. It is enclosed in a double membranous sac called the pericardium. Its average weight is from six to seven pounds.

From the important functions of this organ, and its intricate connexion with every part of the body, through the minute distribution of its blood-vessels, it naturally sympathises with even the slightest derangement of the system or other organs; hence we find in most diseases its functions are either increased or diminished, consequently we make use of the action of the heart to determine the state of the system.

THE PULSE.

The arteries are the vessels which convey the blood from the heart to the system. "The blood nowhere passes through an artery so rapidly as it is forced into it by the ventricles of the heart, on account of the resistance offered by all the 
tubes against which it is forced. The consequence is, that when it receives the wave of blood, both the diameter and the length of the vessel is increased, and this is followed by a recoil and recovery of its previous position owing to the elasticity of the tube; these operations constitute the pulse, which is felt when the finger slightly compresses an artery." -Bennett. Hence the pulsations of the artery correspond with the beatings of the heart, and consequently indicate the irritability of that organ or the system generally.

The average pulse of the horse is from thirty-two to fortytwo beats per minute. The most convenient places to feel the puilse are at the arm, on the inside where the artery (radial) passes over the head of the bone, or on the under part of the lower jaw where the artery (submaxillary) winds round to gain the cheek. "When the pulse reaches fifty or fifty-five some degree of fever may be apprehended, and proper precaution should be taken. Seventy or eighty will indicate a somewhat dangerous state, and put the owner and the surgeon not a little on the alert. Few horses long survive a pulse of one hundred, for by this excessive action the energies of nature are soon worn-out." - Youat.

Various affections of the heart involving its substancelining membrane and valves are known to exist as independent diseases, which for their detection require not only an intimate knowledge of the anatomy and uses of the different parts, but a thorough acquaintance with the sounds observed by auscultation and percussion both in health and disease,knowledge which is possessed by professional men alone, and particularly those who have made it a special study. Hence, any remarks we could make on the subject would be unintelligible and perplexing to the general reader. 


\section{PERICARDITIS.}

Inflammation of the membrane investing the heart is sometimes seen as an independent disease, but more generally in connexion with pleurisy, influenza, rheumatic affections, \&c., giving rise to considerable accumulations of fluid in the sac.

Symptoms.-In three cases which came under our notice during the past year the symptoms were very characteristic ; a description of one of them will best illustrate our views.

On the 14th of February 1866, a gray mare belonging to Mr Hiram Green, Beachville, C.W., was sent to our stables; she had been ailing for several.days. The whole four legs were swollen, especially about the joints; venous regurgitation of the jugulars and beating of the carotid arteries very observable in the neck; pulse from fifty to fifty-five; strong; and intermittent; on applying the ear to the side of the chest, the sounds of the heart were indistinct and feeble, apparently heard through fluid, percussion elicited a dull sound, and pain was evinced on pressure between the ribs in that region; the breathing was but little disturbed, but she sighed occasionally. A peculiar expression of countenance, especially observable in the eyes, was remarked; great disinclination to move. When turned suddenly, or otherwise excited, the palpitation was visible at the side, and she evidently experienced a feeling of suffocation; bowels rather costive; appetite but little impaired; she maintained the standing position.

Treatment.-Effusion having already taken place, our main efforts were directed to check the dropsical tendency. The bowels were opened by the following ball :-

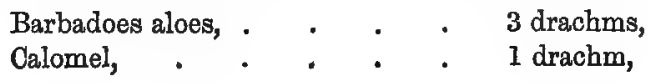


made into a ball with lard, followed by injections of soap and water.

The sides were freely blistered with cantharidine blister, and kept running by biniodide of mercury ointment.

She had twice daily a drachm each of iodine and iodide of potassium, with an ounce of sweet spirits of nitre. She was restricted to easily-digested diet,-bran, carrots, \&c.; frequent hand rubbing and bandages to the legs, and the body warmly clothed.

On the third day the symptoms were very much mitigated; she was observed lying down on her right side. The effort in rising produced considerable fluttering of the heart, which immediately subsided ; on applying the ear to the chest the sounds were more distinct, the fluid was evidently diminishing. She was now ordered a quart of warm beer night and morning, gentle walking exercise, continued hand rubbing to the legs, a diuretic ball every second morning, and small doses of sulphate of iron and arsenic night and morning. In about three weeks she was almost convalescent; the swelling was absorbed from the legs, the pulse became more regular, and she became more active. We recommended a run in a straw yard before working her.

In other cases which presented almost the same symptoms, we have found after death large accumulations of fluid on the pericardial sac.

\section{DISEASES OF THE BLOOD-VESSELS.}

The blood-vessels are not, very liable to diseases of an independent nature; the most common cases which come under our notice are wounds which give rise to

HAMORRHAGE OR BLEEDING.

The bleeding may take place from an extensive surface, 
when general oozing occurs, or an artery or vein of more or less importance may be divided, usually the result of injury or in consequence of operation.

Symptoms.-When no particular stream is distinguishable, no vessel of importance is involved. When an artery is open, the blood is poured forth in a copious stream, which is easily recognised by its bright scarlet colour and jerking or pulsating flow. When from a vein it is darker in colour and escapes in a steady jet.

Treatment.-When it merely oozes out it soon stops of itself, or by the continued application of cold water, or any styptic, such as muriate of iron, tincture of benzoin, sugar of lead, \&c. When an artery of considerable magnitude is severed, it should be taken up and a silk thread applied, the bleeding being stopped by pressure above until it is secured. Sometimes it is difficult to reach, and almost impossible to tie, from its position and restlessness of the animal, as we have often seen it from deep treads with sharp caulkins. In this case pressure must be applied to the artery above, and the open vessel touched with the cautery, or bound up with some styptic dressing.

When a vein is cut it should be secured in the same way; but often in the legs the'skin and vein are merely punctured. In this case it should be secured (as in bleeding) with a pin. In stopping hæmorrhage from a vein, the pressure must be applied below, as the flow of blood is upward. In most cases, however, it is more alarming than dangerous. Copious and continued affusion with cold water will usually suffice to stop it, or the vessels contract of themselves.

\section{ANEURISM.}

By the term aneurism is meant, "A pulsating tumour, arising from a dilated, ruptured, or wounded artery, and 
filled with blood, which in the early stage is a fluid, and at a later period in a more or less coagulated state."-Cooper.

It is a rare occurrence in the horse, and when it does occur in any vessel of importance it invariably proves fatal.

\section{THROMBUS.}

Thrombus is the name given to a round tumour which sometimes occurs around the puncture made in bleeding.

Causes. - It is usually the result of irregularity in pinning up the wound by drawing the skin out, allowing the blood to be extravasated into the cellular tissues; also from the opening in the skin not being opposite the opening in the vein, or too small to allow the blood to escape freely, - often from the tissues being irritated by repeated striking of the fleam, or "perhaps from spontaneous inflammation and serous effusion in the divided integuments and membranes themselves."

Symptoms.-It is easily recognised by the appearance of: a round full swelling surrounding the opening a short time after bleeding.

Treatment.-It should be re-opened, the coagula squeezed out and the edges of the wound again brought together, and a pad, or sponge, saturated with a strong solution of goulard lotion, or cold water, constantly applied for an hour at a time-the pad being supported by a broad bandage round the neck. The head must be tied up for at least twenty-four hours. It usually subsides in a day or two. Should swelling remain, it shopld be blistered and treated as in phlebitis.

\section{INFLAMMATION OF VEINS (PHLEBITIS).}

Owing to the practice of bleeding horses for all ailments, which is still very common among farmers in Canada, phle- 
bitis is not uncommon. It consists of inflammation of the coats of the vein, involving the surrounding cellular tissuesalso.

Causes. - When it occurs it almost invariably follows the operation of bleeding, arising from some mismanagement in performing it, or securing the integuments after. Rusty fleams-carelessness in pinning it up, as in pulling the skin out, allowing blood to filtrate the cellular tissues-bringing the edges unevenly together-or we have known the vein itself to be pinned to the skin. Certain states of constitutional predisposition of the veins to take on inflammatory action are said to exist.

Symptoms.-It is easily distinguished by the inverted edges of the wound, which are red and swollen, and discharge thin serum, which soon gives place to pus. The vein above the incision is hard, hot, and tender, and considerably enlarged. The swelling extends upward to the head; the inflammation extends to the surrounding tissues; the side of the neck is swollen; the neck stiff and the head extended. The symptomatic fever runs high.

Treatment.-The head should be tied up, and almost constant fomentations of hot water applied for several days. The lips of the wound should be touched with the cautery or lunar caustic. A full dose of purgative medicine should be given. When the acute fever has subsided, it should be blistered throughout its entire extent, and repeated if required, the head being kept elevated, and his feed placed within reach.

These cases often terminate in complete obliteration of the vein; but in course of time the smaller vessels of the neck enlarge, and take the place of the lost jugular. He is not suited to be turned to . pasture, as the head is apt to swell. He can never after be passed as a sound horse. 


\section{CHAPTER $\mathrm{X}$.}

\section{RESPIRATORY SYSTEM.}

THE organs of respiration consist of the two outer openings, or nostrils (nasal openings); the cavities in the head into which they open (nasal chambers); the cartilaginous box at the head of the windpipe (larynx); the long tube called the windpipe (trachea), which is made up of separate rings of cartilage; its minute divisions into little tubes (bronchial tubes); and the lungs, two spongy organs situated in the chest, one on each side, separated by folds of the investing membrane (mediastinum) and the heart. Their office is the purification of the blood by the absorption of oxygen and exhalation of carbonic acid, which takes place in the minute air cells in which the bronchial tubes terminate. The lungs are intimately invested by a serous membrane (pleura) similar to that lining the abdomen, which is also reflected over the inner surface of the walls of the chest. This membrane also secretes a humid exhalation to prevent friction during the incessant motion of the lungs.

This system, from the vascularity of every part of it, is very prone to inflammatory attacks, from a slight cold in the head to violent inflammation of the lungs.

\section{CATARRH.}

Catarrh, or "cold in the head," is an affection of the lining membrane of the nasal chambers and cavities of the head. 
It consists in a congested or inflamed state of that membrane, giving rise to a glairy discharge from one or both nostrils, and when the head of the windpipe (larynx) is implicated, accompanied by a cough.

Causes.-May be classed under predisposing and exciting, as the majority of young horses under five years old may be said to be predisposed to this affection. The exciting causes are sudden variations in the state of the temperature; undue exposure to cold when an animal is in a heated state, especially after a hard-day's work or drive; standing in stables badly ventilated, or any place exposed to cold draughts. Perhaps the most common cause in young horses is placing them in warm stables in the fall of the year immediately on taking them off the pastures. A sudden change from a cold to a hot temperature is more likely to cause catarrh than a change from a hot to a cold one.

Symptoms.-If the horse is standing in the stable he will appear dull, and incline to hang his head in the manger; the mouth is hot, and the pulse quickened and weak; the coat is staring, and the lining membrane of the nose is reddened and injected. If the larynx is involved, steady pressure on that region will cause coughing. This is the congestive stage, which speedily passes off, and exudation takes place from the vessels, causing a discharge from the nostrils, at first watery, gradually becoming thicker and thicker, and of a yellowish colour. In some cases this matter becomes pent up within the sinuses of the head, and comes away in large quantities at intervals of three or four hours. A watery discharge from the eye is also very often an accompaniment of catarrh. If these symptoms become aggravated, the appetite is impaired, the bowels are costive, and the foeces passed are of a clayey nature, the legs and ears are cold, and the breathing accelerated. Catarrh, if improperly treated, or the animal 
kept at work and exposed to sudden changes of temperature, is very apt to descend to the chest, and is a prolific source of other and more serious diseases, as inflammation of the lungs (pneumonia), or of the covering of the lungs (pleurisy), or of the bronchial tubes (bronchitis).

In the majority of cases catarrh is but a simple affection, and if the patient gets anything like proper usage or treatment no very serious results generally follow.

Treatment.-At once-as should be done in all affections of the chest-place the animal in a comfortable, well-ventilated loose-box; clothe the body moderately; also hand-rub and bandage the legs; the clothing and bandages must be removed twice a-day, and the body well rubbed over. Give one or two drachms of aloes in solution, combined with half a drachm of powdered ginger. Steam the head with hot water, or by means of a nosebag partly filled with scalded bran. In steaming the head, care must be taken to allow the animal a free current of fresh air, as we have known horses suffocated from the improper use of the nosebag in steaming. In mild cases it is not necessary to use the bag: sponging out the nostrils with tepid water several times a-day will suffice. The horse should be restricted to soft food, as boiled oats or barley, with a little linseed, daily. A few doses of tartar emetic and nitrate of potash may be given daily in a bran mash, and the throat rubbed with a stimulating liniment. (See page 211.)

\section{LARYNGITIS_-" SORE THROAT"-}

Consists in inflammation of the mucous membrane of the head of the windpipe (larynx). It is generally called "sore throat," and is a very common affection amongst horses, occurring in a variety of forms, being sometimes of an exceedingly acute nature, and running its course with 
frightful rapidity; in other cases of a milder type, and assuming what may be called a sub-acute form.

Causes.-Are similar to catarrh, as undue exposure to cold and variations in the state of the temperature; but in some seasons it appears as an epizootic disease, large numbers of horses becoming affected with it about the same time. These, cases are always of a typhoid nature when occurring in stables insufficiently ventidated more especially. It is occasionally caused by injuries, as in the careless administration of medicines.

Symptoms of "sore throat" are well marked. The horse holds his head stiff, with his nose poked out, showing the muscles of the neck prominently; he has considerable difficulty in swallowing; if he attempts to drink, part of the water is returned through his nostrils; the throat is painful to the touch, and the least pressure excites a violent fit of coughing. At the commencement of the disease it is difficult to distinguish it from "distemper" (strangles). By the third or fourth day the difference can be easily seen; the usual tumour of distemper does not appear. The pulse varies; in some cases but little altered, in others very.quick and weak. The coat is also staring, and the funotion of the kidneys partially arrested. In severe cases the breathing becomes heavy and laborious. By the third or fourth day from the beginning of the attack, a greenish yellow matter is discharged from the nostrils.

Treatment.-The general and local treatment should be similar to that of catarrh, therefore we recommend the free use of counter-irritants to the throat externally, as mustard well rubbed in, or any stimulating liniment or liquid blister may be used. (See page 211.) The head may be well fomented or steamed, and the patient encouraged to take soft, easily digested food, as hay tea, linseed tea, boiled barley or carrots. 
When the bowels are constipated, as is often the case, clysters of soap and water must be freely used, and the general comfort of the animal well attended to. When the cough is severe and hacking, the following ball may be given once or twice a-day. Cough BaLL.

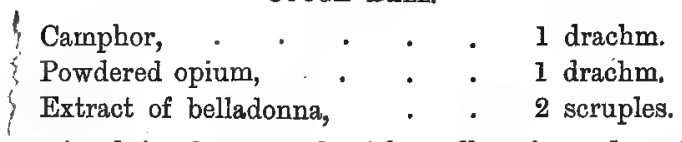

If the animal is threatened with suffocation, the windpipe must be opened and a tube inserted. (See Operations, page 196.) We have also found benefit from sponging out the larynx with a solution of the nitrate of silver.

\section{CHRONIC COUGH}

is often a sequel of sore throat (laryngitis), as also of distemper (strangles), and is a disease, when once fairly established; complete recovery seldom takes place. It consists in a chronic inflammation of the many glands imbedded within the lining membrane of the larynx, causing an irritation of that highly sensitive organ. The cough is easily excited by pressure externally, and is of a deep hollow nature, differing materially from the loud sonorous sound of the healthy cough.

It is often associated with other diseases of the chest, as broken wind, thick wind, \&c., and we believe it sometimes accompanies chronic indigestion, and other diseases of the stomach and bowels, caused apparently by some lesion of the pneumogastric nerve or some of its branches. The cough is generally most severe in the mornings or after meals, and is always aggravated by gross feeding. In many cases chronic cough interferes but little with a horse's usefulness, especially if he is used for ordinary farm work, but it must be considered an unsoundness. 
'Treatment.-If the horse has been affected for some time, treatment is generally very unsatisfactory, and must be more of a palliative than a remedial nature. If only recent, treatment may be undertaken with better chances of success. Give the cough ball as recommended for laryngitis, also apply the liquid blister externally, and in some cases great benefit will attend the use of setons under the head of the windpipe. If occurring from intestinal disorder, the treatment of course must be directed to the proper seat. The medicinal treatment is greatly assisted by feeding the animal properly and regularly, giving small quantities of food at a time, carrots in winter, and green food in summer should be given. The following is also an excellent cough ball in recent cases :-

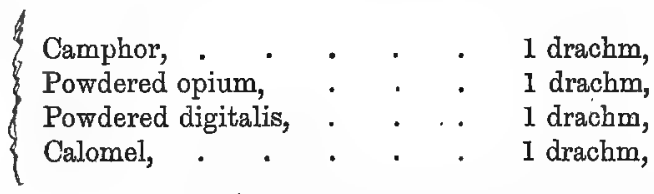

made into a ball and given every second morning until six doses are given.

\section{ROARING.}

This is a very common disease amongst Canadian horses, and may be defined to be, breathing with a loud and unnatural sound upon violent exertion.

Causes.-Like chronic cough it often follows an attack of laryngitis or of distemper. (strangles), and in these cases we believe it is owing to a wasting (atrophy) of the muscles of the head of the windpipe (larynx), whereby its calibre is diminished, and when the air rushes in during violent exertion a roaring sound is produced. The constant tight reining of carriage horses is also a common exciting cause, and 
we believe it is also hereditary-as it is a well-known fact, both in Canada and in Britain, that certain breeds of horses are peculiarly liable to this disease. It may also be caused by some lesion or derangement of some of the nerves. "Percivall mentions the following experiment made by the late $\mathrm{Mr}$ Field of London. Having ascertained that the organs of respiration of a horse were sound, I cast him, and laid bare the recurrent nerve of the off side and passed a ligature loosely around it; he was then allowed to get up, and after a few minutes galloped severely without evincing the slightest defect in his breathing. The nerve was then drawn out by the ligature, and one inch and a-half of it excised; and immediately, on only trotting the horse a short distance, such a degree of roaring was occasioned, that had the exertion been continued he would have fallen. I kept this horse four years, and though his breathing became much better, he continued a sad roarer; at the end of that time I destroyed him for the larynx, which exhibited the usual condition of wasted muscles on the side deprived of the influence of the recurrent nerve."

Symptoms.-When the horse is not excited, and so long as the air passes in a uniform rate through the larynx and windpipe, the animal does not feel any inconvenience; whenever he is excited or galloped, causing a rush of air, the roaring noise is produced. The sound in ordinary circumstances is only produced on inspiration, but in very. severe cases the sound is audible both on inspiration and expiration.

In some horses roaring is difficult of detection. There are several tests which can be resorted to with the view of detecting it. It may often be readily detected by taking the horse firmly by the head and striking him suddenly on the side, causing him to start forward; if a grunting noise is emitted it is always a suspicious circum- 
stance, and in many instances is an unequivocal symptom of roaring. The grunting sound in all cases should not be taken as conclusive evidence of the animal being a roarer, but a better test must be tried; he should be galloped sharply for some distance, then pulled up quickly, and by applying the ear to the nostrils or to the windpipe any abnormal sound will at once be noticed. Professor Sewell says, "The best test we can subject "draught horses to, (suspeced roarers,) is to put them in harness and compel them to draw heavy loads."

Treatment.-Must be principally palliative, and much can be done by generous and regular feeding, and never allowing the animal to overload his stomach and bowels. Occasional doses of laxative and sedative medicines tend to relieve the more distressing symptoms. In very bad cases, where the animal is almost useless from roaring, the operation of tracheotomy, or the insertion of a tube in the windpipe, may : be tried (see Operations, page 196); we have done it with success, and the horse rendered useful for years. Roaring in. all its forms is an unsoundness.

\section{BRONCHOCEIE.}

Bronchocele, or morbid "enlargement of the thyroid gland or body." These are two small glands situatad one on each side of the windpipe (trachea), about three inches from the head of the windpipe (larynx) ; they are ductless glands, having no excretory duct, and they are largely supplied with blood-vessels and nerves.

Bronchocele is a very common affection amongst horses in Canada, and is known as a tumour situated on one or both sides of the windpipe, and the character of the 'swell. ing varies according to its duration. It may be soft on firm, and it may affect the whole gland, or only one side of: 
it ; the tumour seldom causes pain, and the animal appears not inconvenienced by it, although very large. The tumour varies in size, from as small as a pigeon's egg to as large as a man's hand. It is sometimes supposed to be a cause of roaring, but we must confess we have never met with a case of roaring that could be clearly attributed to that cause.

Treatment. - Of all the medicines in veterinary practice, iodine and its compounds appear to be the most efficacious in reducing these enlargements, as well as in other glandular swellings. Iodine ointment should be applied externally, in proportion of one part of iodine to seven of lard (see Ointments, page 216), to be applied daily, and at the same time administer twice a day one drachm of the iodide of potassium given in solution.

\section{NASAL GLEET}

is the name applied to a chronic glairy discharge from one or both nostrils, and is the result of a subacute inflammation or other diseased condition of the lining membrane of the sinuses of the head, and these sinuses more especially involved are the frontal and maxillary. Nasal gleet is not an uncommon disease in Canada, and many horses have been destroyed, supposed to be affected with that most loathsome disease glanders, when in reality they were only suffering from nasal gleet.

Causes. - It is very often the result of catarrh in a chronic form, induced by further exposure to cold, and want of a proper supply of nutritive food. Wé have also met with cases where it could not be traced to a catarrhal attack of the air passages; and it occurs oftener in aged than in young animals.

- Symptoms.-The first noticeable symptom is a yellowish discharge from one or both nostrils. The lining membrane 
of the nose (schneiderian) is altered in colour; it becomes of a pale leaden hue, but does not exhibit ulcerative patches as in glanders. The discharge may vary both in quantity and quality. It is often retained for some time within the sinuses, and comes away in considerable quantities. In other cases the discharge is continuous, and collects about the nostrils; the submaxillary gland, in cases of long standing, becomes tumefied, but not adhering to the bone as in glanders; the frontal and nasal bones are affected, and present an enlargement or bulging out over the seat, of the disease. If tapped with the point of the finger, a dull heavy sound is produced, showing that matter has collected within the sinus. In ordinary cases it is a long time before it materially affects the horse in his working capacity. When the bones are greatly diseased, and the matter collects within the nasal sinuses, it interferes with respiration, causing laborious breathing. We have met with cases, owing to the excessive obstruction in the air-passages, in which it was necessary to open the windpipe (tracheotomy) before we could with safety cast the animal to operate for nasal gleet.

Treatment.-Although a formidable disease, even the worst of cases may recover if properly treated. Give good food and moderate exercise, sponge the nostrils with tepid watêr, or steam the head once or twice a-day, and administer mineral or vegetable tonics, as,

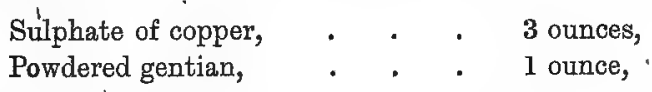

made into twelve powders, and one given in the food morning and night. Or, the sulphate of iron, in two-drachm doses twice a-day. The nasal cavities may be injected with a weak solution of sulphate of zinc or of alum; or of sulphate of copper, about five grains to the ounce of water. When the bone is diseased, and matter collected within the sinuses, it 
is necessary to trephine the bone. After operating, inject the sinus with tepid water twice or thrice a-day, followed by injecting any of the astringents already recommended. The opened sinus sometimes fills up with a fungus growth, which must either be removed by the knife or by means of caustics. We have operated on several cases in Toronto and surrounding district within the past four years, and generally with the best results.

\section{EPISTAXIS,}

or bleeding from the nose, occurs occasionally in horses, and may result from injury, as a blow over the nasal or frontal bones; or it may be caused by a plethoric condition of the system, or of a congested state of the vessels of the nasal septum. Horses most liable to hæmorrhage are those in high condition, and not allowed regular exercise. When the bleeding is confined to the nose it is invariably from one nostril, and may either come away drop by drop or in a small stream. When the bleeding takes place suddenly after violent exercise, and when flowing freely from both nostrils, the lesion is generally situated in the lungs. This is called hæmoptisis, which is a more serious affection than epistaxis, and sets up a greater irritation, causing the animal to cough violently.

Treatment.-When the bleeding is but slight and confined to the nose, rest and moderate feeding will suffice. If the hæmorrhage is such as to create alarm, apply cold water freely to the head, and when only from one nostril, a plug of tow saturated with a solution of alum may be inserted. When from the lungs, the horse should be kept perfectly quiet and sparingly fed, and the acetate of lead given internally in two.drachm doses once a-day, dissolved in distilled water. 


\section{CONGESTION OF THE LUNGS.}

Before proceeding to consider the diseases of the chest, we will briefly notice the structures involved in pulmonary affections. The windpipe (trachea), after entering the chest, divides into the bronchia or bronchial tubes. These divide and subdivide into smaller tubes, finally terminating in the air cells. The lungs are made up of clusters of those cells; of a large mass of pulmonary texture called the parenchymatous structure or substance of the lungs; of blood-vessels, both functional and for the nutrition of the organ ; of nerves and lymphatics, and the whole enclosed in a serdus membrane called the pleura, which is made up of two portions-one portion being reflected over the lungs (pleura pulmonalis), while the other lines the inside of the ribs and diaphragm (pleura costalis). The lungs are exceedingly light in proportion to their size, and are very vascular organs ; consequently we find them very liable to diseases of an inflammatory character, and the precursor of inflammation is congestion.

Congestion of the lungs, a disease common amongst our Canadian horses, consists in an increased determination of blood to the capillaries of the air cells, interfering materially with the process of respiration. It may exist as an independent disease, or accompany other affections of the chest.

Causes.-Perhaps one of the most common causes is violent exertion when an animal is in an unfit state for severe work-as, for instance, a young horse in high condition is taken out of his stable and driven rapidly for five or six miles; this causes an ipcreased quantity of blood to the lungs more than those organs are able to dispose of in their weakened condition from the want of regular exercise. It is also caused by impure air, in horses standing in crowded stables, and it is often a sequel of catarrh. 
Symptoms.-When occurring after a hard ride or drive, the horse will become tired and sluggish in his action; he will perspire profusely, and almost refuse to proceed except with the greatest difficulty; he will stand with his elbows turned outwards, and heaving violently at the flanks; the nostrils are dilated, and the ears and extremities exceedingly cold; the pulse is oppressed, or almost imperceptible at the jaw; the mucous membranes of the nose and eyes are reddened. When of a milder nature, as often occurs in horses suffering from catarrh which have been subjected to a fast drive and exposed to cold draughts, he is seized with a trembling fit; the ears are cold, and the respiration hurried, when the ear applied to the chest can plainly detect the imperfect breathing,

Treatment.-In acute cases it must be energetic. Clothe the body well, and administer stimulants, as,

Sulphuric ether, $\quad \cdot \quad \cdot \quad \cdot \quad \cdot \quad \cdot \quad \cdot \quad 2$ ounces,
Laudanum , · $\quad \cdot \quad \cdot \quad \cdot \quad 1$ ounce,

to be given in half a pint of cold water; or nitrous ether may be given in place of the sulphuric. If no medicinal agents can be conveniently procured, give a quart of warm ale, or a tumblerful of gin, whisky, or brandy, mixed up with hot water an'd sugar. Blood-letting, which is often practised, is highly injurious. It may appear to momentarily relieve the patient, but at the same time it increases the weakness. Have him put into a warm place, with plenty of ventilation, as pure air is an indispensable adjunct in the treatment of all pulmonary diseases. /If no relief follows the stimulants, apply hot,cloths to the sides and loins, and cover up with dry blankets, so as to induce a copious perspiration, and thereby assist in relieving the lungs. 
"PNEUMONIA"—“ INFLAMMATION OF THE LUNGS"-

Consists in inflammation of the parenchymatous structure or substance of the lungs.

Causes.-It is often a sequel of neglected or improperly treated catarrh, and frequently congestion of the lungs terminates in pneumonia. A frequent cause is a sudden change of temperature, also breathing vitiated air in over-crowded, ill-ventilated stables.

-Symptoms.-Pneumonia, like other chest diseases, is almost invariably ushered in by shivering and irregular heat of the skin; the mouth becomes hot and clammy, the breathing is increased, and the breath is hot. The pulse is full and oppressed, differing in its character from the pulse of pleurisy, which is hard and wiry. The animal stands persistently, and has his elbows turned outwards; the standing posture affords him the greatest amount of relief; if he lies down he is threatened with suffocation; the bowels are constipated. If in a loose-box, he stands with his nose towards the door or window instinctively to breathe the pure air.

A healthy horse breathes at an average of ten times in the minute, viz., ten inspirations and ten expirations, and the time occupied by the inspiratory movement is longer than the expiratory. In pneumonia the expiration is as long, if not longer, than the inspiration, and these movements are very much quickened, being an effort of nature to compensate for the impaired action of the lungs. When a cough is present, it is freer and less painful than the cough of pleurisy. By applying the ear to the sides of the chest, in the early stage a crepitating sound is heard, which becomes altered as the disease progresses.

X Treatment.-When occurring from exposure to cold it can be treated satisfactorily, but when occurring in an 
epizootic form, or brought on from impure air, it is a very fatal disease. As we recommend in all diseases of the chest, the animal should be placed in a comfortable and thoroughly ventilated loose-box, and the body comfortably clothed. It is almost useless to attempt the treatment of a case of pneumonia, if the animal is allowed to stand in an impure atmosphere. When the disease is commencing, and the pulse full and oppressed, take blood, from six to eight quarts for an ordinary sized horse, and give two drachms of aloes. Full doses of purgative medicine must not be given, as superpurgation is easily brought on, and generally proves fatal. Clysters of soap and water should be given regularly, every four or five hours, until the bowels are gently moved. Sedatives must also be given, as Fleming's tincture of aconite, in doses of ten or twelve drops every two hours; until the increased action of the heart is somewhat abated. Blankets wrung out of hot water should be applied to the sides in the early stage, and is preferable to blisters. Another good sedative in pneumonia is:-

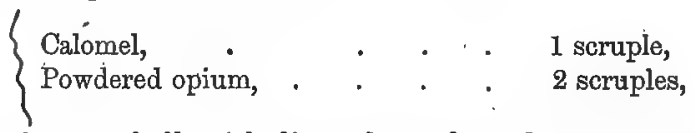

made into a ball with linseed meal, and one given three times a-day.

When the disease has lasted for a couple or three days, blisters are beneficial; the hair should be removed from off the sides, and mustard or cantharidine ointment well rubbed in, and the patient encouraged to take cold water, impregnated with nitre:

\{ Recovery commonly takes place about the fifth or sixth day, and is expedited by the free use of stimulants and tonics, or the liquor acetate of ammonia, in two ounce doses four times a-day. When the pulse is weak, and the disease hav- 
ing existed for a considerable time, blood-letting is contraindicated, stimulants must be given, as,

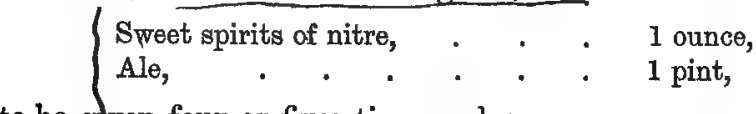

to be gtven four or fives times a-day.

\section{PLEURISY- " INFLAMMATION OF THE PLEURA."}

That portion of the pleura covering the ribs (pleura costalis) is stronger, thicker, and more vascular than the portion which is reflected over the lungs, (pleura pulmonalis,) hence we find in inflammation it is mainly implicated. It is not an unfrequent occurrence, and is one of the most serious diseases to which the chest of the horse is liable. "In man it is different, an attack of pleurisy is but lightly thought of." In the horse, when ending fatally, death seldom takes place before the fourth or fifth day. Recovery may take place in two or three days, or it may be a fortnight or three weeks before he is well. Pleurisy occurs as an independent disease, or it may be accompanied by inflammation of the lungs.

Causes.-Are similar to other diseases of the chest, as variations in the temperature, impure air, \&c. It is also caused by an animal drinking greedily of cold water when sweating profusely ; and in some cases it is the result of injuries.

Symptoms.-It is invariably preceded by a shivering attack, speedily followed by inflammatory fever, and the animal begins to blow. If you move him, and press upon the intercostal spaces, he evinces pain; he will stand with his hindlegs well under him, placing himself in a position similar to what he does when labouring under an attack of laminitis. The pulse in the early stage may be but little affected, it becomes hard and wiry, and vibrating strong under the finger. A well marked symptom of pleurisy is a prominent line, 
extending along the side of the abdomen. The respiration becomes increased and peculiarly laboured; and the ear applied to the chest will detect a rough rasping noise, and there is generally present a short, painful, suppressed cough, easily excited by pressure on the larynx; the legs and ears are cold, the bowels unmoved, and the urine scanty. At times the appearances of recovery are deceptive, the fever and breathing are not so intense, and the horse apparently seems relieved, he will, perhaps, eat a little, the skin looks sleek and glossy. These signs of amendment may even continue for several days, but if the pulse is gradually increasing in frequency, and its strength diminishing, in all probability water is forming in the chest, constituting

\section{HYDROTHORAX, " OR WATER IN THE CHEST."}

When this has taken place to any great extent, there is difficulty in breathing, and flapping of the nostrils ; the eyes are clear and unnaturally prominent, the intercostal spaces bulge out, and the ear applied to the chest can only detect the respiratory murmur above the surface of the fluid. The legs and breast swell, the circulation becomes more and more impaired, the pulse getting weak and indistinct.

Treatment of Pleurisy is similar to that of pneumonia. In the first stage we recommend bleeding, but after the second or third day blood-letting is not advisable. Give laxatives-as aloes four drachms, or one pint of linseed oilclothe the body well, and apply,to the sides hot cloths, or the ammoniacal liniment. (See page 212.) Administer in cold water, every two or three hours, ten drops of Fleming's tincture of aconite, combined with "two drachms of the nitrate of potash ; after giving six doses of the aconite, discontinue it, and give instead- 


\section{Calomel, . . . . . 1 scruple, \\ 、 Powdered opium, . . . . . 1 scruple,}

to be given every three hours, until four doses are given. When water has formed in the chest, (hydrothorax), stimulants, tonics, and diuretics must be given, as a pint of warm ale, combined with one ounce of nitrous ether three times a day, blisters applied to the sides, and the iodide of potassium in one drachm doses twice a day. Feed the animal on nutritive and easily-digested food. When a large accumulation of fluid takes place it must be removed by tapping (paracentesis thoracis.) (See Operations, page 197.)

Bronchitis; "or inflammation of the mucdus membrane of the bronchial tubes," is often associated with inflammation of the lungs, but also occurs as a separate affection.

Causes.-Are similar to other pulmonary diseases, and is a result of laryngitis or catarrh ; or it may depend on atmospheric influences, and in those cases it is always accompanied with great weakness and prostration. It sometimes follows the careless administration of medicines, whereby it passes into the windpipe (trachea) and descends to the bronchial tubes, setting up, great irritation.

Symptoms.-The first symptom often observed is a short, dry, and husky cough, speedily becoming more prolonged. When a horse gives a natural cough he opens his mouth a little, bu't when labouring under this disease he keeps his mouth close trying to, suppress the cough. As the disease advances the mouth becomes hot and dry, the ears and extremities alternately hot and cold, the pulse not hard and wiry as in pleurisy, but soft and compressible, and the respirations are quick and hollow; the ear applied to the breast can easily detect a rattling sound, the bowels are inactive, and his appetite is gone. Death may occur in from three to five days. 
/Treatment is also similar to the treatment recommended for pneumonia, with the exception that bloodletting should not be practised in bronchitis, and purgatives must also be used with extreme caution; it is often much safer to open the bowels by means of clysters than have recourse to purgative medicines, as the bowels are so extremely sensitive in this disease. If the cough is very distressing, the following, ball will be found serviceable-

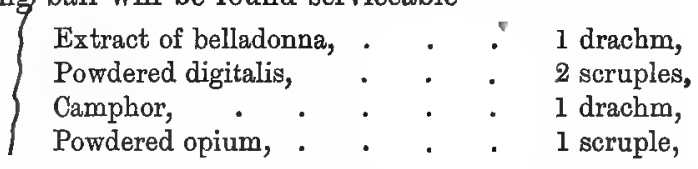

to be given morning and night.

After the second or third day, if the weakness increases, the following drench should be given four times a day广

Sweet spirit of nitre, . . 1 fluid ounce.

$\begin{array}{ll}\text { Aromatic spirits of ammonia, . } & \text { I } \\ \text { Water }(\text { cold, }) \text {. . . . I pint. }\end{array}$

HEAVES OR BROKEN-WIND

is a very common affection of horses, and in some cases it is attributed to emphysema of the lungs, or rupture of some of the air-cells, whereby air escapes into the cellular or intercellular tissue; in other instances it is due to some lesion of the pneumogastric nerve.

Causes.-A common cause is from riding or driving fast immediately after feeding, or drinking a large 'quantity of water. It is also produced by feeding on dusty clover hay; it is also a sequel of some of the diseases of the air passages, and of the chest.

Symptoms.-Respiration is conducted with remarkable difference, the process of inspiration is quickly performed, whilst the expiratory process takes place by a sort of double action; and owing to the abdominal muscles being brought 
into action, their contraction produces a line extending downwards. and forwards along the flank. The horse is also generally pot-bellied, and has a great tendency to eat his bedding and also to drink large quantities of water. A wellmarked symptom is the loud, prolonged, and hacking cough. Changes of weather also affect the broken-winded horse.

Broken wind in a confirmed state is incurable, and no reliance can be put upon the many specifics sold for the cure of heaves. This disease may be palliated, and the horse rendered serviceable for moderate work, by giving nutritious food in small quantities, and feeding regularly. Occasional doses of laxative medicine may be given with advantage. During the day the quantity of water should be restrioted, but at night he may have his regular allowance. In fact, more can be done to relieve this complaint by proper attention to feeding than by medicinal remedies. 


\section{CHAPTER XI.}

DISEASES OF THE NERVOUS SYSTEM.

THE nervous system consists of the brain, which is lodged in the cavity of the skull (cranium); the spinal cord, lodged in the cavity of the vertebral chain; and numerous little white cords, called nerves, which are given out from the brain and spinal cord, and distributed to the different parts of the body, especially those parts endowed with sensibility, and under the control of the will. Besides this system of nerves, there is another set, independent of the cerebrospinal axis, called the sympathetic or ganglionic system, which supply the organs of nutrition and other viscera, blood-vessels, \&c. It consists of numerous small centres, called ganglia, extending in two great chains from the head to the tail, on each side of the bodies of the vertebræ, closely associated with the other system by intricate communication.

\section{INFLAMMATION OF THE BRAIN (PHRENITIS.)}

Phrenitis is not a very common disease, though the substance of the brain itself, or, as is more commonly the pase, its membranes or coverings become inflamed. It has received various appellations, such as mad staggers, sleepy staggers, \& $c$.

Causes.-The causes are not thoroughly understood. Injuries to the skull, metastasis, or the transference of inflam- 
mation from some of the other organs, high condition and over-work, undue exposure to a hot sun, all seem to be favourable to its production.

Symptoms.-It is usually ushered in by dulness and persistent drowsiness; he stands with his head between his legs, or sometimes resting on the manger or leaning against the wall; the eyes shut, and the pupils dilated; the pulse is full, soft, and slow; the breathing is heavy and loud; he is very difficult to arouse, and when startled he looks dreamily about; may take a few bites of hay but soon drops asleep again ; the bowels are costive, and the urine scanty and high coloured.

In a day or two the symptoms are either mitigated or it goes on to the second stage, when the pulse becomes quick, general excitement takes the place of lethargic stupor; the countenance is wild and excited looking; the eyes are bloodshot and staring; delirium sets in; he dashes himself furiously about, reels and staggers, often throws himself ( ( violently down; lies trembling, blowing, and convulsed; his bloodshot eyes like to start out of their sockets; he will soon get up, rear and plunge forward, breaking everything around him; evidently unconscious of the injuries he.is sustaining; and, what is characteristic of the complaint, his destruction is carried on evidently without purpose, as is "evinced in rabies or madness. The convulsions become more frequent and continuous, and death ends his misery in from twenty to twenty-four hours.

Treatment.-Copious blood-letting must be at once resorted to; no time should be lost in giving a strong dose of purgative medicine. One or both jugulars may be opened, or where, from the restlessness of the patient or danger in working about him, this is impracticable, the lancet should be plunged into the temporal artery, which 
will be found about three inches below the ear, between it and the nostril.

The following drench should be given :-

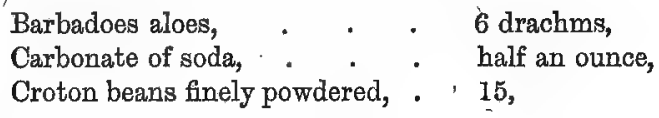

shaken up in a quart of warm water.

Three drachms of aloes may be given every three hours with copious injections every hour, till the bowels are freely opened.

Sedatives should also be used-such as extract of hyoscyamus and calomel, a drachm of each shaken up in a little thin gruel, given every two hours. Seldom is repetition of blood-letting advisable; cold water should be constantly applied to the head; a small hose made to play upon it in a constant stream, where it is convenient, will be found very useful.

\section{MEGRIMS OR VERTIGO.}

The form of nervous complication known as megrims is not uncómmon in Canada. Its nature is but imperfectly determined.

Causes.-It is often connected with worms or other derangements of the stomach or bowels, said also to depend on over-accumulation of blood in the head. The late Professor John Barlow found tumours in the choroid plexus of the brain. In these cases, it is often connected with over-feeding, and its consequence, derangement of the digestive organs. It is most commonly seen in harness horses, usually during hot weather, occurs generally on a heavy pull going up hill; probably from pressure, of the collar interrupting the return of blood from the head, or "the long continued constraint the bearing-rein puts the head to," may prove the exciting causes in animals predisposed to it. 
Symptoms.-All at once, when going along the road, he is observed to jerk up his head in a convulsive manner; he seems giddy, reels, staggers, and may fall down and lie for a few moments insensible; he gets up, looks stupidly about, shakes himself, and proceeds as if nothing had happened.

At other times he merely stops, experiences a few convulsive movements of the head, with slight giddiness, which by letting him stand a few minutes soon passes off. He is ever after subject to these fits, especially during the hot summer months.

Treatment.-When depending on organic changes in the brain it is incurable, and is subject to these attacks from time to time. When a fit comes on, on the road, stop him at once, throw the collar forward off his shoulders and let him stand; if convenient, pour a stream of cold water over his head. Bleeding in the mouth has been recommended, but is quite empirical; it soon passes off. When occurring in a young horse for the first time, he should be well physicked out, and if worms are suspected, treated as recommended for worms. Tonics are often beneficial, especially arsenic given in doses of from three to five grains daily. Megrim subjects are dangerous hacks, and should only be used where they can do no harm to life or property.

\section{PARALYSIS, PALSY.}

By paralysis is meant either the partial or complete loss of power of voluntary motion of a part of the body.

Causes.-It depends on some lesion or other interruption of function in the spinal cord, usually arising from injury of the vertebræ, causing bruising pressure or effusion on to the cord or its membranes. Injury of the spine sometimes arises from being cast for operations, falls in leaping, turning in a narrow stall, \&c. It may be complete fracture or partial, giving rise to enlargement of the bone producing pressure 
on the cord, or the membranes may become inflamed and effusion follow, producing partial or complete paralysis.

Symptoms.-A thorough acquaintance with the anatomy of the part is necessary to be able to give an opinion in these cases.

When the "back is broken" the power of motion is completely destroyed in the parts of the body behind the injury, though sensibility sometimes remains in a slight degree. It may be seen at once by the complete loss of power following a violent struggle, or he may merely be stiff, dragging the quarters as he is being led home, but he soon goes down, loses the use of the hind extremities entirely. This must not be confounded with laceration of the psoas muscles, which sometimes occurs from similar causes, also causing loss of power behind; in the latter he retains the power of motion in the tail, and the sensibility of the legs remains. Generally in complete paralysis the sphincters of the rectum and bladder are relaxed and the dung and urine are involuntarily passed.

In cases of only partial loss of power, where effusion of fluid is taking place, or bony enlargement pressing on the cord, the palsy is gradual and seldom complete. The difficulty in moving the hind limbs is very observable ; he drags them after him in a manner very graphically given by $\mathrm{Mr}$ Mayhew,- - one foot is perpetually getting in the way of the other, and constantly threatening to throw the animal down, whose walk already is rolling and unsteady." .

Treatment.--When fracture of the spine is ascertained to have taken place, producing complete paralysis, he may be destroyed, as even should partial recovery be attained, he is not worth much. When only partial or diminished nervous power exists, complete recovery may take place. Turn him into a loose-box, open the bowels by laxatives. 
The spine should be freely blistered, and either of the following balls given night and morning :-

$$
\text { Nux vomica in powder, . I drachm, }
$$

made into a ball, with linseed meal and extract of gentian. Or,

$$
\text { Strychnine, . . . } 2 \text { grains, }
$$

made ints a ball in the same way.

The nux vomica or strychnine, whichever be used, should be gradually increased, until they produce their physiological actions, known by twitching of the muscles and slight tetanic convulsions, when it should be stopped, or the dose diminished. He must be well fed and regularly groomed.

The treatment must be persevered in, as it is often tedious.

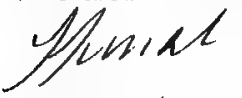

PARTIAL PARALYSIS.

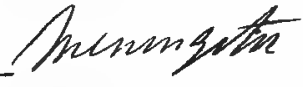

Under this name we will notice a disease which is very common in this country, and very alarming in its aspect from the suddenness of its attack and severity of its symptoms, producing almost complete loss of power of the hind quarters.

Causes. - It usually occurs in horses which are being "fed up," or which have been accustomed to hard work, and are allowed to remain in the stable for a few days, having a. liberal allowance of good feed, the system becomes plethoric, more blood being formed than the system can dispose of, whereby the vascular organs are overloaded, and consequently, under increased action caused by exertion, they are apt to become congested.

Symptoms - The animal is apparently in excellent health and spirits/ $-\mathrm{He}$ starts off lively; but before he has gone far, he suddenly stops, crouches, seems very much distressed. The sweat rolls off him in streams; he blows and heaves' at 
the flanks; he cannot move for a few minutes. He drops on his hind quarters; can hardly drag them after him. When made to move, he drops as if his leg was dislocated or broken. The pulse is very high, from sixty to eighty, and the muscles of the quarter are swollen and hard. In some cases he gets down, and cannot get up again; but seldom is loss of power at first complete, or sensibility entirely lost. The urine is generally very high coloured; we have seen it black, and always voided with difficulty.

XTreatment.-When seen in the early stages, fabstract six quarts of blood, remove the urine with a catheter, diligently apply hot water cloths to the loins, and cover them well up with dry blankets, changed every half-hour. Give twenty drops of tincture of aconite in a little cold water every two hours, till the fever subsides. If the pain is very severe and twitching, give the following

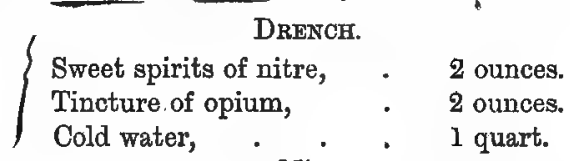

Mix.

Injections of soap and water should be given, and the legs well rubbed and bandaged. Eight drachms of aloes should / also be given.

In most cases it will yield to this treatment, and in three or four days he will be convalescent. However, in many the loss of power increases; he makes frequent efforts to get up, but cannot support himself behind. In these cases the spine should be freely blistered with mustard and turpentine, or the strong ammoniacal liniment Frequent small doses of warm beer and sweet nitre should be given, and restricted diet, carrots, bran-mash, \&c. When all fever and acute symptoms have subsided, and recovery of power is 
tardy, small doses of nux vomica or strychnine, as recommended under paralysis, should be given. He should be well bedded up with straw, and turned night and morning until he is able to rise. It often runs its course in from thirty-six to forty-eight hours, usually, however, in from three to six days. It is more fatal in stallions and geldings than in mares.

\section{TETANUS OR LOCKJAW.}

Tetanus is a peculiar irritability of the nervous system, inducing gonstant spasmodic contraction of the voluntary, and after a time the involuntary, muscles. I It is not uncommon in this country, especially during the summer months It is usually called lockjaw, from this becoming a prominent symptom, but the term is objectionable, inasmuch as we have often cases of tetanus in which the jaws are not " locked," and are but slightly implicated. Other technical terms are used, according to the extent and predominance of the muscles affected. We use the general term tetanus to express the peculiar state of the system when affected with the peculiar spasmodic rigidity of this disease in the whole or part of the body.

Causes.-It commonly occurs in consequence of wounds, when it is called traumatic tetanus; also from other causes not apparent, when it is distinguished as idiopathic tetanus. It often arises from wounds of the foot-pricks, corks, \&c., punctures of the tendons or their sheaths, deep punctured wounds of the groin, as from being staked, saddle-galls, \&c. Sometimes follows castration, docking and pricking; worms and other intestinal irritation sometimes give rise to it ; undue exposure to wet and cold, \&c., are common causes.

Symptoms.-We are unable to detect it until the wellmarked symptoms present themselves, which, once seen, can never be forgotten, yet no doubt it exists in the system for a 
few days previous. A horse labouring under this awful disease is one of the most pitiable objects we can look at. He stands with his legs wide apart, like four posts, to support his body; which, from the head to the tail, is rigid and quivering. The head is protruded, the muzzle and facial muscles contracted, the nostrils open, and the whole expression of the countenance haggard and excited, evincing great suffering. The haw (membrana nictitans) is pushed forward over the eye-ball, which is drawn into the socket, and squints outward. The jaws in most cases become early closed by the spasm of the masseter muscles; hence the name " lockjaw." The neck is very stiff, and the flank drawn up; the tail is raised and quivering; he drags his legs, and straddles very much in walking. The bowels are constipated, the urine scanty, and passed with difficulty. The pulse is not usually very high, but is easily raised by excitement; he is very nervous, starts and quivers when any one approaches him. His appetite remains gaod, and from inability to feed, his hunger amounts to starvation; he will make every effort to suck up gruel or fluids, when, from the fixidity of the jaws, be is unable to masticate. The breathing, at first not much altered, becomes difficult and loud. The symptoms generally reach their climax about the third or fourth day.

Treatment.-He must be thoroughly examined to see whether any wound or puncture can be discovered; if found, it must be thoroughly opened up, and diligently fomented with warm water and poultices of linseed meal, and hyoscyamus leaves applied to soothe it and allay the irritation. He must be removed into a cool, dark, rogmy loosebox, and a strong purgative, such as

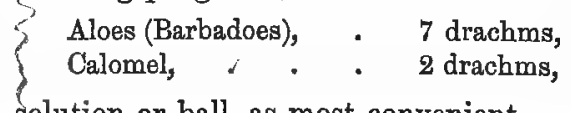

given in solution or ball, as most convenient. 
Injections of alkaline solution of aloes should also be given, as it is of the greatest importance to get the bowels open early. Belladonna in half-drachm doses should be given four or five times a day. If it cannot be given otherwise, place it up in the cheek, when he will suck it up ; or good effects will sometimes be obtained from doses of twentyfive drops of prussic acid given four or five times a day. He must be kept perfectly quiet, and the box cool and dark, no one being allowed to go near him but the attendants, and they must work about him noiselessly. A newly-flayed sheepskin should be laid over the loins, and well covered up to excite perspiration, but blisters and other irritating treatment must be avoided. He must be treated as in a nervous fever. He should be allowed all the nutriment he will take; and when he cannot eat, sloppy drinks of linseed tea, barley water, well boiled, oatmeal gruel, \&c., should be frequently placed within his reach.

It may run its course in four or five days, or it may continue for one or two weeks. It very often proves fatal.

\section{RABIES OR MADNESS.}

This dreadful malady is, providentially, of rare occurrence, and does not arise spontaneously in horses, but is usually the effects of the bite of a "mad dog."

Symptoms.-The attack is usually sudden, as it is severe, and seldom extends beyond the third day. It usually appears from two to eight weeks after the animal has been bitten. Sometimes it comes on gradually; he is observed dull, and his manner is peculiar. The other animals in the barn-yard seem afraid of him; he is observed to snap and bite at poultry, pigs, sheep, or other horses, when roused, then relapses into his dull state again. In a short time his 
eyes become staring wild and excited, and he runs at anything that comes in his way.

At other times it comes on suddenly, with all the fury of genuine madness; he becomes wild and frantic, bites and tears at everything within his reach; he rears up, kicks and plunges, presently gets down, gnaws at his own legs or sides, snaps at anything that is pushed towards him, gets up and runs with open mouth at any one who goes near him; palsy of the hind legs is apt to supervene; thirst is excessive; and the act of swallowing apparently difficult."

Treatment.-Curative treatment is hopeless, hence our efforts must be directed to preventing it.

When an animal is known to have been bitten by a mad dog, a string should at once be tightly tied above the injury, and the bitten part cut out or burned with the cautery or nitric acid, and some stimulant, such as good brandy, freely given; the same treatment is applicable to all animals.

\section{STRINGHALT.}

This peculiar and unsightly action of the hind leg is generally supposed to depend on "irregular action of the nervous energy" supplying the muscles of the leg. Various views of its nature have been promulgated, but its pathology is not well understood. It is said to arise from "some obscure disease of the sciatic nerve," or "local irritation, or of pressure on some nervous fibril." According to Mr Mayhew, it is the imperfect development of that form of disease which in man and dogs is called chorea, or St Vitus's dance, arising too, he thinks, from "the pressure of a spicula of bone on the spinal marrow."

We are not prepared to venture an opinion on the nature of this peculiar affection. We have frequently seen, in colts suffering from worms, and in horses from derangements of 
the digestive organs, a temporary spasmodic jerking of one or both hind legs, genuine stringhalt, from which they completely recovered under good keep and mineral tonics.

However, in older animals confirmed stringhalt is incurable, but beyond its ungainly appearance, it does not interfere with his usefulness. It is considered unsoundness,

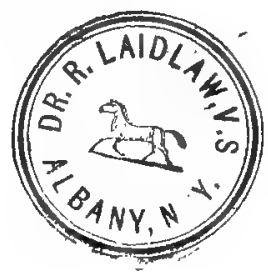




\section{CHAPTER XII.}

DISEASES OF THE BLOOD AND SYSTEM IN GENERAL.

WE' have already noticed the chief diseased condition in which the vital fluid is implicated, viz., inflammation. In the present chapter we treat of those diseases distinguished as specific affections, originating in a faulty state of the blood, and characterised by their specific effects on the system in general.

$$
\text { / GLANDERS AND FARCY. ) }
$$

Veterinary science has made great advancement in the elucidation of the true nature of disease, but the pathology of this loathsome and fatal disease is as yet far from being thoroughly understood, notwithstanding the researches of Dupuy, Vines, Coleman; Percival, Dick, and others.

This disease is not very common in Canada; only a few cases have come under our notice.

It is a generally received opinion that it depends on the formation of tubercles in the various tissues of the body, particularly in the lungs and membranes lining the nostrils, as in true glanders, or the absorbent glands of the groin, shoulder, neck, \&c., as in farcy.

Causes.-We cannot agree with Dupuy in considering glanders as hereditary. It arises in most cases spontaneously, from being kept in low, damp, ill-ventilated stables, particularly when debilitated by hard work and insufficient nourishment, also as a sequel of weakening complaints, such 
as neglected or improperly treated strangles, influenza, diabetes, \&c., injuries and exposure to cold in certain states of the system may give rise to the development of the virus in the blood. From whatever cause it,arises, it becomes very contagious, and apt to spread in a stable; not only horses are subject to it, but the mule and ass are not exempt, and numerous cases are recorded of students and attendants having been inoculated in working about them, and died from this horrible malady.

Symptoms.-The distinctive appearances which glanders present may be slow in their development, and may continue for years, during which he may feed and work well, constituting chronic glanders; or they may. run on rapidly, and in two or three weeks are well marked and soon run on to a fatal termination, when it is called acute glanders.

The coat is rough and staring; he is usually hide-bound; the belly drawn up, and constitutional disturbance exists, the pulse being easily excited; the membrane lining the nostrils is of a leaden hue; the glands under the jaw are enlarged, especially on the side from which the discharge takes placeusually the right, sometimes the left, or even from both; the discharge is clear and watery at first, becoming thicker and sticky, accumulating round the nostril ; cough may be present, but it is not an invariable symptom. As it advances, the discharge increases, becomes purulent, of a greenish colour, sometimes mixed with streaks of blood; it is of a heavy specific gravity, and if dropped in to water sinks to the bottorn it has a very offensive smell; the gland on the affected side becomes hard and adherent to the side of the jaw; ulcerating tubercles form on the nostril, which have a mouse-eaten appearance, being rarsed and irregular at the edges and depressed in the centre; they run into patches and spread over the whole nasal septum; weakness and 
emaciation set in. The ulceration in some cases extends to the cartilages, and even the bones are sometimes implicated, when occasional bleedings ensue. The tubercles increase in the lungs ; cough is troublesome ; farcy buds appear in some cases over the body, and he dies a disgusting and loathsome spectacle.

Other diseases have been mistaken for glanders; symptoms which are apt to mislead the uninitiated arise from the existence of diseased teeth, as occurred in a case of a valuable gelding which was destroyed, supposed to be affected with glanders, belonging to a gentleman near Aurora, York county, and on examining the head, which was sent to us, it was found to have been ulceration arising from a diseased tooth. Professor Dick in his lectures relates several similar cases. We have frequently had horses sent to us for examination said to have glanders, when in reality it was simply nasal gleet, which recovered completely under treatment.

In many cases the gland is not adherent to the bone, and still genuine glanders exists; on the other hand, the gland may be adherent without glanders. Neither is much dependence to be placed on the increased specific gravity of the discharge, as in some cases of diseased teeth it will also sink to the bottom in water.

Farcy.-Farcy and glanders are essentially the same disease, and depending on the same specific poison in the blood, but manifesting itself in a different locality. It often occurs in connexion with glanders, but is also seen independent of it, running into glanders as it progresses.

Symptoms. - It usually affects the superficial absorbents of the hind limbs in the groin, extending downwards on the inside of the thigh, following the line of the lymphatics, also along the absorbents of the neck and shoulders; little tubercles or farcy buds form, which in some cases become indurated and 
lie dormant for a time, but in most cases they go on to ulceration, producing angry irregular ulcers similar to the ulceration in glanders; the virus being conveyed along the absorbents, the buds extend in knots; lines of corded and inflamed absorbents are felt extending from below upward, the hair being rough and bristling along their course; by and by swelling of the legs sets in; as it gnes on he becomes emaciated; the ulceration attacks the nostrils, and glanders and farcy are combined, and death relieves him at last. A disease called watery farcy must not be mistaken for genuine farcy.

Treatment of Glanders.-Almost every article of the materia medica has been experimented with to cure this disease, but as yet it has baffled all attempts. From the danger arising by contagion to other animals and the attendants, the sooner he is destroyed the better.

X Before destroying a horse it is well to be satisfied that the diagnosis is correct. $\backslash$ We generally inoculate his own shoulder, or some worthless animal, so as to satisfy ourselves. Glandered matter Iard under the skin will produce considerable tumefaction, followed by discharge of sticky unhealthy matter, and in some cases farcy buds, and in another animal either glanders or farcy. Treat care should be taken not to let the matter come in contact with any sore on the hands, as we have known fatal results follow from this cause. The stable must be thoroughly renovated, and the walls washed with chloride of lime, Conde's or Sir William Burnett's disinfecting fluid, and every precaution talsen to prevent it extending to other horses

STRANGLES OR HORSE DISTEMPER.

Strangles is a disease peculiar to the horse, occurring mostly" in young horses from two to five years old. "It 
may be defined a catarrhal affection, accompanied by a specific phlegmonous affection of the cellular membrane of the throat, tending to abscess, with slight fever" (Dick). It is contagious, and but few horses escape it.

Causes.-We are rather inclined to the opinion that it consists of some "animal poison" latent in the system, which is being thrown off by this process. The exciting causes are similar to catarrh, transition from cold to heat, as from the pasture to the stable, change of stable from the country to the city. Occurs most commonly in spring, and usually seen in cold damp weather.

Symptoms.-It is usually ushered in by slight feverishness; the mouth is hot and dry; the membrane lining the nostrils is red; the eyes dull and watering; the pulse quick and weak; the throat sore; and cough is troublesome. He is dull, and weakness becomes a prominent symptom. In a few days a hard inflammatory tumour forms between the branches of the jaw, which is hot and tender; the breathing becomes quick and laboured; from the soreness and tumefaction of the throat, he swallows with difficulty.

In ordinary cases the tumour goes on to suppuration; a copious discharge of thick yellow matter takes place from the nostrils. In about a week the tumour has matured, become soft, and points, and either bursts or is opened; continues to discharge for some time; and gradual recovery takes place.

In some seasons it does not follow this regular course. The tumour is imperfectly developed, is tardy in maturing, sometimes disappears without suppurating, and forms in the breast, flank, or some other part of the body. This is known as irregular strangles. It may be suspected when the weakness increases, and recovery is delayed. When forming in the internal organs, it presents different and often com- 
plicated symptoms. When the lungs are implicated, the breathing is affected; the pulse is quick and weak; he maintains the standing position; pain is evinced by pressure between the ribs behind the arm, and auscultation and percussion afford conclusive evidence. If forming in the bowels or mesenteric glands, colicky pains are frequent; he looks wistfully to his flanks; in the stable he lies most of his time; and at work he is languid and easily sweated. These cases are ustially hopeless when the essential organs are involved.

Treatment.-No attempt should be made to drive it back, for, like all eruptive fevers, it must run its course, and cannot be checked without danger. He should be turned into a comfortable loose-box kept at a temperature of $60^{\circ}$, plentifully supplied with pure fresh air; the bowels should be opened by injections, the body being warmly clothed, and the legs bandaged; he must be fed on bran, carrots, boiled oats or barley, and green food when procurable. Hot fomentations and poultices should be freely applied to the tumour, so as to encourage its proper formation. Small doses of saltpetre should be given in the feed, or the following powders, one night and morning :-

Nitre, . . $\quad 1$ ounce and a half.
Tartar emetic, . $\quad 6$ drachms.

Mix, and make into six powders.

When the tumour is matured, it may be allowed to burst of itself, or it may be carefully opened by cutting through the skin, and pushing in the finger.

Recovery will be expedited by generous feed and mineral tonics.

The irregular form must be treated on the same principles, being guided by the, symptoms. 


\section{INFLUENZA.}

Influenza belongs to the class of diseases termed epizootic, which are distinguished by extending over a large tract of country, and attacking a number of horses at the same time. In its nature it resembles an epidemic form of catarrh, but it is essentially different, and is easily distinguished from that complaint by its epizootic character, and the marked prostration and low typhoid form of fever which always accompanies it. It does not affect horses alike in all seasons; some years it is apt to involve the lungs principally, with a marked tendency to dropsical effusion, whereas in others the liver and digestive organs are chiefly implicated.

Causes. - It is usually supposed to arise from "atmospheric" causes, - some changes which are said to exist in the atmosphere which are not easily explained. It occurs mostly in spring or autumn, and is most commonly seen in over-crowded, ill-ventilated stables. City horses are more liable to it than those in the country, and coarser breeds are more subject to it than the finer breeds.

Symptoms. - It is early characterised by weakness, a quick, weak pulse, hot mouth, shivering, dulness, watery eyes. The lining membrane of the nose is reddened, accompanied by a watery discharge, which soon becomes thick and purulent, accompanied by sore throat and difficulty of swallowing; the appetite is impaired, and the bowels costive. These symptoms, instead of abating, as in catarrh, increase, the breathing becomes hurried, and there is lifting of the flanks. The low form of fever is characteristic, as also its occurring in spring or fall, and attacking a number of animals in the same way, distinguish it from common catarrh.

In some seasons the lungs are primarily affected, and 
there is great weakness, with a tendency to dropsical effusion; water accumulates in the chest; the heart and its coverings are seriously involved; often the eyelids, lips, and whole head are enormously distended with fluid. In other cases the liver and bowels seem to suffer most, causing great thirst, general uneasiness, costive bowels, and light-coloured foeces, sometimes covered by slimy mucus, and rapid prostration. "When an unfavourable termination occurs, the dulness increases to stupor, the extremities get colder, the breathing more difficult and abdominal, the pulse quicker, weaker, and more irregular, and death occurs from the tenth to the twentieth day."

Treatment.-The general principles laid down for the treatment of common catarrh are applicable to the treatment of influenza; bleeding, purging, and depletion must be avoided, as the debilitating tendency is great from the first. $\widetilde{\mathrm{He}}$ should be placed in a loose-box, the body clothed, and the legs bandaged. I If noticed while the shivering fit lasts, one or two ounces of acetate of ammonia may be given with advantage. 1 The bowels should be gently opened by a pint of castor-oil and one or two drachms of calomel, supplemented by injections of soap and water. When the rigour has passed off, and the fever runs high, tincture of aconite, in doses of fifteen drops, should be given every two hours; he should be encouraged to drink water holding small doses. of nitre in solution; should he not drink it, he may have a few mouthfuls of cold water every hour; nothing is better for reducing fever. He should have green food when procurable, or a spare allowance of boiled barley, or oats, bran mash, \&c. When the throat is very sore, and the cough troublesome, rub the throat well with tincture of cantharides or the ammoniacal liniment, and give the following ball night and morning:- 


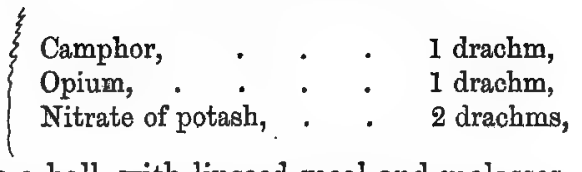

made into a ball, with linseed meal and molasses.

Should the lungs or bronchial tubes become involved, indicated by the heaving flanks and careful breathing, the sides should be blistered and other ways treated as directed for inflammation of these organs. / From the first stimulants are beneficial in the treatment of influenza to counteract the debilitating tendency, and during recovery frequent small doses of beer and sweet spirits of nitre are very useful.

$X$ When all inflammatory symptoms have disappeared, mineral and vegetable tonics will expedite the recovery. $\mathrm{He}$ requires great care for some time.

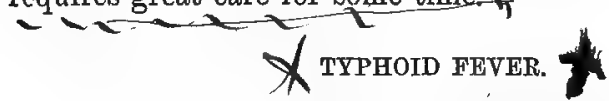

A disease of a very fatal character, evidently; an equine species of this disease has been noticed to prevail during the spring months for the last three or four years in this country. Until lately, typhoid fever was not recognised in veterinary nosology as a primary disease, although as an accompaniment of epidemic diseases, such as strangles, influenza, \&c., we were familiar with it in all its forms. It now occurs in forms so well marked that we are justified in giving it a place in professional nomenclature as a distinct disease.

Causes.-It is mainly attributable to those influences which interfere with the general health and vigour of the animal, among which stand pre-eminently overcrowding, improper ventilation, confinement in damp filthy stables, drinking bad water, holding in solution decomposing organic matters, insufficient nourishment, and undue exposure, together with what may be termed generally, atmospherie causes. 
Symptoms. - It is ushered in by shivering, dulness, and languor. The animal stands hanging his head; is listless and stupid; the pulse is quick and weak; the mouth hot and dry ; a watery discharge trickles down the nostrils, which are pallid or of a yellow tinge. He is very thirsty; but is unable to swallow either food or water. The throat is tender; but there is no observable tumefaction. He has a painful cough, but not very frequent. The secretions are sluggish, and the surface temperature variable.

The great predominant symptom is the extreme prostration which from the first characterises the complaint. In from twenty-four to forty-eight hours the weakness has so much increased that he is unable to stand; he gets down; colicky pains set in; the pulse increases in frequency; becomes weaker and weaker, till it is altogether imperceptible; the breathing is quick and short, and the breath fetid. It usually runs its course in three or four days. After death the body emits the foulest odours.

Treatment is very unsatisfactory. It often proves fatal. ¿Stimulants must be freely given from the first. The throat \{should be freely blistered and gargled internally with the following gargle:- -

$\left\{\begin{array}{lllllll}\text { Nitrate of silver, } & \cdot & \cdot & \cdot & \cdot & 40 \text { grains. } \\ \text { Rain water, } & \cdot & \cdot & \cdot & \cdot & \cdot & 4 \text { ounces. }\end{array}\right.$

, The back part of the throat to be touched carefully with it by means of a piece of sponge on the end of a whalebone

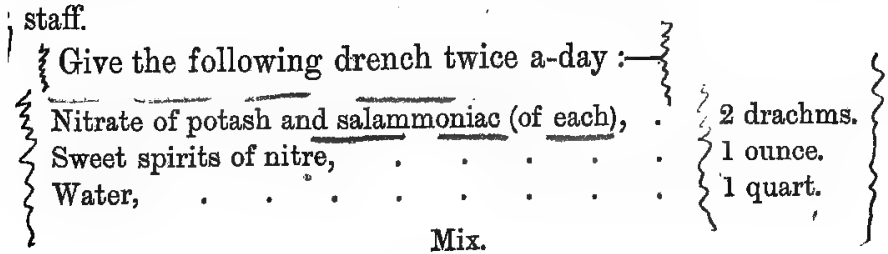


The legs should be well rubbed and bandaged, the body clothed, and comfort otherwise attended to.

It should be prevented by improved ventilation and drainage, and a change of water, with good food and regular exercise. 


\section{CHAPTER XIII.}

\section{DISEASES OF THE EYE.}

THE eye, or organ of vision, is composed of three tunics or coats, and of the same number of humours. To the external coat (sclerotic and cornea) it owes its form. The middle tunic is made up of the choroid, or vascular coat, of the iris, or the thin curtain suspended in the aqueous humour, and perforated in the centre by an opening called the pupil, or pupillary opening, which in the horse is of an elliptical form; in man it is round. The inner coat is called the retina, or nervous covering, and is the terminal expansion of the optic nerve.

The humours are three in number, and they serve as reflectors of the light. They are-the aqueous humour, crystalline lens, and vitreous humour. The latter is the largest, and occupies about four-fifths of the whole interior of the globe or eyeball. The appendages of the eye are-the eyelids, the eyelashes, and the membrana nictitans, generally called the haw, which is situated in the inner or lower angle of the eye. It is connected with the different muscles of the eyeball. 'By the contraction of the straight muscle of the eye, the haw is forced outwards, and is one of the beautiful arrangements that nature has provided for the protection of so delicate and sensitive an organ. The eye is wholly covered by a thin membrane called the conjunctiva. 


\section{SIMPLE OPTHALMIA, OR CONJUNCTIVITIS,}

Is a common disease amongst horses, and consists of inflammation of the conjunctival membrane covering the eye.

Causes.-It may be produced from many different causes, and perhaps the most common is from the introduction of any foreign substance into the eye, as a hay seed, or chaff pickle becoming lodged in the external covering (cornea), or from the lash of a whip. It is also caused by allowing horses to stand in foul stables, especially in the summer months, whereby ammoniacal gases are generated, proving very injùrious to the eyesight. It proceeds from exposure to cold, and is often an accompaniment of catarrh.

Symptoms.-There is partial closure of the eyelids; a copious secretion of tears; the conjuctiva is swollen, and in some cases protruding from under the eyelids, which are generally tumefied. A white film, the result of inflammation, comes over the cornea, and may vary from a slight cloudiness to perfect opacity.

Treatment.-This must in a great measure depend upon the cause; therefore it is of the greatest importance to make a careful examination. Any substance lodged on the cornea must be removed, which can be done either by means of a feather or a pair of forceps. The eye should be fomented with tepid or warm water, and the horse kept in a darkened stable or loose-box; or the eye may be kept constantly moist by means of a sponge or cloth, saturated with tepid or cold water, and applied over the eye. If accompanied by great pain, the following lotion should be applied áround the orbit several times a-day :-

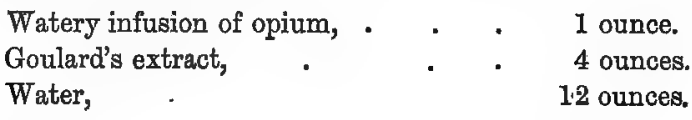


When the cloudiness or opacity of the cornea is tardy in being removed, the eye should be stimulated daily with the following collyrium :-

Nitrate of silver, . . . . . 5 grains.

Distilled water, . . . . . 1 ounce.

Apply by means of a feather or camel hair brush.

\section{SPECIFIC OR PERIODIC OPTHALMIA ,}

Is the most severe affection to which the horse's eye is liable, and we are sorry to say it is not an unfrequent disease amongst horses in this country. The parts principally and primarily involved are the internal structures of the eye, and the changes which occur vary in degree to the severity of the attack.

Causes.-The great cause of this affection can be traced to an hereditary predisposition, always ready to burst forth when exposed to certain exciting causes, such as injuries of any kind, being kept in very dark and ill-ventilated stables, and then suddenly exposed to the glare of a hot sun; and, like simple iopthalmia, it may follow continued exposure to cold.

Symptoms.-Among the first symptoms is a watery discharge from one or both eyes, and on being exposed to the sun's light he exhibits a peculiar uneasiness, with a partial closure of the affected eye. In this stage a common expression is, "that he has got a cold in the eye." As the disease advances, the eyelids become swollen, and if turned upwards, the conjunctiva appears reddened and injected; and altogether the symptoms are very like those of simple opthalmia, and often leads to the supposition that the eye has received a blow or other injury. The above symptoms become more and more aggravated, and the patient becomes affected constitutionally, - the circulation is increased, the mouth hot, 
and the appetite impaired. These symptoms may continue for several days, and then gradually disappear, or they may be prolonged for weeks, and end only with the destruction of the eye. A prominent and well-marked symptom of this disease, is its shifting from one eye to the other; in many cases one eye has no sooner recovered than the other becomes affected. At other times recovery is rapid, and to all appearance the eye looks perfectly healthy; in a short time, however, the disease returns, and ' often with increased severity. As the disease still further advances, the eye begins to clear, the cornea becoming transparent, leaving a slight muddiness in the anterior part (chamber) of the eye ; the púpil diminishes in size, and the disease gradually terminates in more or less opacity of the crystalline lens or its capsule, constituting cataract.

Treatment.-As a general rule, the treatment of specific opthalmia is very unsatisfactory, but still medicinal remedies are found beneficial in palliating the disease. The horse should be placed in a comfortable and darkened loose-box, with a plentiful supply of pure air. A brisk dose of purgative medicine may be administered, and, if much constitutional fever is present, ten drops of the tincture of aconite should be given every three hours, until six or eight doses are given. Bleeding from the facial vein, followed by fomen-, tations of hot water. After the third or fourth day, cold applications are preferable to hot. The extract of belladonna may be applied around the orbits, and also administered internally in doses of two scruples, three times a-day. When the acute inflammatory symptoms are somewhat abated, the absorption of the effused products by a stimulating collyrium, as,

$$
\begin{aligned}
& \begin{array}{l}
\text { Sulphate of zinc, } \\
\text { Distilled water, }
\end{array} \\
& \text { a } \\
& \text { of the collyria. (See page 212.) }
\end{aligned}
$$




\section{ANIAUROSTS, OR GLASS EYE,}

Consists in either partial or complete paralysis of the optic nerve, or its terminal expansion, the retina.

Causes.-Injuries to the brain, causing an extravasation of blood upon the deep origin of the special nerve of sight, (optic,) from disease of the internal coat of the eye (retina.) It occasionally occurs as a sequel of stomach staggers or indigestion. We have also known it to occur in pregnant mares. "Percival mentions several cases of amaurosis occurring in mares in foal, where vision was perfectly restored after parturition."

Symptoms.-The eye has a peculiar glassy appearance; the horse carries his head very high, and is continually moving his ears, and his action is high, lifting his feet as if he 'was stepping over some obstacle. $\mathrm{He}$ is easily alarmed by any noise. The pupil is dilated, and loses its natural elliptical form. If the glare of a lighted candle is brought to bear upon the eye, the pupil refuses to contract, thus showing that nervous influence is lost.

Treatment.-The horse should have rest, and a strong dose of purgative medicine given. If supposed to arise from effusion or pressure on the nerve (optic,) blisters and setons to the poll are recommended, and diuretics should be used. In some instances the powdered nux vomica, in doses of one scruple twice a-day, has been used with advantage. If amaurosis has continued for a lengthened period, it is incurable, and treatment in such cases would be entirely useless.

\section{CATARACT}

Is the name applied to a deposition of a pearly white substance within the eye, and is a very common affection in Canada. It consists in an effusion of lymph either on the 
middle humour, (crystalline lens,) or on its capsule, and is variable in size, sometimes not larger than the head of a pin, whilst in other cases it covers the whole lens.

Causes.-It is generally a result of repeated attacks of specific opthalmia, or it may even supervene upon a first attack ; it may follow a severe injury to the eye.

Symptoms. -The eyesight is, either partially or completely gone, and when covering the greater part of the lens, it is easily known by its pearly white appearance. When small, it is somewhat difficult of detection; the eye is smaller than in health, and the pupil becomes greatly contracted when exposed to light. It may be detected by placing the animal in a bright light, and carefully examining the eye; if the eye appears smaller than the other, it indicates something amiss with it. He should then be placed in a darkened stable, and allowed to stand quietly for ten or fifteen minutes before being subjected to an examination. Stand in front of him, and bring a lighted candle close up to the front of his eye, when any alteration in the structure of the lens can be readily detected.

Treatment.-In the horse is useless, as when permanently established it cannot be recovered. When the cataract is confined to one eye only, it interferes but little with the horse's usefulness for ordinary work.

\section{FILARIA (OR WORM IN THE EYE.)}

In Canada the phenomenon of worm in the eye is of rare occurrence; in Britain it has never been known, but in India it is a prevalent affection amongst horses. We can best illustrate our views on this subject by giving a brief description of the following case:-In the beginning of May 1864, we were requested by $\mathrm{Mr}$ Armstrong of York township to examine a horse belonging to him, and suffering from a 
disease of the left eye. On looking into the eye, the true nature of this phenomenon could be plainly seen; the worm appeared to move in every direction, and with remarkable quickness. We recommended its removal from the eye by an operation, and immediately brought the horse to our infirmary. He was cast in the usual manner; and with a -small lancet we made an incision into the antero-inferior part of the cornea, allowing the aqueous humour to escape, and with it the little worm, which measured one and a-half inches in length, and was thickest in the middle, tapering towards either extremity. After the operation the eye was covered with a cloth saturated with cold water, a dose of purgative medicine administered, and three days afterwards he was put to his usual work.

FUNGUS HAMATOIDES, OR BLEEDING FUNGUS.

The mucous membrane of the eye is occasionally the seat of cancerous deposits. They are generally rapidly developed, and are largely supplied with blood-vessels, which are readily ruptured by the least pressure, hence the name, "bleeding fungus."

These tumours are very often the result of some injury to the eye, and sometimes grow to an enormous size; we have met with cases where the fungus extended half-way down the cheek, giving the animal a very ungainly and most loathsome appearance. In such cases the eye is totally destroyed.

Treatment.-This must consist in the free use of the knife, and in the early stage they may be completely removed; every particle must be carefully cut away, and the parts afterwards dressed with a mild caustic. When very large and. involving the eyeball, it is necessary to remove the whole orbit. 


\section{"INJURIES TO THE EYE."}

The cornea is frequently injured from the puncture of a nail, allowing the aqueous humour to escape, and perhaps injuring the crystalline lens, completely destroying vision. When the injury is confined to the cornea the humour may be reproduced. The parts should be diligently bathed, either with hot or cold water, and the fomentations nust be applied several times a-day; and the eye supported by means of a wet sponge or cloth, which tends to subdue the acute inflammation and allay the pain, and also by keeping the eyelids closed it supports the lacerated parts.

After a few days it may be necessary to stimulate the part, when any of the stimulating applications recommended for simple opthalnia may be used.

The membrana nictitans, or haw, sometimes becomes enlarged, the result of an injury, or from being implicated in other diseased conditions of the eye. Even in its healthy state we have known it mistaken (by ignorant persons) for an abnormal structure and barbarously removed. It is not an unusual circumstance to hear persons boast of the rapidity with which they can remove this beautiful and most essential appendage of the eye. 


\section{CHAPTER XIV.}

DISEASES OF THE SKIN.

THE skin is a membrane of variable thickness which covers the whole body, and is reflected inwards by all the natural openings, so as to line, by its internal reflections, the eye, the nasal cavities, the mouth, \&c. \&c. Skin diseases in the lower animals generally do not prove so inveterate, as in the human being.

\section{SURFEIT}

Is an affection of common occurrence amongst horses in the spring and summer months, and is an eruptive disease showing itself in the form of small tumours or pimples, and extending along the neck or over the whole body.

Causes.-It very often proves a sequel of some derangement of the digestive organs; as from feeding for a lengthened period on one kind of food, and more particularly if it is of a stimulating or heating nature. It is also apt to occur in horses that are in high condition when subjected to violent exercise, causing them to sweat freely and then being exposed to sudden chill; in this form it is often met with in colts, when being first put to work.

Symptoms.--It appears suddenly; small pimples or tumours arise on different parts of the body and neck, and particularly underneath the mane; in some instances they disappear rapidly by absorption, whilst in others they burst and discharge a thin fluid; the hair comes out, and small 
scales form, which are easily pulled off. At times this affection proves very irksome and troublesome to the horse, .causing him to rub violently against his stall, or bite at the parts affected with his teeth. In its simple form it appears to inconvenience the animal but little, and is generally easily removed.

Treatment.-In the first place the food should be changed, and a mild purgative given, as Barbadoes aloes, four to six drachms; the kidneys should be got to act freely, and for that purpose the following ball may be given daily for four or five days :-

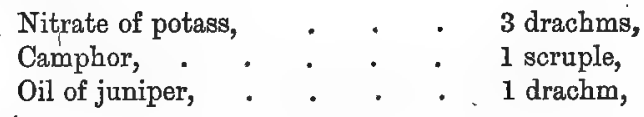

with soft soap and linseed meal sufficient to form an ordinary sized ball.

In inveterate cases small doses of calomel and opium may be used with success. The eruptions should be thoroughly cleaned with soap and water, and afterwards dressed with a mild solution of the chloride of zinc, about twenty grains to the pint of water. He should have regular exercise and good grooming, using the wisp instead of the curry-comb. Surfeit differs from mange in not being contagious.

\section{MANGE}

Is another eruptive disease, and is very contagious, and is caused by the repeated attacks of minute insects which burrow into the skin; these insects are called acari, and can be easily seen by means of a magnifying glass.

Causes.--In the majority of cases it is the result of contagion, either from coming in direct contact with a mangy horse, or it may be carried by means of his harness or . blankets. It is also generated by uncleanliness and insuff- 
cient nourishment; the skin, from being allowed to become covered with dirt, loses in a great measure its highly important function in maintaining an animal in health.

Symptoms.-Generally the first symptom observed is the animal rubbing his head and neck against the stall or manger ; small pimples appear and the hair falls off; the skin is dry and hard, and upon the hardened patches may be seen small red spots. A horse affected with mange is kept in a constant state of irritation, which soon reduces him in flesh.

Treatment.-He should be separated from other animal's, and thoroughly washed with soap and water every second or third day, afterwards dressed with the following application:-

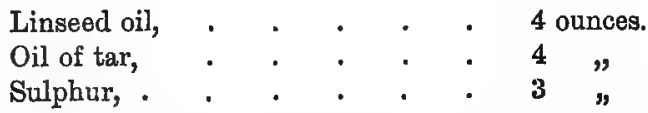

Mix and rub well into the affected parts.

Alternately with the above application mercurial ointment may be used. The horse should have a generous diet and moderate and regular exercise. In inveterate cases arsenical solutions are beneficial, but must be used with caution. All clothing, harness, \&c., which has been used on a horse affected with mange, should be thoroughly cleansed before they are again used.

\section{GREASE}

Is a diseased state of the skin of the legs, and more especially of the hind ones. In the early stage, it consists in inflammation of the sweat glands, followed by an offensive oily discharge.

Causes.-Certain breeds of horses may be said to be predisposed to this disease, and those animals especially subject to it are such as have coarse heavy limbs. The great exciting cause of grease is uncleanliness, as allowing horses to stand 
in damp filthy stables, exposed to obnoxious gases. In the fall of the year it is often caused by washing the legs with cold water and not carefully drying them afterwards. In other cases it is the result of keeping horses in high condition, and not giving them sufficient exercise to keep the skin in a healthy state.

Symptoms.-Grease is a disease easily detected; there is generally more or less swelling of the legs, which if not speedily relieved is followed by a discharge; the hair falls partly off, and the skin is reddened and inflamed, as can be plainly seen in a white heel. The parts are very painful and hot, and in many cases the least pressure of the hand will make the horse twitch up his leg, and continue to hold it up for some time. In other cases, when made to move abont in his stall, or when taken out of his stable in the morning, he will keep twitching up his legs as if he was affected with stringhalt. Exercise appears to relieve the pain, as after being walked for ten or fifteen minutes he goes quite free. As the disease advances the skin cracks and the discharge increases, becoming more and more purulent and offensive ; the swelling increases, not being confined to the heels, but involving the front of the fetlock joint, and in some cases extending upwards to the hoek. The cracked condition of the legs and heels undergoes a change of structure, and fungoid granulations spring up similar in form to a bunch of grapes; this is called the "grapy stage," which may vary considerably in structure-at one time being very vascular, bleeding readily when touched, in other instances it looses its vascularity and becomes hard and horny; from between the crevices of the grapes an ichorous glairy discharge continues.

Treatment.-Without cleanliness all medicinal remedies are useless. The heels should be washed with soap and water every day, and the general comfort of the animal 
attended to. If the patient is in high condition, a dose of purgative medicine must be given, and the animal restricted to a cooling diet, as carrots, bran, \&c., or if in summer, green food is preferable. The following lotion may be daily applied, which in mild cases will generally suffice:-

Chloride of zinc, . $\quad$ - $\quad 30$ grains.
Water, - $\quad 1$ pint.

In cases of long standing the hair must be cut off, and the parts softened with linseed-meal poultices; to which may be added charcoal, yeast, or bleaching powder. After removing the poultices, dust the parts over with oxide of zinc powder, or apply the following ointment every morning, to be washed off at night :-

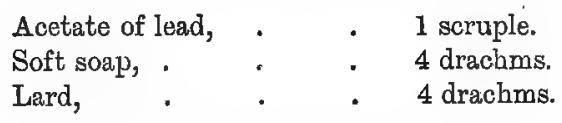

As in other skin diseases, small doses of Fowler's solution of arsenic is generally attended with beneficial results.

SCRATCHES, OR CRACKED HEELS,

Is a very common occurrence amongst our Canadian horses, especially in the spring and autumn months, and the hind legs are oftener affected than the fore ones.

Causes.-Like grease, they are very often the result of keeping horses standing in damp or filthy stables; but perhaps the most common cause amongst our agricultural horses is the habit of washing the legs with cold water, and not drying them thoroughly afterwards; the sebaceous glands in the hollow of the pasterns become inflamed, their secretion is increased, the skin cracks and discharges an ichorous matter.

Symptoms.-They usually cause lameness, more or less severe according to the severity of the attack, always most 
painful for the first few steps-the hollow of the pasterns are swollen, red, hot, and tender, with transverse cracks which open at every step and often bleed, especially in cold weather.

Treatment.-Must be regulated according to the extent and duration of the disease. In all cases the horse should be kept in a dry place, with an abundance of clean litter; the heels should be thoroughly cleansed, and if painful, poultices of linseed meal applied for several days. If the horse is in high condition, and the legs much swollen, a full dose of purgative medicine must be given, followed by two or three doses of diuretic medicine, as,

$\begin{array}{lcc}\text { Nitrate of potash, } & \text {. } & 3 \text { drachms, } \\ \text { Rosin, - } & \text { do. }\end{array}$

with soft soap sufficient to make an ordinary-sized ball.

After poulticing, the parts should be dressed once or twice a day with the following lotion :-

$\begin{array}{lll}\text { Sulphate of zinc, } & \text {. } & 6 \text { drachms. } \\ \text { Acetate of lead, } & \text { l ounce. } \\ \text { Water, . } & \text {. } & 1 \text { pint. }\end{array}$

Occasionally scratches prove very troublesome and difficult to cure; if the ulcerations extend, it will be necessary to change the dressing, dry powders, such as oxide of zinc, calomel, \&c., should be tried.

\section{RINGWORM.}

This is not a common disease amongst horses. It consists in a parasitic growth of organic cells in the surface of the skin. Ringworm is a common affection in man, and is said to be communicable from him to the lower animals. Like other diseases of the skin, it is also generated by uncleanliness.

Symptoms.-The hair falls off on various parts of the body, especially about the face, eyelids, cheeks, neck, and thighs, leaving small and apparently ulcerated patches, which 
appear white and scaly, and have a peculiar tendency to spread; the animal loses flesh, and his coat becomes dry and dirty looking.

- Treatment-Ringworm, if attended to in the early stage, is easily cured. The affected parts should be well cleansed, and touched with a mild caustic, and dress daily with the following ointment :-

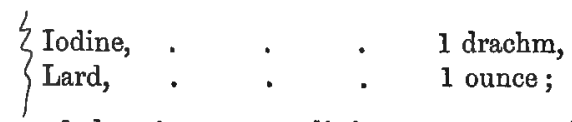

$r$, in place of the ointment, a liniment composed of

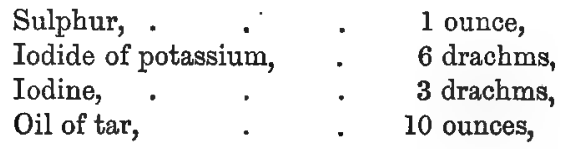

may be used daily.

\section{SALLENDERS}

Is the name given to an eruption on the front of the hock joint, consisting in a scurfiness of the skin, accompanied by an ichorous discharge and falling out of the hair.

Causes.-High feeding without sufficient exercise, disorder of the digestive system, uncleanliness, and bad grooming. In stallions of the heavy draught breed they are a very common affection, and prove difficult to remove.

Treatment.-Dress the parts with mercurial or iodine ointments, keep the legs dry and clean, and give regular but not severe exercise, and occasionally a dose of laxative medicine. When only slight, the following lotion may remove them :-

$$
\begin{array}{ll}
\text { Corrosive sublimate, } \quad & 20 \text { grains. } \\
\text { Water, . } & 1 \text { pint. }
\end{array}
$$

Apply twice a day. 


\section{MALLENDERS}

Is the name given to a similar affection located at the back of the knee. The treatment must be the same as for sallenders.

\section{SADDLE AND COLLAR GALLS,}

A very common occurrence amongst horses, are caused by uneven pressure of the saddle or collar; the skin becomes excoriated, and the hair falls off ; large inflammatory swellings appear, which may form into abscesses, or the skin may become indurated and thickened.

Treatment.-The parts should be fomented with warm water, and some simple or cooling lotion applied, as,

$$
\begin{aligned}
& \text { Acetate of lead, . . } 1 \text { ounce. } \\
& \text { Water, . . } 1 \text { pint. }
\end{aligned}
$$

If abscesses form, they must be freely opened and well fomented or poulticed. When the skin becomes indurated, forming what are called sitfasts, they must be dissected out. 


\section{CHAPTER XV.}

\section{SHOEING OF HORSES.}

History.-Arcbæologists have paid but little attention to the history of the art of shoeing horses, consequently we find it difficult to determine the precise period at which it was first practised. The early Romans, we are told, used a covering probably woven of hemp or rushes, which enclosed the whole foot, and was tied round the fetlock by a cord: this kind of shoe they called solea spartea. This, however, must have been very inconvenient and troublesome, as they would require to be repeatedly renewed in the course of a journey. Something more durable had to be substituted, so we find that mention is next made of the solea ferrece, or iron shoe. Writers are not agreed as to how the Romans attached these solea ferreæ; some suppose that they were attached to a leather sock bound on by a thong of the same material; others again suppose that they were acquainted with our modern methods of fastening them. This last opinion is in some measure confirmed by the discovery of old iron shoes, in some of the Roman remains in England, having nail holes punched in them of a square shape. It is evident that the Britons had some sort of protection for the foot of the horse, either at the Roman invasion, or soon after, from their having a name for it ; they called it pedol, -from the celtic ped, a foot. Some suppose that horseshoeing was introduced into Britain at the Norman Invasion. 
This idea probably arose from the great importance which William the Conqueror attached to farriery.

Professor Dick has summed up the whole discussion on shoeing in the following remark:- "After a personal experience of nearly fifty years, I have come to the conclusion that the whole art of shoeing consists in applying a shoe so that it will serve as a defence to the foot, without injuring it." Within the last fifty years great improvements have taken place in the art, and a great many able experiments with different forms of shoes, and different methods of applying them, have been made by veterinarians. The works of Coleman, Osmer, Moorcroft, Turner, Clark, Dick, Miln, Fitzwygram, and others, are particularly worthy of a careful perusal.

\section{THE SEATED SHOE.}

Ingenious as many of the experiments have been, and valuable the information they have furnisked, none of them have yet been able to surpass, for all purposes, the plain seated shoe first introduced by Osmer, and subsequently slightly improved by Moorcroft. It is now almost universally used, and can be seen in almost every forge; and were our farriers to follow out the objects which Osmer's shoe is so well adapted to secure,--viz., equable bearing for the crust, and safe protection for the sole,-we would have fewer horses lamed from shoeing. Seldom, indeed, does the country smith take the trouble to make the shoe properly.

In making the seated shoe, the work the horse is intended for, and the nature and condition of his foot, must be taken into consideration, and the weight and size of the shoe, the width of the web, \&c., must be regulated accordingly. The upper or foot surface must be seated ; that is, the part which is to receive the crust should be perfectly flat all round, of the width of the crust to the heels, where it is flat the whole 
breadth of the shoe, to afford a level surface for the heels and bars to rest upon. The web must be bevelled out all round the extent of the sole to admit of the elastic action which it possesses. This is seldom sufficiently hollowed out, and, especially in flat feet, often gives rise to bruises of the sole. The width of the web must be regulated by the nature of the foot and the work he is intended for; if flat and thin, it should be broad and strong. The hunter requires a narrow shoe to prevent it being torn off on soft ground, while the dray horse requires a broad shoe to protect his feet from bruises on the roads.

The ground surface should be perfectly level, so as to present as many points of bearing as possible. The fullering should be deep enough to receive the heads of the nails, and may extend from heel to heel, or merely, as in most cases, on each quarter. The nail-holes require remark; they should be directed so as to correspond with the direction of the crust; thus, at the toe they should be punched obliquely inward, and brought out near the inner edge of the seating, getting more perpendicular as they approach the heels. They should always be placed as far from the heel, particularly the inner heel, as practicable with the safe retention of the shoe.

When the foot is properly prepared, the shoe should be of the same thickness throughout, and sufficiently strong to prevent bending or breaking; but when, as is the common custom, the heels are unduly reduced, and the toe elongated, it is necessary to thicken the heel of the shoe to compensate for what has been removed by the knife or rasp.

\section{PREPARATION OF THE FOOT.}

The old shoe must be removed by carefully cutting or raising the clenches, and gently wrenching it off with the 
pincers. Too much force should never be used, and if the clenches are properly raised much violence is seldom needed. All old stubs must be carefully removed. The question of paring the foot has long been a subject of controversy; but experience has proved that there is no fixed rule as to the exact extent to which the hoof should be removed by the knife or rasp-in fact, that we must prepare the foot according to the state we find it in. Few feet are the same, and while some require moderate removal of superfluous horn, others cannot bear the least thinning. We differ in opinion from those who recommend the sole to be thinned at every shoeing till it yield to the pressure of the thumb-at least in a healthy foot. Such thinning of the sole renders it liable to be bruised by every stone the animal steps upon. On the other hand, in most feet it is necessary to remove those loosened and detached flakes, which, were it not for the. shoe, would have exfoliated themselves, the retention of which must render the foot uncomfortable. The angles between the bars and crust should be moderately pared out, as accumulations here, with continued pressure of the shoe, are apt to induce corns. The frog seldom requires paring more than the removal of ragged parts. The crust requires reduction, particularly at the toe, which should be well shortened at every shoeing. The heels must be left strong, especially the inner heel. The frog-band which passes round the back part of the heel must never be removed, as is done by most smiths for the purpose of "opening up the heels."

\section{FITTING THE SHOE.}

Still more important is the proper fitting of the shoe. It is in this branch we find most difficulty in getting qualified farriers. As the feet differ in shape, in the manner of wearing the shoes, in peculiarities of action, \&c., so must the 
farrier study the art of arranging his shoe so as to "fit the shoe to the foot, and not the foot to the shoe," keeping the great primary objects always in view of protecting without injuring. While, therefore, there are no special rules for fitting the shoe, there are general rules which are applicable to all cases. Thus, the bearing must be perfectly level and even in a strong healthy foot. The weight should be removed off weak parts, and thrown on to those parts which are capable of sustaining it-not, however, by twisting the shoe, as is commonly done, but by reducing the crust beyond pressure. It is always advisable to shoe "easy" at the heelsthat is, to rasp the heels down so that daylight may be seen between the crust and the shoe. The shoe should be allowed to project an eighth or a quarter of an inch beyond the heels in draught horses; but in saddle or road horses it should be cut off at the heels. It must not be left too wide, especially the inner heel, as it is apt to cause interfering; and when too wide at the outer heel it is liable to be torn off, especially in soft ground, or by being trod on by another horse. On the other hand, it must not be too close, as the hoof is apt to overgrow it, and in time get sunk into the foot and bruise the sole.

\section{NUMBER OF NAILS.}

For this there is no rule. We find, for most feet, eight are required in draught horses, seven for saddle, and five for ponies. They should be placed where the crust is strongest, principally to the outer quarter and toward the toe of the inner, and in some feet it will be found necessary to place them round the toe. The nails should be as small as practicable, and if the feet are good, should not be driven too high. The clenches should be short and carefully hammered down, so as to prevent them raising and cutting the opposite leg. 
RASPING.

The rasp should never be used above the nails. It is very useful in removing superfluous horn, but should never be used to remove the natural unctuous covering of the crust.

\section{CALKINS, CLIPS, ETC.}

The use of calkins are indispensable in this country during the winter season, to prevent slipping, and afford more secure footing, and thereby increase the animal power considerably. These are formed by turning down the heel of the shoe. When calkins are used, they should be raised to the same height on both heels; and in draught horses the toe should also be raised, and thus keep the foot level without throwing weight unduly on any part. During frosty weather the calks should be made sharp, so as to catch on the ice and prevent slipping.

The shoe is made more secure by a clip being turned up at the toe to embrace the front part of the crust, into which it is received by a small part being cut out with the toe knife. This relieves the crust from a great deal of stress from the nails which it would otherwise sustain. Side clips should only be used when they cannot be done without, as in cases where the animal by stamping or uneven action of the foot displaces the shoe.

\section{THE HIND SHOE.}

The hind shoe does not require the care in seating and hollowing out of the web that is so essential in the fore shoe. The quarters are straighter and stronger at the heels, and the shoe must be made accordingly. The toe is usually made square, so as to shorten the foot and thus prevent overreaching. The outer heel is better to have a calkin raised to 
give a catch, and the inner heel thickened in the form known as a feather heel. In draught horses they may have toes and calkins, as in the fore feet.

\section{THE MANAGEMENT OF THE FOOT IN THE STABLE.}

The smith frequently gets blamed for many things which really are chargeable to the owner or the groom, either by neglecting the feet in the stable or allowing the shoes to remain too long on. The feet should be kept clean; all sand and dirt should be carefully picked out every night, and the feet kept soft and cool by frequently stuffing with soft clay, wet tow, or cow dung, and by occasional dressing with oil or hoof ointment.

The shoes should never be allowed to remain on longer than three weeks or a month for horses regularly on the road, and farmers often lame their horses by letting them carry their shoes for three or four months.

However, many injuries occur in the shoeing shop through carelessness or ignorance of the farriers; hence it would be well if the owners of horses would occasionally accompany them to the forge and see that the principles above enunciated be enforced. Every horse should be carefully examined by the proprietor of the forge before being allowed to leave. By this simple precaution he will save himself considerable annoyance, and his customers a great deal of disappointment through the carelesshess of his men. 


\section{CHAPTER XVI.}

\section{OPERATIONS.}

OPERATIONS have been stigmatised as the "opprobria of surgery;" we regret that there is too much truth in the remark, especially with regard to the rude and barbarous operation to which the subjects of veterinary surgery were subjected under the primitive methods of practice. And even at the present day, with all the advantages of the improved systems of modern surgery and anatomical and physiological researches, the system of veterinary surgery is still deficient. Among the uneducated, self-taught practitioners more especially, there is no operation which is considered too outré for practice in human surgery but is forced on the poor dumb animal, without regard to the suffering they occasion, and that, too, often with the consent and approval of the too confiding owner in the mysterious knowledge of the crafty farrier, who is usually very wise, and can predict to a certainty the result of his skill! Much has been done, however, within the Jast four years in introducing veterinary surgery, and exposing empiricism; and we are proud to see that the art is fast assuming its proper position, and the rude practices of the old school are giving place to the more scientific and humane practices of modern surgery.

Although we are not called upon to perform so many capital operations as the human surgeon, we have often to perform operations requiring not only an intimate acquaint- 
ance with the anatomy of the part, but also a thorough knowledge of the principles of surgery. We would, therefore, recommend our readers, in all cases requiring surgical interference, to obtain the services of a qualified veterinary surgeon, if within his reach, as he alone is qualified safely and scientifically to operate; for, bear in mind, surgery is not a simple mechanical art, it has to do not with inert matter, but with a complex organised structure, possessed of life, "and capable of maintaining health and repairing disease, the intricate processes of which can only be understood by careful study and deep research.

A short account of the principal operations will prove useful to many who are beyond the assistance of a veterinary surgeon.

\section{BLEEDING, PHLEBOTOMY.}

The operation of blood-letting is now almost discarded in modern practice. It is simple, and can be performed by alnost any one with a steady hand.

For its performance a fleam and blood-stick are required; the star of the fleam should be large at the shoulder to máke a sufficient opening to allow a free flow of blood, and the blade should be broad to prevent it sinking in when the vein is deep. The jugular vein of the neck is usually selected to bleed from. The head should be moderately raised and slightly turned off-the eye next the operator being covered by the hand of the assistant holding the head. The left side is easiest operated on; the vein is raised by the pressure of the third and little fingers of the left hand, which holds the fleam. It is most superficial about two inches from its division, and from six to eight inches from the angle of the jaw, consequently this point is usually selected for the operation. The vein being raised, and the hair smoothed down by the moistened finger, the star of the fleam is placed 
in a line with the course of the vein, with one smart tap of the blood-stick the skin and coats of the vein are punctured, and the blood will flow. When sufficient has been abstracted, the edges of the wound should be carefully taken together, and hairs and clot carefully wiped away; a small pin is passed through them, and a little tow wound round it, and the point of the pin cut off. The head should be tied up for a few hours to prevent him rubbing the pin off.

\section{THE ROWEL.}

Rowels are used as counter-irritants in treating deep-seated inflammations, and "whenever any morbid disease is to be stopped, as in grease and in thrushes;" they have long been favourite remedies among horsemen.

In applying a rowel, the skin is taken up between the finger and thumb, and a cut is made in the skin with the rowelling scissors, and with the hook on the handle of the scissors it is separated from its cellular connexions for about two inches, and a dossil of tow, or a circular piece of leather, with a hole in it, previously dipped in digestive ointment, is inserted, which must be cleaned and moved every day. A discharge is soon set up, which has a tendency to remove any deepseated morbid action.

\section{SETONS.}

Setons are similar in their action to rowels, and are used for much the same purposes. They are usually made of broad white tape. In inserting a seton, the skin is cut with the rowelling scissors as above; a seton needle, which should be large and well polished, is passed in and pushed under the skin as far as is necessary; another cut is then made in the skin, through which it is passed out; the needle in its course should separate the skin on each side from its cellular at- 
tachments. The lower opening should always be so placed that the matter will have a dependent outlet. The ends of the seton should be tied to circular pieces of leather so as to prevent it being pulled through. It is necessary to wash it frequently with warm water, and pull it up and down often, to keep it open, dressing it occasionally with digestive ointment to keep up the discharge.

Setons are now used with considerable success in the treatment of spatin.

\section{FIRING.}

Firing is often resorted to as a counter-irritant, and also as a means of corrugating the skin over weak parts so as to form a permanent bandage.

The frequent abuse of this operation has led to its almost universal denouncement, so that it is not often resorted to in modern practice; however, we are not disposed to deprive ourselves of this valuable curative agent on these grounds; we do not, however, recommend its general use, but in many cases we have succeeded by judicious firing, when all other. counter-irritants have failed. Firing, therefore, when judiciously employed by a skilful operator, is a valuable remedy for stimulating absorption, and counteracting inflammatory action in deep-seated structures. In performing it, the hair should be cut close off with the shears, the animal for greater security being cast; straight lines about half an inch apart are drawn with a red hot small smooth-edged iron. The lines must not be too deep, otherwise blemishes are apt to be produced. If the action is not considered sufficient, it may be blistered as well as fired. The discharge is to be kept up as long as necessary by digestive ointment. When it is desired to heal it, simple dressing with oil is all that is required. He must not be put to work till it is thoroughly healed up, 
DOCKING, NICKTNG, ETC.

Professor Dick in his "Manual of Veterinary Science," says of these operations:- "I believe the time is near at hand when even the cow-leech will perceive the absurdity of endeavouring to improve upon the fair forms of the most graceful works of nature, and will leave the horse's tail no less ornamental than useful."

As a general custom inflicted on the horse, merely to please some ignorant fancy, docking is most justly reprobated, it is a cruel operation, not only from the pain of the operation, but even more cruel in depriving the poor animal of the beautiful provision which nature has given him as a defence from flies and other equine torments, with which this country especially abounds. It also sometimes induces lockjaw, and results in death.

There are a few instances, however, in which it may be somewhat justifiable, as, for instance, some horses are very troublesome in driving, by getting the line under the tail, 'when they will start to kick or run away; sometimes from the ungainly manner of carrying the tail, it materially depreciates his value. When by docking or pricking it he may be made more safe and serviceable, or his market value be increased, we are justified in operating with as little unnecessary torture as possible.

In performing it, the joint at which it is to be amputated being determined on, the hair above it is shed back and tied with a cord, the part is clipped close, and the tail being held out by an assistant, with one cut of the docking shears it is severed. The bleeding is stopped by lightly searing with an iron with a hole in the centre so as not to burn the bone. Some practitioners amputate it so as to leave flaps to cover the bone; by this method the stump is entirely covered by 
hair, and though more troublesome is preferable. Too much searing is to be avoided, as exfoliation of the bone sometimes follows. the injudicious use of the firing iron.

Nicking and pricling are one and the same operation, the latter being an improved method of performing it; the object being to cause the tail to be carried in an elevated position, which is much admired in road horses. It is also performed to set the tail straight when carried awry, which is a serious eyesore to a good-looking horse. Youat terms it " a barbarous operation which has long been sanctioned by fashion ;" as a fashionable operation we most decidedly denounce it, but as remarked above, there are exceptional cases in which it is justifiable. Pricking is nothing more nor less than tenotomy of the depressor muscles of the tail-an acquaintance with the anatomy of which is necessary before it can be satisfactorily performed.

It is best to secure him with a twitch and side line; the hair at the end of the tail is firmly tied, and a loop formed, to which the weight is to be attached. The only instrument used is a long-bladed scalpel, or the common pricking knife ; the tail is raised with the left hand, while with the right the centre of the bone is felt for, and the knife is passed in (with its flat surface next the skin) to the opposite side, when the cutting edge is turned toward the bone and the muscles carefully divided. When simply to straighten a wry tail, if the faulty tendons are discovered and divided, one incision may be sufficient, but in "setting up" a tail two and sometimes three are required. The muscles having been thoroughly divided the tail is supported by means of the double pulley over the back part of the stall; the cord. attached to the end of the tail is passed through the wheels of the pulley, and sufficient weight attached to keep the tail elevated, to prevent readhesion of the divided muscles. He 
should be taken out of the pulleys twice a-day and gently exercised, but the pulleys must be continued until the parts have thoroughly healed, and he carries the tail in the manner desired.

\section{TRACHEOTOMY.}

It sometimes happens that from the tumefaction of strangles, the impaction of foreign bodies, and other sudden causes of obstruction, the life of the patient is threatened from suffocation; it is found necessary to open the windpipe to avert the untoward result, until the cause of the obstruction be removed.

It consists in making an incision through the skin and muscles in the mesian line down on the trachea or windpipe, cutting through two rings of this tube and inserting a bent tube, which is usually made of block-tin, with a broad flange, to which tapes or straps are attached to tie it round the neck. It is usually employed to give temporary relief, but we have known horses work with a tube in the windpipe for years. It must be frequently taken out and cleaned. When the cause of the obstruction is removed the tabe is withdrawn, and the edges of the skin being scarified, they are carefully brought together, and treated as a simple wound.

\section{GESOPHAGOTOMY.}

In some cases where a foreign body becomes lodged in the gullet, it is found necessary to cut down on it and remove it. This is only to be undertaken by one thoroughly acquainted with the anatomy of the part, otherwise the carotid artery, jugular vein, and pneumogastric nerve are liable to be injured.

This operation is only warranted as a dernier ressort when all others have failed. It may be performed in the standing position, but for greater safety it is preferable to have him 
cast. The skin is divided over the part for about three inches in length, when the muscles are separated from their cellular connexions, either by the finger or the handle of the scalpel, while the gullet is pushed up with the hand underneath, a longitudinal incision is made sufficiently large to allow the removal of the foreign body; this done, the part being carefully wiped clean and the edges of the gullet brought together by sutures of fine catgut, as recommended by Dick, and a few stitches of wire suture to bring the muscles and skin together, and a carefully adjusted pad supported by a bandage, cold water must be freely applied to moderate the inflammatory process.

He must be restricted to gruel, linseed tea, and other bland fluids. Great care is necessary to keep the part clean and promote adhesion, which is sometimes very difficult to produce, and death often results.

\section{TAPPING (PARACENTESIS.)}

In cases of extensive dropsical effusion into the chest or belly, it is sometimes found necessary to remove it by operation.

In tapping the chest (paracentesis thoracis) the puncture may be made in the intercostal space, anywhere between the seventh and eleventh ribs, near their junction with the cartilages. The space between the eighth and ninth is usually recommended. An incision is first made with a lancet through the skin, the trochar and canula is carefully pushed through the muscles and pleura, directed slightly upward and backward, keeping it close to the anterior border of the ninth rib, so as to avoid wounding the intercostal artery; when the trochar is withdrawn, the fluid flows freely through the tube, sometimes it gets obstructed by coagula of lymph, which should be cleared by inserting a small whale- 
bone staff. Care must be taken not to allow air to enter the cavity, as death has often occurred from this cause during the operation. The incision is to be brought together by sutures and adhesive plasters.

The operation may be repeated in a day or two on the other side. In most cases the relief is but temporary.

In tapping for dropsy of the belly (paracentesis abdomenis) the puncture may be made in any part of the middle line, from the navel (umbilicus) to the sheath in the horse, and from the umbilicus to the udder in the mare. As in the other, relief is but temporary, and requires frequent repetition.

Iodine should be freely given while conducting these experiments, and the general health should be attended to.

\section{LITHOTOMY.}

The formation of calculi in the bladder is of rare occurrence in the horse, compared with its frequency in the human subject. So formidable an operation should never be undertaken but by an experienced surgeon.

Having ascertained beyond doubt the existence of stone, a course of preparation is necessary before operating, consisting in bran mashes, and opening medicine, with small doses of alkaline carbonates, to render the urine alkaline and less irritating to the wounded urethra and bladder.

He must be secured on his back and well propped up by bundles of straw, and steadied by assistants. Having all the instruments, sponges, ligatures, \&c., within easy reach, the operator proceeds by emptying the rectum out with the hand, and again satisfying himself of the presence and position of the stone, he passes a curved metallic bougie as far as the curvature of the urethra will admit, which is held by an assistant. A large incision is now made with a common scalpel in the perineum, carried for about four inches out- 
ward and downward toward the angle of the thigh by the side of the anus. The skin and superficial tissues being divided, the finger is then placed in the wound, and by gently pushing aside the muscles and dilating the opening till the sound is felt with the finger; the outer wound should be sufficiently enlarged to admit of freedom of operation in the deeper incisions. A long scalpel is now passed in till it meets the point of the finger on the sound, when the urethra is carefully divided, the finger is kept in the incision, while the bougie is withdrawn and a straight grooved sound is passed in through the outer opening direct into the bladder, which should strike the stone at once. A long straight bistoury should now be passed in along the groove of the director, which divides the urethra and prostatic portion of the bladder, being careful not to wound the pudic artery, or injure the bowel; the cutting edge should be directed outward and downward in the same direction as the outer incision. The forceps are now introduced, directed by the finger till they come in contact with the stone, when, assisted with one hand in the rectum, the stone is seized in the blades, and turning it round to see that it is not attached to the bladder, it is carefully removed by a sort of vacillating " motion. At this stage there must be no hurry or excitement, otherwise the stone is apt to be crushed; any little impediments must be carefully divided by the knife, and any exigencies must be met by the tact and judgment of the operator. The debris must now be washed out with water or removed by the scoop; if much oozing of blood continue, cold water must be freely applied; any vessels of inportance must be taken up and tied, which is often difficult to do. One or two stitches may be put on the upper third of the wound, leaving it entirely open below; he may now be released and led to his box, where he should be inade comfort- 
able, and allowed some well-boiled gruel. No further interference is necessary, except to allow a free outlet for the urine, which will escape partly by the wound and partly by the urethra; occasional introduction of the catheter may be necessary until the bladder regains its power of contraction. In a few weeks the urine ceases passing through the wound, and escapes by its natural outlet, and the wound heals up.

During recovery, when the inflammatory state of the system consequent on the operation has subsided, he should be liberally fed on good solid food, and have frequent small doses of the mineral acids (nitro-muriatic) with a little gentle exercise, which is to be increased as recovery progresses, and keeping the wound clean is all the after-treatment required when the case is favourable.*

\section{NEUROTOMY.}

This operation has been practised for more than half a century; but to the late Professor Sewell we are indebted for bringing it prominently forward. Many objections have been raised against it; some in consequence of ignorance of its action and effects, and others in consequence of mishaps which have arisen from its injudicious application.

It consists in excision of a portion of the nerve supplying sensation to a part labouring under painful disease of an otherwise incurable nature, the effect of which is to destroy all sensation or feeling, without, however, interfering, as some suppose, with the nutrition or other functions of the part. It is applicable to any part of the body in which it is practic-

* In October 1865, we operated on a gray pony belonging to Mr James Gunn, Ingersoll, from which we removed an oxalate of lime calculus, weighing nearly three ounces. The pony is now as well as ever, and has never been off his work since the middle of December. For an account of the case, see Canada Farmer, January 1st, 1866. 
able. In the horse, however, it is confined entirely to diseases of the foot, such as incurable cases of navicular disease, painful side-bones, ring-bones, and sometimes, from feelings of humanity, in aggravated cases of canker, which are tedious and painful in the extreme.

It is well to bear in mind that, the sensation being destroyed, the animal will not feel a bruise or prick; hence by carelessness in shoeing much mischief has been done, "and the hoof has actually dropped off after the division of the nerve"-not, however, from any interference with the nutrition of the foot, but from the suppuration burrowing under, and detaching the hoof without being felt by the animal.

Again, in cases of aggravated navicular disease, with ulceration of the navicular bone, from want of that care which the animal naturally takes of a lame member, the rough bone saws through the tendon, which gives way, allowing the foot to turn up, necessitating the destruction of the animal.

Great care is therefore required in selecting subjects suited for the operation. Weak flat feet should never be operated upon-more especially if the horse has high action. If much used on the road he is apt to batter his feet to pieces. The greatest care is required in shoeing not to prick, and in driving not to bruise the sole. The feet should be washed and picked every night, and well tarred, to keep them from becoming dry and hard.

We have operated on over three dozen cases within the last five years with almost complete success. When properly performed, and judiciously applied, it is a great boon, not only to the poor sufferers themselves, but also to the owners, who have hitherto useless animals restored to usefulness.

The operation consists in excising a portion of the metacarpal nerves, either above or below the fetlock as the judgment of the operator sees the case requires. 
The artery vein and nerve occupy the same sheath. These are feit for between the tendons and the bone. The spot for the incision being selected, the hair is cut close off. He is now cast, and the leg released or otherwise fixed to suit the operator. A longitudinal incision, about an inch long, is made through the skin, the cellular tissues are pushed aside, and the artery vein and nerve exposed. The latter is easily known by its white glistening appearance and sensitiveness to touch or pressure.

The neurotomy knife, or a blunt needle with a thread, is passed under it, and it is severed: the upper cut being made first, the part can then be cut out without pain. The edges of the wound are brought together by a single suture. The same is repeated on the other side, and on the other leg if required. Cold water bandages should be applied for some time, and in aweek he is fit for work. Non-professionals should never attempt this operation.

\section{TENOTOMY.}

As the name indicates, it consists in division of the tendons in cases of morbid contraction giving rise to knuckling over the fetlock, causing the whole weight to be thrown on the toe.

To the late Professor Dick belongs the credit of first publicly introducing the operation, although, as he used to remark in his lectures, it was previously performed by his father; yet until it was prominently introduced by himself it was considered too formidable for general practice.

An erroneous idea long existed that tendinous fibres would not be reproduced: however, in the museum of the Edinburgh Veterinary College specimens may be seen in which the reproduction of true tendinous fibres is so complete as to defy the closest observer to distinguish the point of division. 
It is gratifying to know that the veterinary profession may be said to have given this operation to surgery, - and even the far-famed Professor Lizars gladly took lessons and directions from the distinguished principal of the Veterinary College in the treatment of talipes or clubfoot. It is only applicable to cases in which we have no anchylosis of the joints.

The horse being cast and properly secured, the leg is taken out of the hobbles and a rope attached to the foot, which is held by assistants. A longitudinal incision is made about an inch in length a little in front of the tendons and below any point of thickening that may exist. A common small bladed scalpel, or the curved tenotomy knife, is passed in, care being taken to avoid the artery vein and nerve, and the tendons are divided; the skin behind must not be cut, as the ends of the tendon may protrude, giving rise to fungus growths. The foot should now be easily brought into its natural position-if not, some force should be used to bring it back "by placing the knee against the front or projecting part of it, at the same time laying hold of the foot with one hand and the upper part of the leg with the other, and using considerable force." This is sometimes necessary to break up adhesions which may have formed. A stitch or two should be put in the wound, and a thick woollen bandage kept constantly wet with cold water should be applied for some days. If much inflammation ensue, a poultice should be applied and some purgative medicine given. If the fetlock descends too much, the heels should be raised. If adhesions take place during recovery, a tipped shoe should be put on the foot. In from two to three months he will be fit for work.

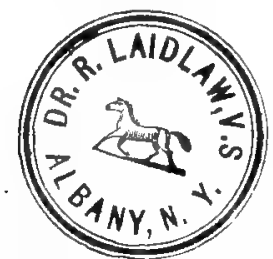




\title{
CHAPTER XVII.
}

\author{
CASTRATION。
}

CoLTs may be castrated at any age, but we would recommend from one to two years old as the best age; if well formed, and not deficient in front, one year old is more safe ; but if light in the fore-hand, a year more will improve the crest and shoulder, and give him a more furnished appearance. The best season is in the spring when the pasture is becoming green, after the cold is past, but before the heat and flies begin. We have castrated at all seasons of the year; except when running at pasture, preparation by bran mashes, \&ic., is necessary, and old horses in high condition should be physicked out. Before being cast for the operation, he should be carefully examined, to make sure that no hernia exists, and that both testicles are down. The hobbles or rope may be used for casting; in young colts we prefer the latter.

The operation may be performed in one of three ways, - viz., cauterisation and ligature of the artery of the cord, as recommended by Blaine and others of his day, taught by Dick, and almost invariably practised by ourselves; caustic clams, the method taught in the French schools, and extensively practised on this continent; or by the more novel method of torsion, now becoming fashionable in Europe: Like the able author of "The Horse," "we must confess we 
are disposed to adhere to the old way of opening the bag on either side, cutting off the testicles, and preventing bleeding by searing the vessels with a hot iron;" and in older horses searing lightly, and making more secure by applying a ligature on the artery, allowing the ends to hang out of the wound. Very little after-treatment is required; the wounds should be kept open till the cord has healed; if much swelling ensues, a few punctures may be made in the sheath with a penknife or lancet. He should be turned into a loose-box or paddock, and fed on cooling easily digested diet.

Year-old colts may be at once turned to pasture, but sheltered from cold and wet. 


\section{CHAPTER XVIII.}

FORMULA OF RECEIPTS AND PRESCRIPTIONS.

IN this chapter is given a list of compounds which we have found by experience to be valuable; many of them have long been used by the profession; most of them have been recommended by the best authorities, and are in daily use at the Colleges of Edinburgh and London; while others are prescribed by ourselves as more suited to the Canadian Horse and his Diseases. We are aware that we may be attacked for presenting these formulæ to the public, and it may be said that we are supplying "the bolsters to ignorance and empiricism." Our answer is, that such an addition is necessary to enable the farmer to take advantage of the information contained in the text; and it must be remembered that but few of our readers are possessed of sufficient knowledge of chemistry and materia medica to enable them to prescribe for the cases which may be thrown on their hands, away from professional assistance; hence the addition of some proved formulæ must prove useful.

Of some prescriptions it may be said that they are not thoroughly chemical in their composition; but from their virtues having been proved for a number of years, we feel justified in retaining them.

We the more gladly make this addenda, in the hope that these safe compounds may take the place of the dangerous nostrums usually given in receipt books. 


\section{ALTERATIVES.}

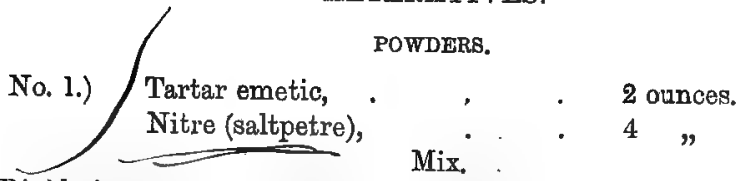

Divide into twelve powders, one to be given twice a day in the foou. Useful in catarrh, influenza, and skin diseases.

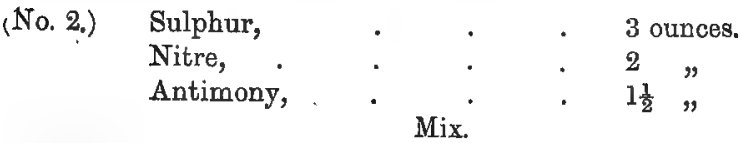

To be divided into six powders, one daily in the food. Useful in skin diseases.

BALLS,

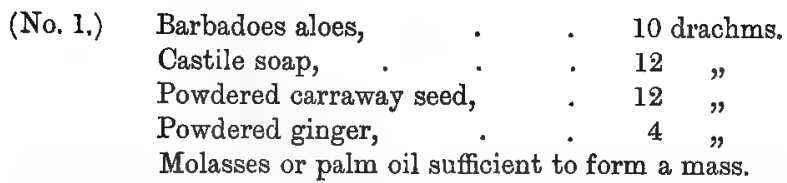

Divide into six balls, one to be given every morning till the bowels are freely opened. Useful in hide-bound, costive bowels, and skin . diseases.

\begin{tabular}{|c|c|c|c|c|}
\hline \multirow[t]{5}{*}{ (No. 2.) } & Barbadoes aloes, & • & & 10 drachms. \\
\hline & Calomel, & & & 2 \\
\hline & Powdered fenugree, & & & 12 \\
\hline & Ginger, . & & & 4 \\
\hline & Oil of cloves, & ${ }^{\circ}$ & ${ }^{\circ}$ & 40 drops. \\
\hline
\end{tabular}

Soft soap sufficient to form a mass.

I Divide into four, one every second day ; while taking these, he must have mashes, chilled water, \&c., and carefully preserved from cold and damp. Useful in hide-bound, grease, unthrifty condition, \&c.

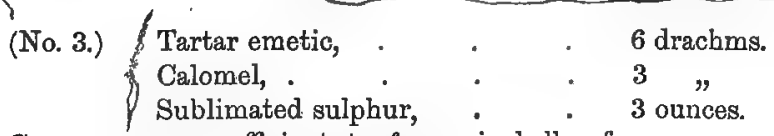

Cummon mass sufficient to form six balls of an ounce each, one daily. Useful in mange, worms, and skin diseases. 


\section{DIURETIC ALTERATIVES.}

POWDERS.

No. 1.) Resin, finely powdered, .

- 2 ounces.

Nitre,

- $1 \frac{1}{2}$,

Linseed meal, - . . 3 "

Mix.

Divide into six balls, one daily. Regulate the kidneys and improve the coat.

\section{BALLS.}

(No. 1.) Powdered resin, . . 4 ounces.

Castile soap, - . 3 "

Venice turpentine, . . 2 "

Powdered carraways sufficient to form the mass. Divide into balls of a convenient size, one daily till diuresis is produced. U'seful in swelled legs, dropsical effusion, weed, \&c.

\section{ANTACIDS.}

(No. 1.) Prepared chalk, . .. . 4 ounces. Powdered ginger, . . 1 "

Barbadoes aloes, :. 1 "

Common mass sufficient to make six balls of convenient size; one daily. Useful in acidity of the stomach and indigestion.

$\begin{array}{ll}\text { (No. 2.) } & \left.\begin{array}{l}\text { Carb. (bicarbonate) soda, } \\ \text { Gentian, } \\ \text { Ginger, }\end{array}\right\} \text { of each } \\ \text { a ounces. }\end{array}$

Molasses sufficient to make a mass. Divide into four; one night and morning.

\section{ANTISPASMODICS.}

No. 1.) Sulphuric ether, Infusion of opium, Peppermint water,

Mix.

To be given in a quart of cold water. Useful in flatulence, spasm, \&c. 


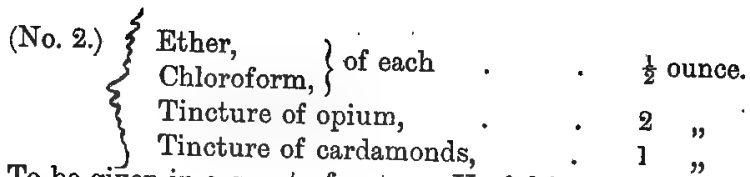

To be given in a quart of water. Useful in colic.

(No. 3.) Spirits of ammonia (aromatic), . 2 ounces.

Dilute hydrocyanic acid, - 20 drops.

Tincture of ginger, . . 2 ounces.

To be given in a quart of beer, well shaken. Useful in spasmodic colic, \&c.

\section{ASTRINGENTS.}

(No. 1.) Powdered opium,

- 1 drachm.

" catechu,

" chalk,. . . 1 ounce.

To be given in arrowroot, starch, or thick flour gruel. Useful, in diarrhoea or superpurgation.

(No. 2.) Powdered catechu, $\begin{gathered}\text { alum, } \\ \text { alu each }\end{gathered}$

2 drachms.

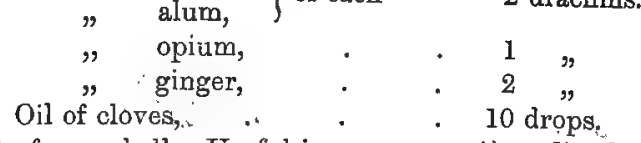

Molasses to form a ball. Useful in superpurgation, diarrhcea, \&c.

(No. 3.) Opium,

Acacia gum, $\}$ of each . - 1 drachm.

Prepared chalk, . . . 4 ounces.

Carefully dissolved in warm water, and given in plenty of flour or starch gruel, which, alternated with linseed tea, is to be often repeated.

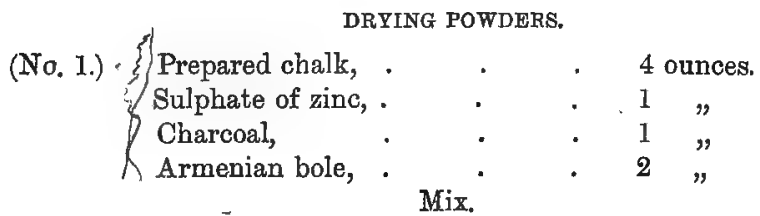

To be finely powdered." To be dusted over raw surfaces. Useful for healing wounds. 


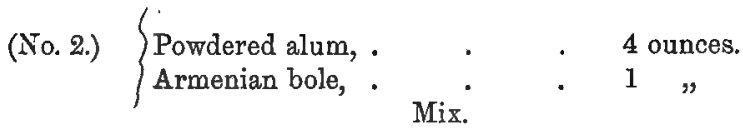

To be powdered and used as above.

(No. 3.) $\left\{\begin{array}{lll}\text { Sulphate of zinc, } & . & \text {. } \\ \text { Oxide of zinc, } & . & 1 \text { Mix. }\end{array}\right.$

To be used as above.

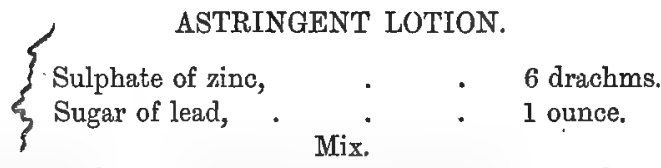

To be dissolved in a quart of water. Wet the wound twice a-day with the lotion, well shaken. Useful for wounds, bruises, \&c.

\section{ASTRINGENT OINTMENT.}

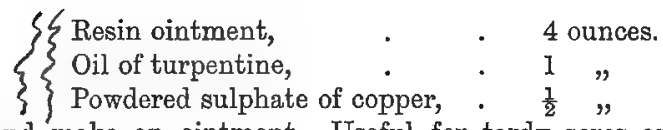

Mix and make an ointment. Useful for tardy sores and fungus growths.

\section{BLISTERS.}

(No. 1.) - Ointment-

\begin{tabular}{|c|c|c|c|}
\hline Lard, & & 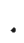 & 12 ounces. \\
\hline Canadian turpentine, & & & 2 \\
\hline Bowdered cantharides, & • & e & 3 \\
\hline
\end{tabular}

Malt the lard and turpentine, stir in the flies, keep stirring till cold.

(No. 2.)-Ointment-

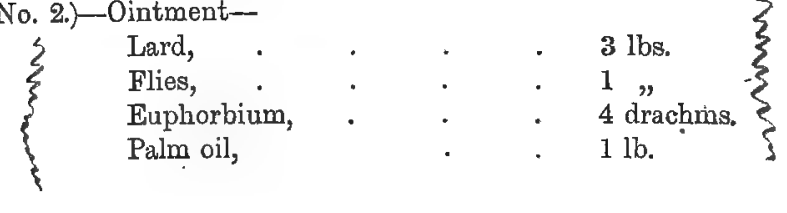


Melt the lard and oil over a slow fire, and when cooling, stir in the other ingredients.

(No. 3.)-Ointment-

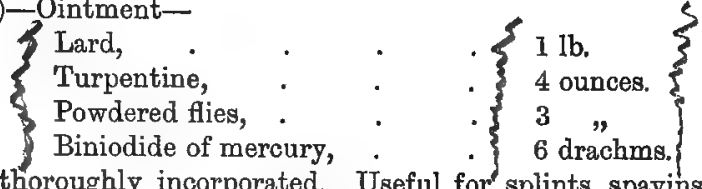

To be thoroughly incorporated. Useful for splints, spavins, ring- . bones, and enlargement of glands.

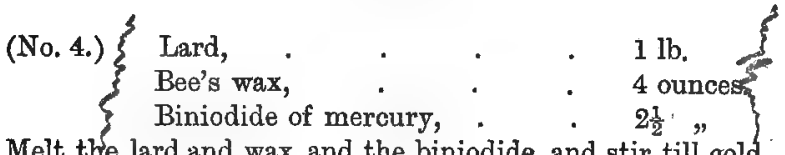

Melt the lard and wax, and the biniodide, and stir till cold. Useful for enlargement of bone or glandular tissues.

(No. 5.)-Liquid blister-

Rectified spirits of wine, - 15 ounces.

Macerate for ten days. To be used as a sweating blister.

(No. 6.)-Liquid blister-

Olive ail,

Oil of turpentine, \}equal parts.

Aqua àmonia,

To be well shaken. Useful for sore throat, chronic swellings, and callous enlargements.

\section{COLIC MIXTURES.*}

(No. 1.)-Professor Dick's-

Linseed oil, . . . ' i quart.

'Tincture of opium, . . 2 ounces.

Oil of turpentine,

Mix.

2 "

To be given as a drench. 
(No. 2.) . Linseed oil,

Tincture of opium,

1 pint.

Sweet spirits of nitre,

2 ounces.

Mix.

As a drench.

(No. 3.) Aromatic spirits of ammonia, . 1 ounce.

Whisky, .

Oil of peppermint

2 ,

Water, .

Mix.

(No. 4.) Alkaline solution of aloes,

Oil of peppermint,

Tincture of opium

Water,

Mix.

20 drops.

1 quart.

4 to 6 ounces.

30 drops.

2 ounces.

1 quart.

\section{COLLYRIA (EYE-WATERS.)}

(No. 1.) Nitrate of silver,

Rain or distilled water,

Infusion of opium,

Mix.

To be applied to the eye with a feather or camel's hair pencil. Useful in opacity of the cornea, specific opthalmia, \&c.

(No. 2.) Sulph. zine, Acetate of lead, Distilled water,

To be used as above.
2 to 10 grains.

1 ounce.

$$
5 \text { drops; }
$$

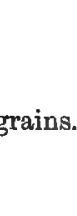


Spirits of lavender,

Liquor ammonia,

Mix.

Useful in sprains, or as a mild blister.

1 pint.

6 ounces.

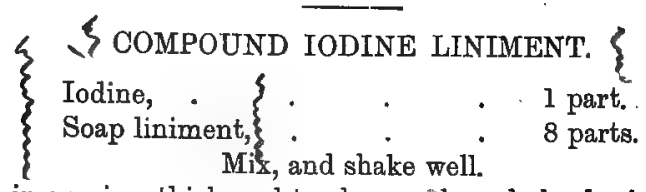

Useful in sprains, thickened tendons, eñlarged glands, \&c.

\section{CONDITION BALLS.}

(No. 1.) Powdered ginger,

- 1 drachm.

Sulphate of iron,

. 2 . 2 "

Molasses sufficient to form a mass. To be made into one ball. Improves the appetite, and stimulates digestion.

(No. 2.) Powdered ginger, . . 1 drachm.

Allspice, .

Carraway seed, .

Molasses to form a ball. As above.

2 "

. 3 "

\section{CORDIAL DRENCH.}

(No. 1.) Good old beer, (warm), . . 1 quart.

Powdered ginger, . . $\frac{1}{2}$ ounce.

Shake well.

To be given in exhaustion, and recovery from debilitating diseases.

(No. 2.) Best brandy, :

Molasses,

Warm water,

As above.

COUGH BALLS.

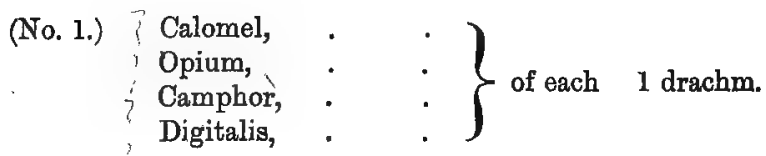


Made into a ball, with molasses. One daily, till six are given, when a gentle laxative should be administered.-(Dick.)

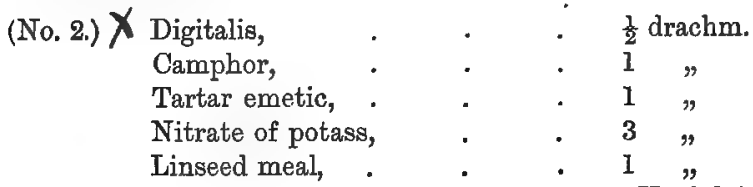

To be made into a mass, with Barbadoes tar. Useful in chronic cough. Used as above.--(Spooner.)

(No. 3.) X Gum ammon,

2 to 3 drachms.

Powdered squills,

Camphor,

Castile soap

Oil of anise,

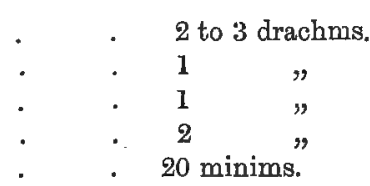

Syrup and flour sufficient to form a ball.-(White.)

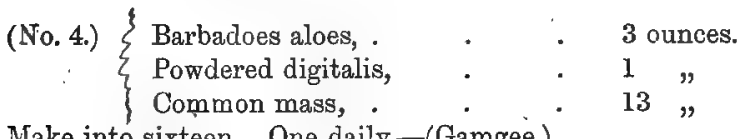

Make into sixteen. One daily.-(Gamgee.)

\section{DECOCTION ÔF ALOES.}

$\begin{array}{llll}\text { Barbadoes aloes, } & \cdot & \cdot & 2 \frac{1}{2} \text { ounces. } \\ \text { Bicarb. potass, } & \cdot & \cdot & 2 \\ \text { Acacia gum, } & \cdot & \cdot & 2 \\ \text { Boiling water, : } & \cdot & \cdot & 1 \text { pint." }\end{array}$

Mix.

If required to keep, two ounces of alcohol may be added.-(Percival،)

\section{DIGESTIVE OINTMENT.}

(No. 1.

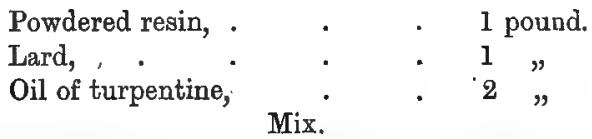

Dissolve the resin and lard, and stir in the turpentine. Useful for stimulating unhealthy wounds, keeping up the action of blisters, and smearing setons. 
(No. 2.) Hog's lard,

Common turpentine, . $\}$ of each 4 ounces.

Melt over a slow fire, and add-

Powdered acetate of copper, . 1 n

Stir till cool. Used as above.

DIURETIC OR URINE BALLS.

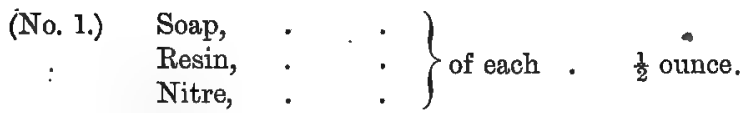

One every second day till two or three are given. Useful in swelled legs, grease, \&c.

(No. 2.)

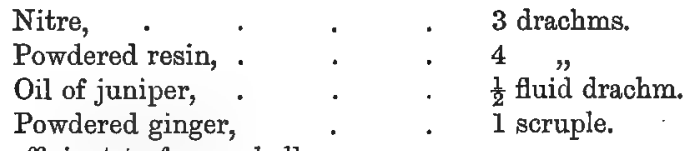

Soft soap sufficient to form a ball.

(No. 3.) Powdered resin, . . . . 4 drachms.

Palm oil sufficient to form a ball.

" nitre, $\quad$. $\quad \cdot \quad 3 \%$

\section{DIURETIIC MASS:}

Common resin, .

3 lbs.

Soft soap,
Melt over a slow fire, and when cool add- - 2 "
Nitre (powdered finely,)
2 "
Venice turpentine,
10 ounces.

To be made into balls as required. Dose, 1 ounce.

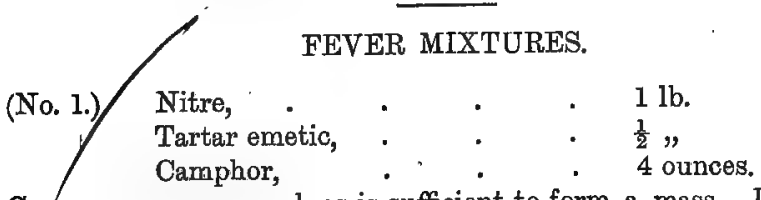

Common mass as much as is sufficient to form a mass. Dose, one ounce, made into a ball. One every three hours, while fever lasts. 
(No. 2.) / Tincture of aconite, . . . 10 to $15 \mathrm{drops}$.

To be given every two hours in a little water till fever subsides.

(No. 3.) $\left.\int \begin{array}{l}\text { Calomel, } \\ \text { Opium, } \\ \text { Common mass, }\end{array}\right\}$ of each $\cdot 1$ drachm.

Made into a ball as above. Very useful in inflammation of the lungs, \&c.

\section{HOOF OINTMENT.}

Archangel tar,

Tallow,

Bee's wax,
$1 \mathrm{lb}$.

$\frac{1}{2}$

4 ounces.

Melt together, and stir till cool. Useful dressing for weak feet, keeping the hoof soft, and stimulating the growth of horn.

\section{GOULARD'S EXTRACT.}

$\begin{array}{lll}\text { Sugar of lead, } & \text {. } & 6 \text { ounces and } 6 \text { drachms. } \\ \text { Litharge (powdered, }) & \text {. } & 4 \text { ounces. } \\ \text { Water, } & \text {. } & 1 \frac{1}{2} \text { pint. }\end{array}$

Boil for half-an-hour, and when cool, if required, add water to make a pint and a half ; filter, and keep in well-stoppered bottles. Useful in bruises, inflammation of the eyes, skin eruptions, \&c.

unid.

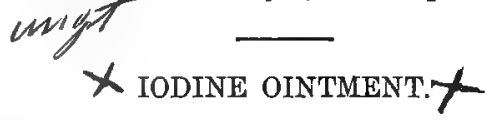

$$
\left\{\begin{array}{l}
\text { I } \\
\text { L }
\end{array}\right.
$$

Iodine,

Iodide of potassium,

1 drachm.

Lard,

\section{Mix.}

Useful in glandular and bony enlargements, mallenders, sallenders, ringworm, \&c.

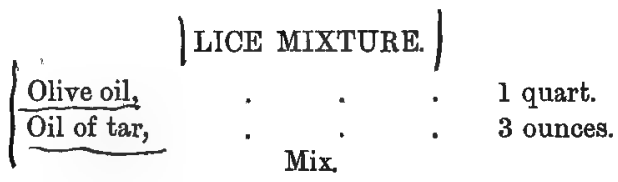


To be well shaken. Wash well with soap and water, rub dry, and rub well in. At the same time feed well, and attend to the cleanliness.

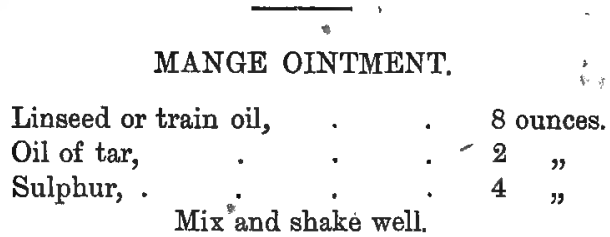

Wash well with soap and water, then rub the mixture well in, washing every second day.

\section{PURGATIVES.}

PURGATIVE DRENCH.

(No. 1.) Linseed or castor oil, . . 1 quart.

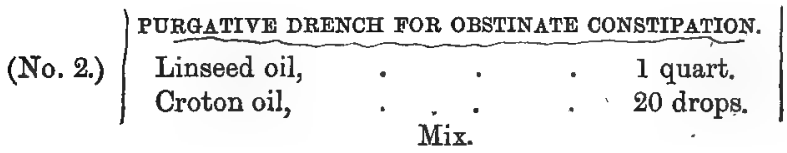

\section{PURGATIVE BALLS.}

(No. 1.) Barbadoes aloes, . . 5 to 6 drachms.
Ginger,
2

Lard or soft soap sufficient to form a ball. Before giving this, he should be prepared by bran mash for a day or two. While under it he should have no hay or oats, and gentle walking exercise.

(No. 2.) Barbadoes aloes, . . . 5 drachms.

Calomel, . . . . 1 ,

Lard or soap to form a ball.

This is equal to eight drachms of aloes alone.

\section{PURGATIVE MASS.}

(No. 1.) Barbadoes aloes,

Molasses,

Powdered ginger,

$\begin{aligned} \text {. } & 1 \mathrm{lb} . \\ \text {. } & 2 \text { otunces. }\end{aligned}$


Dissolve over a slow fire, stirring constantly till thoroughly incorporated.

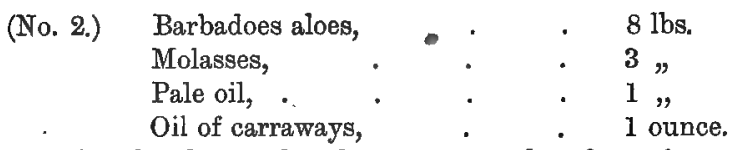

Dissolve the aloes and molasses over a slow fire; then add the oil and carraways, and stir well.

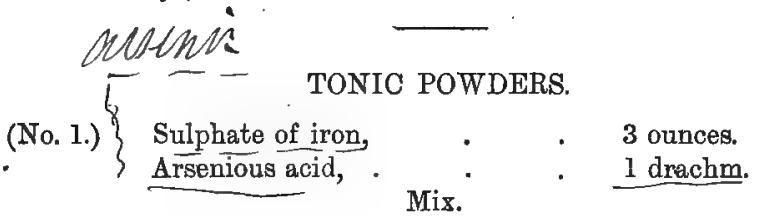

Powder the iron finely, and divide into twelve powders; then add the arsenic (five grains) to each. One night and morning in the feed. Useful in loss of appetite and recovery from debilitating diseases.

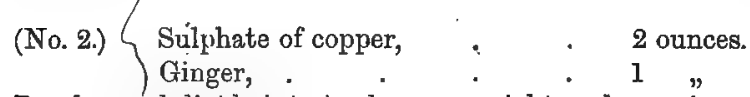

Powder, and divide into twelve ; one night and morning. Useful in farcy, nasal gleet, and chronic discharges.

\section{TONIC MASS.}

(No. 1.) Ginger (powder) gentian,
Carraway seed and anise seed, equal parts.

Molasses sufficient to form a mass.

Dose, one ounce in a ball night and morning.

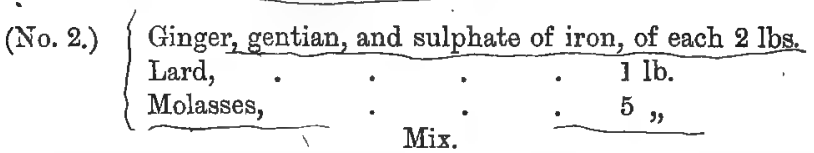

The sulphate of iron to be finely powdered, and thoroughly incorporated with the other ingredients; the lard and molasses to be dissolved, and the mixed powder to be stirred in. Dose, one ounce night and morning. 


\section{WORM POWDERS.}

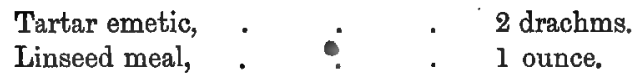

To be given night and morning in a little bran; on an empty stomach.

\section{/ WORM BALLS. / ,}

(No. 1.) Gentian quassia,

Camphor, sulphate of iron, $\cdot \dot{\cdot}\}$ of each 2 drachms.

Made into a ball with common mass.-(Dun.)

(No. 2.) Assafoetida
Calomel and savin, each
Oil of male fern,
$1 \frac{1}{2}$,
30 drops.

2 drachms.

Common mass sufficient to form a ball given at night, and a purge in the moraing.-(Gamgee.)

\section{WORM DRENCH.}

Linseed oil, . $\quad$. $\quad$. 1 quart.

Oil of turpentine, . $\quad$. 2 ounces.

To be prepared by bran mashes for two days; allowed to fast for at least eight hours, when the drench is to be carefully given; and, if thought necessary, repeated next morning, and followed by a purgative.

THE END.

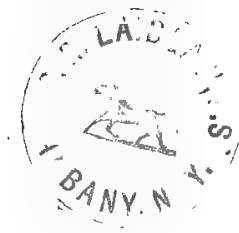








